Chipcflow - validação e implementação do modelo de partição e protocolo de comunicação no grafo a fluxo de dados dinâmico 

SERVIÇO DE PÓS-GRADUAÇÃO DO ICMC-USP

Data de Depósito: 15/12/2010

Assinatura:

\section{Chipcflow - validação e implementação do modelo de partição e protocolo de comunicação no grafo a fluxo de dados dinâmico}

\section{Francisco de Souza Júnior}

Orientador: Profa. Dr. Jorge Luiz e Silva

Dissertação apresentada ao Instituto de Ciências Matemáticas e de Computação - ICMC-USP, como parte dos requisitos para obtenção do título de Mestre em Ciências - Ciências de Computação e Matemática Computacional. .

USP - São Carlos

Dezembro/2010 



\section{Dedicatória}

Aos meus queridos pais e minha querida irmã Francisco de Souza, Ana Madalena Cortichone de Souza (in memoriam) e Luciana Cortichone de Souza. 


\section{Agradecimentos}

Agradeço ao Prof. Dr. Jorge Luiz e Silva, pela orientação do trabalho realizado, pela paciência em corrigir meus erros no decorrer desse processo e pelos conselhos ao longo desses últimos anos.

Agradeço aos colegas de projeto Lucas Sanches e Vitor Astolfi, pelas discussões e pelo subsídio à este trabalho, no qual não seria possível sem eles.

Agradeço ao CNPq, pelo auxílio financeiro de Agosto de 2008 até Fevereiro de 2010.

Ao Instituto de Ciências Matemáticas e de Computação da Universidade de São Paulo pela oportunidade de realizar esse curso de mestrado. Aos professores pelos ensinamentos,e aos funcionários pelos excelentes serviços prestados.

Agradeço aos funcionários do ICMC pela presteza, paciência e dedicação em sanar minhas incontáveis dúvidas, em especial às funcionárias Lhaís Visentin, Ana Paula, Laura Aparecida e Elizabeth Luisa Moretti e Silva.

Agradeço aos meus amigos de laboratório Daniel F. Bonetti, Bruno Mazzotti, Christiane Brasil, Marcilyanne Gois e Vinicius Melo, pelo auxílio, paciência e ajuda na correção de trabalhos e total apoio nas minhas necessidades.

Agradeço aos meus amigos Renato Rodrigues e Rodrigo Córdoba pela paciência pelo convívio ao longo desses anos e pela ajuda preciosa na elaboração deste trabalho.

Agradeço aos meus amigos e colegas de São Carlos, Adalberto Gonzaga, Bruno Drugowick Muniz, Danilo Coimbra, David Neto, Heitor Luis Polidoro, José Augusto, Michele Bortolotti, Paulo Gabriel, Priscila Uiliam, Rafael Messias, Ricardo Cerri, Tácito Trindade, Willian Watanabe, pelo convívio ao longo desses anos, proporcionando uma das melhores épocas da minha vida e me inspirando para meu trabalho de mestrado.

Agradeço também aos meus eternos amigos André Gonzaga Coelho, Carlos Gonzaga Coelho, Carlos Motta Júnior, Edson Mulero Grupioni, Gabriel Nogueira e Maurício Nogueira, por sempre me apoiarem e ajudarem no decorrer da minha vida. 


\section{Resumo}

A ferramenta ChipCflow vem sendo desenvolvida nos últimos quatro anos, inicialmente a partir de um projeto de arquitetura a fluxo de dados dinâmico em hardware reconfigurável, mas agora como uma ferramenta de compilação. Ela tem como objetivo a execução de algoritmos por meio do modelo de arquitetura a fluxo de dados associado ao conceito de dispositivos parcialmente reconfiguráveis. Sua característica principal é acelerar o tempo de execução de programas escritos em Linguagem de Programação de Alto Nível (LPAN), do inglês, High Level Languages, em particular nas partes mais intensas de processamento. Isso é feito por meio da implementação dessas partes de código diretamente em hardware reconfigurável - utilizando a tecnologia Field-programmable Gate Array (FPGA - aproveitando ao máximo o paralelismo considerado natural do modelo a fluxo de dados e as características do hardware parcialmente reconfigurável. Neste trabalho, o objetivo é a prova de conceito do processo de partição e do protocolo de comunicação entre as partições definidas a partir de um Grafo de Fluxo de Dados GFD, para a execução direta em hardware reconfigurável utilizando Reconfiguração Parcial Dinâmica (RPD). Foi necessário elaborar um mecanismo de partição e protocolo de comunicação entre essas partições, uma vez que a $\mathrm{RPD}$ insere características tecnológicas limitantes não encontradas em hardwares reconfiguráveis mais tradicionais. O mecanismo criado se mostrou parcialmente adequado à prova de conceito, significando a possibilidade de se executar GFD na plataforma parcialmente reconfigurável. Todavia, os tempos de reconfiguração inviabilizaram a proposta inicial de se utilizar RPD para diminuir o tempo de tag matching dos GFDs dinâmicos. 


\section{Abstract}

The ChipCflow tool has been developed over the last four years, initially from an architectural design the flow of Dynamic Data in reconfigurable hardware, but now as a compilation tool. It aims to run algorithms using the model of the data flow architecture associated with the concept of partially reconfigurable devices. Its main feature is to accelerate the execution time of programs written in High Level Languages, particularly in the most intense processing. This is done by implementing those parts of code directly in reconfigurable hardware - using FPGA technology - leveraging the natural parallelism of the data flow model and characteristics of the partially reconfigurable hardware. In this work, the main goal is the proof of concept of the partition process and protocol communication between the partitions defined from Data Flow Graph for direct execution in reconfigurable hardware using Active Partial Reconfiguration. This required a mechanism to partition and a protocol for communication between these partitions, since the Active Partial Reconfiguration inserts technological features limiting not found in traditional reconfigurable hardware. The mechanism developed is show to be partially adequate to the proof of concept, meaning the ability to run Data Flow Graphs in a platform that is partially reconfigurable. However, the reconfiguration time inserts a great overhead into the execution time, which made the proposal of the use of Active Partial Reconfiguration to decrease the time matching Data Flow Graph unfeasible. 


\section{Sumário}

$\begin{array}{lll}1 & \text { Introdução } & 1\end{array}$

1.1 Objetivos . . . . . . . . . . . . . . . . . . . . . . 3

1.2 Organização da Monografia $\ldots \ldots \ldots \ldots$. . . . . . . . . . . . . 4

2 Computação Reconfigurável 5

2.1 Pré-FPGA . . . . . . . . . . . . . . . . . . . . . . . 8

2.1 .1 Máquina Fix-plus . . . . . . . . . . . . . . . . . . . . . . . . . . 8

$2.1 .2 \quad$ A Máquina de Ramming . . . . . . . . . . . . . . . . . . . . . . 8

2.1 .3 XPuter . . . . . . . . . . . . . . . . . . . . 9

2.2 Pós-FPGA . . . . . . . . . . . . . . . . . . . . . . . . . . 11

$2.2 .1 \quad \mathrm{FPGA} \ldots \ldots \ldots \ldots \ldots \ldots \ldots$

$2.2 .2 \quad$ Arquiteturas clássicas . . . . . . . . . . . . . . . . . . . . . 14

$2.2 .3 \quad$ Arquiteturas atuais . . . . . . . . . . . . . . . . . . . . . . 20

$2.2 .4 \quad$ Arquiteturas baseadas em fluxo de dados . . . . . . . . . . . . . . 22

2.3 Considerações Finais $\ldots \ldots \ldots \ldots$. . . . . . . . . . . . . . . . . . . . . . . 23

3 Reconfiguração Parcial em FPGAs 25

3.1 Arquiteturas de FPGAs com reconfiguração dinâmicas . . . . . . . . . . 27

3.1 .1 Contexto único . . . . . . . . . . . . . . . . . . 27

$3.1 .2 \quad$ Múltiplos contextos . . . . . . . . . . . . . . . . . . . . . . . . 28

3.2 Reconfiguração Parcial Dinâmica ． . . . . . . . . . . . . . . . . . . . . . . 29

3.2 .1 Reconfiguração Parcial nos dispositivos Virtex . . . . . . . . . . . . 30

3.3 Trabalhos Relacionados . . . . . . . . . . . . . . . . . . . . . . . . . . . . 40

3.3 .1 Computação Bioinspirada . . . . . . . . . . . . . . . . . . 40

3.3 .2 NoCs e SoCs . . . . . . . . . . . . . . . . . . . . . . . 41

3.4 Considerações Finais $\ldots \ldots \ldots$. . . . . . . . . . . . . . . . . . . . . 41

4 ChipCflow: Proposta de Partição e Protocolo 43

4.1 Fluxo de Desenvolvimento . . . . . . . . . . . . . . . . . . . . . . . . . . 43

4.2 Fluxo de Execução $\ldots$. . . . . . . . . . . . . . . . . . . . . . . . . . 45 
4.2 .1 Nós do GFD . . . . . . . . . . . . . . . . . . . . . . . . 45

4.2 .2 Subgrafos do GFD e Reconfiguração Parcial Dinâmica . . . . . . . 47

4.3 Proposta de Partição $\ldots \ldots \ldots \ldots \ldots$

$4.3 .1 \quad$ Partial Reconfigurable Regions . . . . . . . . . . . . . . . . . . . 49

4.3 .2 Partições . . . . . . . . . . . . . . . . . . . . . . . . 52

4.3 .3 Gerenciador de Entrada e Saída . . . . . . . . . . . . . . . . 53

4.3 .4 Árbitro . . . . . . . . . . . . . . . . . 54

4.4 Proposta do Protocolo de Comunicação . . . . . . . . . . . . . . . . 54

4.4 .1 Sinais de Controle. . . . . . . . . . . . . . . . . . 56

4.4 .2 Transferência de tokens. . . . . . . . . . . . . . . . . . . . 58

4.5 Metodologia de Validação e Implementação . . . . . . . . . . . . . . . . 59

4.5 .1 Metodologia de Validação … . . . . . . . . . . . . . 59

4.5 .2 Implementação $\ldots \ldots \ldots \ldots$. . . . . . . . . . . . 60

4.6 Considerações Finais $\ldots \ldots \ldots \ldots$

5 Experimentos, Resultados e Discussão



$5.1 .1 \quad$ Algoritmo Fibonacci $\ldots \ldots \ldots \ldots \ldots$

5.1 .2 Modelo de Partição e Protocolo . . . . . . . . . . . . . . . 71

5.2 Análise de Overhead . . . . . . . . . . . . . . . . . 78

5.2 .1 Tempos de Reconfiguração . . . . . . . . . . . . . . . . 81

5.3 Considerações Finais $\ldots \ldots \ldots \ldots$. . . . . . . . . . . . . 83

6 Conclusões e Trabalhos Futuros $\quad 85$

6.1 Primeiro Requisito . . . . . . . . . . . . . . . . . . . . . 85

6.2 Segundo Requisito $\ldots \ldots \ldots \ldots \ldots$

6.3 Trabalhos Futuros. . . . . . . . . . . . . . . . . . 86

\begin{tabular}{ll}
\hline Referencias & 94
\end{tabular}






\section{Lista de Figuras}

2.1 Comparação de Flexibilidade versus Desempenho de classes de processa-

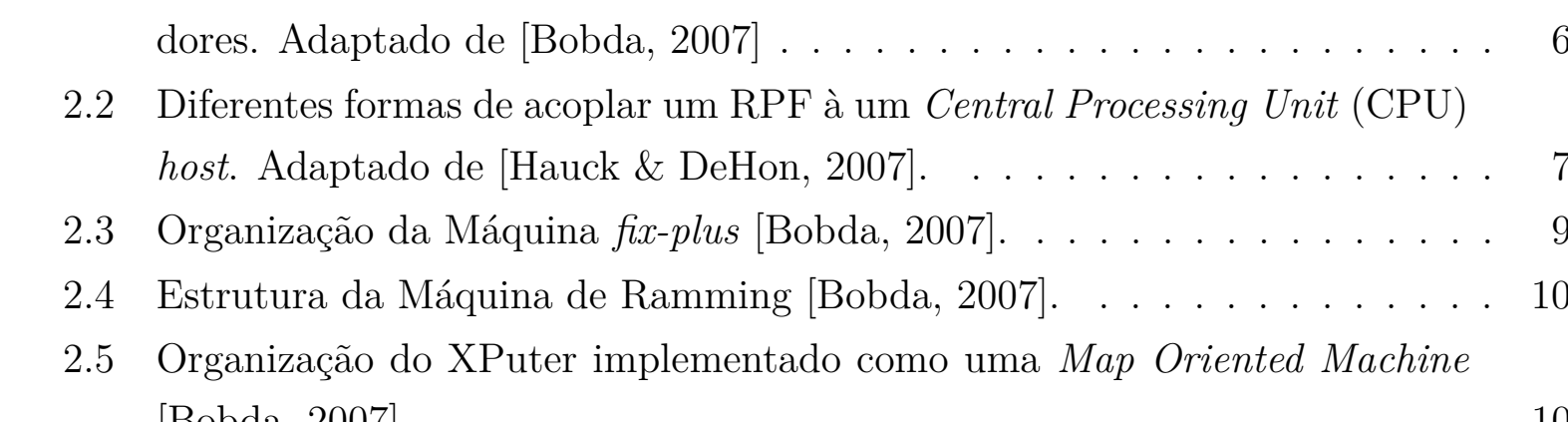

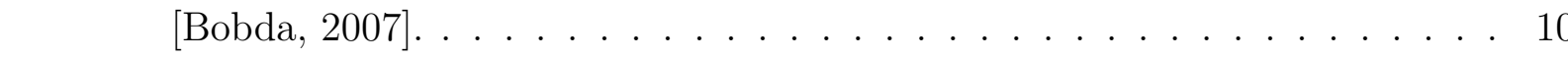

2.6 Arquitetura da Reconfigurable ALU Array (RALU), demonstrando as \begin{tabular}{|c|c|}
\hline Elemento de Processamento (EP)s e uma estrutura de controle $\mid$ Bobda, \\
\hline
\end{tabular} 2007]. . . . . . . . . . . . . . . . . . . 11

2.7 Gráfico ilustrativo da correlação entre paralelismo de operações e frequência de clock. Entre parênteses, exemplos de empresas que fabricam tais chips. . 12

2.8 Diagrama da estrutura de um|FPGA. . . . . . . . . . . . . . . . . . . 14

2.9 Diagrama da estrutura de um $\mid$ FPGA $\mid$ Xilinx (R) Virtex 2 modelo XV2P30,



2.10 Arquitetura de uma hipotética máquina Programmable Active Memory (PAM) de 4x4 Processing Array Bits (PAB)s. [Bobda, 2007]. . . . . . . . . . 16

2.11 Arquitetura da máquina DECPeRLe-1 |Vuillemin et al.[1996]. . . . . . . . 16

2.12 Arquitetura da máquina DISC. Adaptado de [Wirthlin \& Hutchings. [1995].] 17

2.13 Estrutura do Controlador Global da arquitetura DISC |Wirthlin \& Hut-



2.14 Organização da arquitetura Garp. O retângulo tracejado indica a área da pastilha de silício $\mid$ Hauser \& Wawrzynek [1997]. . . . . . . . . . . . . . . . 18

2.15 Arquitetura da $\mid$ RPF $\mid$ da arquitetura Garp $[$ Hauck \& DeHon, 2007]. . . . . . 19

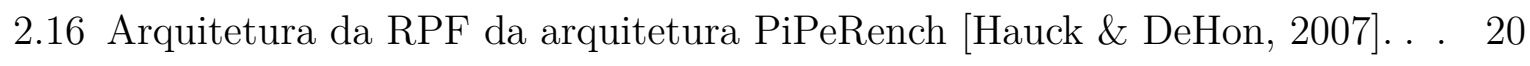

2.17 Diagrama da arquitetura ARRIVE $\mid$ Kohler et al.] 2008]. . . . . . . . . . . 21

3.1 llustração da reconfiguração dinâmica. $\ldots$. . . . . . . . . . . . . . . . . 26 
3.2 llustração da reconfiguração parcial dinâmica. $\ldots$. . . . . . . . . . . . . 27

\begin{tabular}{|ll|l|l|}
\hline 3.3 & Cadeia de shifts utilizados para programação do & FPGA & Cada quadrado \\
\hline
\end{tabular} representa um bit em Static Random Access Memory (SRAM) |Hauck \&



\begin{tabular}{|ll|l|l|l|}
\hline 3.4 & 2 bits de configuração em uma & FPGA & de 4 contextos. Cada contexto re- \\
\hline
\end{tabular} presenta um plano de memória. [Hauck \& DeHon, 2007] . . . . . . . . . . 29

\begin{tabular}{|ll|l|l|l|}
\hline 3.5 & Diagrama da estrutura de um & FPGA & Xilinx(R) Virtex 2 modelo XV2P30, \\
\hline
\end{tabular}

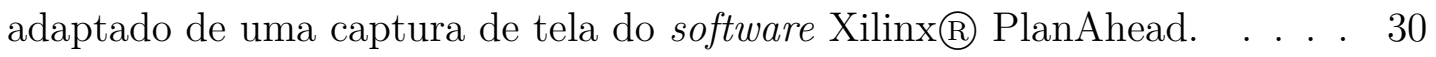

3.6 Demonstração da disposição de frames de configuração através dos blocos Configurable Logic Block (CLB)s. . . . . . . . . . . . . . . . . . . . . . . . 31

3.7 Interface SelectMAP. Adaptado de $\mid$ Xilinx $[\mid 2007 \mathrm{~b}] . \ldots$. . . . . . . . . . . 32

3.8 Interface e Estrutura da porta ICAP . . . . . . . . . . . . . . . . . . 32

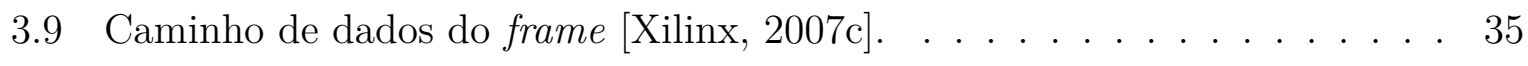

3.10 Exemplo de roteamento possível. $\ldots \ldots \ldots$. . . . . . . . . 36

3.11 Fluxo de desenvolvimento do Early Access Partial Reconfiguration (EAPR). Adaptado de $\mid$ Xilinx $\mid 2008]$. . . . . . . . . . . . . . 37

3.12 Diagrama exemplificando dois roteamentos distintos para dois módulos reconfiguráveis diferentes para uma mesma área reconfigurável. ...... 38

3.13 Diagrama exemplificando a utilização de bus macros. . . . . . . . . . . . . 39

3.14 Desenho de uma bus macro assíncrona do tipo "direita para a esquerda".

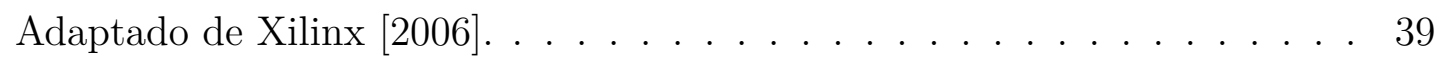

3.15 Filas de entrada $[$ Matos et al. $[2009] \ldots$. . . . . . . . . . . . . . 42

4.1 Diagrama de Fluxo de desenvolvimento da ferramenta ChipCflow. Adaptado de $\mid$ Souza Junior et al. $[|2010| .$. . . . . . . . . . . . . . . . . . . 44

$4.2 \quad$ Diagrama da arquitetura do circuito de um operador de soma. . . . . . . . 45

4.3 Diagrama de estados do protocolo de comunicação entre nós do GFD| . . . 46

4.4 Duas instâncias de uma mesma partição. Adaptado de |Souza Junior et al.

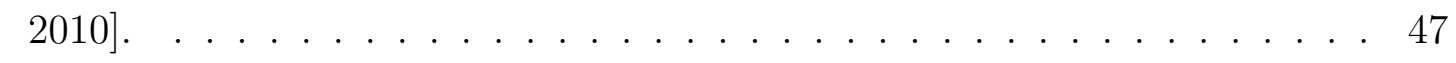

4.5 Diagrama simplificado da arquitetura proposta do modelo de partição da ferramenta ChipCflow para uma Virtex II/II Pro. . . . . . . . . . . . . . . 49

$4.6 \quad$ Exemplo de um GFD na arquitetura proposta de uma Partição. . . . . . . . 52

4.7 Diagrama simplificado da arquitetura da proposta do Gerenciador de Entrada e Saída (GES). . . . . . . . . . . . . . . . . . 53

4.8 Diagrama simplificado da arquitetura da proposta do Controlador de Comunicação. . . . . . . . . . . . . . . . . . 55

4.9 Exemplo de subgrafo particionado: $i$ representa o identificador da partição, $a_{j}$ são os índices dos arcos de entrada e de saída da partição. . . . . . . . . . 58

5.1 Diagrama do GFD do algoritmo Fibonacci (Algoritmo 5.1 . . . . . . . . . . 65 
5.2 Diagrama da primeira partição do GFD $p_{1}$ do algoritmo Fibonacci (Algo-



5.3 Diagrama da segunda partição do GFD $p_{2}$ do algoritmo Fibonacci (Algo-



5.4 Diagrama do GFD do algoritmo Fibonacci utilizando o método de codecopying para $n=3 . \ldots \ldots \ldots \ldots$. . . . . . . . . . . . . 68

5.5 Resultados dos testes realizados em GFDs estáticos do algoritmo Fibonacci sem utilização do modelo de partição e protocolo. . . . . . . . . . . . . . . 69

5.6 Gráfico comparativo do Speedup do Código em C sobre o GFD estático. . . 70

5.7 Hardware da implementação da partição 1 do GFD do algoritmo Fibonacci. 72

5.8 Hardware da implementação da partição 2 do GFD do algoritmo Fibonacci. 73

5.9 Screenshot da ferramenta FPGA Editor com uma visão da ocupação do

\begin{tabular}{|l}
\hline hardware sintetizado da implementação estática do GFD do algoritmo Fi- \\
\hline bonacci no modelo de partição e protocolo em um dispositivo xv2p30. Os
\end{tabular} retângulos indicam onde ar PRRs estão localizadas. . . . . . . . . . . . . . 75

5.10 Simulação temporal de envio de token para uma instância da partição $p_{1}$. $\quad 75$

5.11 Screenshot da ferramenta PlanAhead com uma visão da ocupação dos módulos sintetizados da implementação dinâmica do GFD do algoritmo Fibonacci no modelo de partição e protocolo em um dispositivo xv2p30. Os

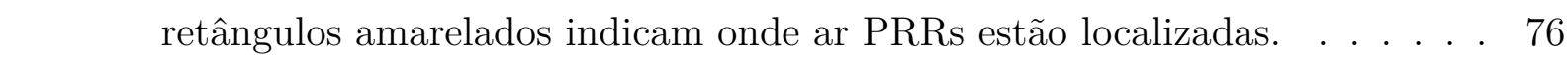

5.12 Screenshot da ferramenta FPGA Editor com uma visão da ocupação do hardware sintetizado da parte estátida da implementação dinâmica do GFD do algoritmo Fibonacci no modelo de partição e protocolo em um disposi-

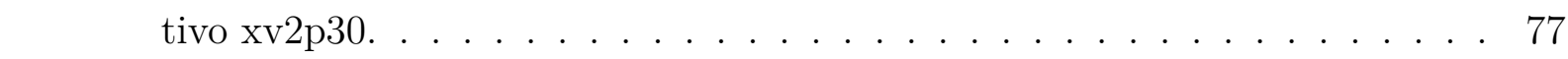

5.13 Screenshot da ferramenta FPGA Editor com uma visão da ocupação do hardware sintetizado do módulo PRM1 na PRR2 da implementação dinâ\begin{tabular}{|c|}
\hline mica do GFD do algoritmo Fibonacci no modelo de partição e protocolo \\
\hline
\end{tabular} em um dispositivo xv2p30. . . . . . . . . . . . . . . . . . . . . . 78

5.14 Screenshot da ferramenta FPGA Editor com uma visão da ocupação do hardware sintetizado do módulo PRM2 na PRR2 da implementação dinâ\begin{tabular}{|c|}
\hline mica do GFD do algoritmo Fibonacci no modelo de partição e protocolo \\
\hline
\end{tabular} em um dispositivo xv2p30. . . . . . . . . . . . . . . . . . . . . 79

5.15 Gráfico com os tempos de execução do GFD estático e o GFD no modelo de partição e protocolo. . . . . . . . . . . . . . . . . . . 80 


\section{Lista de Tabelas}

3.1 Cabeçalho do pacote tipo 1. . . . . . . . . . . . . . 33

3.2 Cabeçalho do pacote tipo $2 . \ldots \ldots \ldots \ldots \ldots \ldots$

3.3 Lista parcial de endereços de registradores do hardware de reconfiguração. 34

3.4 Composição do endereço de um frame. . . . . . . . . . . . . 34

$4.1 \quad$ Resultados dos testes experimentais da relação entre número de operadores por coluna. Adaptado de $\mid$ Souza Junior et al., $|2010| .$. . . . . . . . . . . . 50

4.2 Tempo de reconfiguração para áreas das Partially Reconfigurable Region (PRR)s testadas. Adaptado de [Souza Junior et al.[2010] . . . . . . . . . . 51

4.3 Pacote do token do protocolo de comunicação. . . . . . . . . . . 58

5.1 Tempo de execução do GFD estático do Algoritmo Fibonacci sem utilização do modelo de partição e protocolo. . . . . . . . . . . . . . . . 70

5.2 Tempo de execução do código em C do Algoritmo Fibonacci para o método

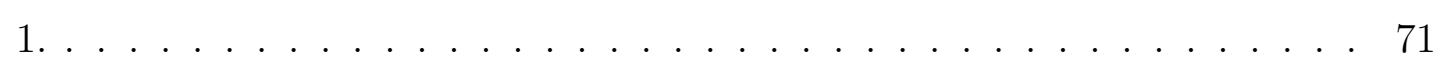

5.3 Tempo de execução do código em C do Algoritmo Fibonacci para o método

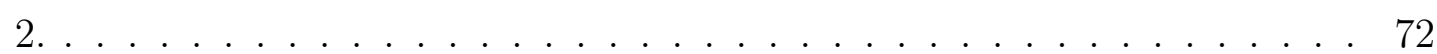

$5.4 \quad$ Speedup do tempo de execução do código em C do Algoritmo Fibonacci sobre o GFD Estático. . . . . . . . . . . . . . . . . . . . . 73

5.5 Tempo de execução do GFD estático do Algoritmo Fibonacci sem utilização do modelo de partição e protocolo. . . . . . . . . . . . . . . . . . 80

5.6 Tempo de reconfiguração do GFD dinâmico do Algoritmo Fibonacci com a utilização do modelo de partição e protocolo. . . . . . . . . . . . . . . . 82 


\section{Lista de Algoritmos}

5.1 Algoritmo Fibonacci iterativo $\quad \ldots \ldots \ldots$. . . . . . . . . . . . . . . . 64 


\section{Lista de Siglas}

API Application Programming Interface

ASIC Application-Specific Integrated Circuit

BRAM Block Random Access Memory

CAD Computer-Aided Design

CCM Context Configuration Manager

CLB Configurable Logic Block

CPU Central Processing Unit

DISC Dynamic Instruction Set Computer

DORGA Dynamic optically reconfigurable gate arrays

DPGA Dynamic-progammable Gate Array

DRAM Dynamic Random Access Memory

DSP Digital Signal Processor

EAPR Early Access Partial Reconfiguration

EDA Eletronic Design Automation

EP Elemento de Processamento

EEPROM Electrically Erasable Programmable Read-Only Memory

EPROM Erasable Programmable Read-Only Memory

FPGA Field-programmable Gate Array

GES Gerenciador de Entrada e Saída 
GFD Grafo de Fluxo de Dados

GR Gerenciador de Reconfigurações

HLL High Level Language

HWICAP Hardware Internal Configuration Memory

ICAP Internal Configuration Access Port

JTAG Joint Test Action Group

LPAN Linguagem de Programação de Alto Nível

LDH Linguagem de Descrição de Hardware

LUT Look-up Table

MAC multiply accumulate

MIPS Microprocessor Without Interlocked Pipeline Stages

NoC Network on Chip

PAB Processing Array Bits

PAR Place and Route

PAM Programmable Active Memory

PLD Programmable Logic Devices

PPC Power PC

PRM Partially Reconfigurable Module

PRR Partially Reconfigurable Region

PSN Packet Switched Network

RALU Reconfigurable ALU Array

RAM Random Access Memory

RaPiD Reconfigurable Pipelined Datapath

RD Reconfiguração Dinâmica

RISC Reduced Instruction Set Computer

RTL Register Transfer Level

RTR Run-Time Reconfiguration

xxiv 
RPD Reconfiguração Parcial Dinâmica

RPF Reconfigurable Processing Unit

SIMD Single Instruction, Multiple Data

SPLD Simple Programmable Logic Devices

SoC System on Chip

SoPC System on Programmable Chip

SRAM Static Random Access Memory

TTL Transistor-transistor logic

ULA Unidade de Lógica e Aritmética

ULAr Unidade de Lógica e Aritmética reconfigurável

VIC Virtual Instruction Configuration

VHDL VHSIC Hardware Description Language

VHSIC Very-High-Speed Integrated Circuits

VLSU Vector Load/Store Unit

WASMII What A Steap Machine Is It

XUP Xilinx@ University Program 


\section{Introdução}

A lei de Moore prevê que haverá uma duplicação de transistores em um chip a cada 24 meses. Todavia, esta é uma tendência que perdurará apenas os próximos dez ou vinte anos Intel, 2005. Não obstante, apenas o aumento do número de transistores não necessariamente aumenta o desempenho do chip. Para isto, existem três barreiras

que precisam ser transpostas: escalabilidade, potência e memória Ronen et al., 2001; Gelsinger, 2001; Parkhurst et al., 2006; Spracklen \& Abraham, 2005, Collins, 2003.

A primeira barreira de escalabilidade, refere-se ao aumento de complexidade dos circuitos, o que diminui o time-to-market e consequentemente aumenta a possibilidade de inserção de bugs nos circuitos. Essa barreira também refere-se à crescente disparidade entre o desempenho dos processadores e da comunicação interna do chip, além da decrescente confiabilidade da tecnologia dos circuitos, devido ao processo de miniaturização de seus componentes.

A segunda barreira de potência, representa a crescente energia gasta pelo chip por unidade de área, o que leva à um decréscimo da eficiência devido ao aumento da temperatura.

Finalmente, a terceira barreira de memória, elucida as limitações ocasionadas pelo compartilhamento de barramentos e da largura de banda de memória, que constituem gargalos da arquitetura de von Neumann.

Ainda, a tradicional arquitetura de von Neumann acaba limitando o uso do chip. Sua natureza de execução serial faz com que partes do chip fiquem ociosos esperando que outras partes executem. Para tentar reduzir esse problema, foi introduzida a técnica de pipeline nos processadores. Assim, foi possível que cada parte de uma instrução fosse executada paralelamente dentro do chip, o que aumentaria seu desempenho. Entretanto, devido a própria natureza serial dos programas na arquitetura de von Neumann, essa técnica apresentou-se limitada, posto que não é possível prever perfeitamente saltos (branchs) no 
código.

A arquitetura baseada em fluxo de dados (do inglês Dataflow) é uma alternativa não convencional a arquitetura de von Neumann, sendo que esta possui um paralelismo de fina-granularidade inerente. Tal paralelismo é proporcionado pelo controle de execução baseado na disponibilidade dos dados, ao contrário da arquitetura de von Neumann, que tem seu controle de execução baseado nas suas estruturas de controle, necessitando, assim, de um contador de programa (program counter) Dennis \& Misunas, 1974; Veen, 1986; Dennis, 1980; Arvind, 2005]. Desta forma, um alto grau de paralelismo pode ser alcançado, posto que as instruções são executadas assim que os dados necessários para as mesmas estejam disponíveis.

Nas arquiteturas baseadas em fluxo de dados, os programas são previamente convertidos para um GFD. Neste processo, as dependências de controle são convertidas em dependências de dados. Desta maneira, nessas arquiteturas os nós presentes em um GFD são executados em diferentes unidades de processamento paralelamente. Todavia, existem várias limitações que impossibilitaram até hoje implementações com utilidade prática deste modelo [Lee \& Hurson, 1993]. As maiores limitações podem ser citadas: (a) dificuldade em mapear com eficiência o GFD no hardware de destino; (b) a dificuldade de lidar com as pilhas de tokens geradas. Assim, o paralelismo desejado com o modelo baseado em fluxo de dados é muitas vezes absorvido pelo overhead gerado na implementação do modelo Gajski et al. 1982.

O interesse em pesquisar essas arquiteturas se dá na necessidade de certas aplicações, como aplicações científicas, por um alto poder de processamento. Ainda assim, muitas vezes essas arquiteturas não são suficientes para satisfazer as necessidades dessas aplicações. Dessa forma, uma solução bastante popular atualmente consiste em criar uma implementação diretamente em hardware de pontos de intenso processamento dessas aplicações. Geralmente, essa pesquisa faz-se por meio da utilização de FPGA, que é um tipo de hardware que permite reconfiguração, possibilitando rápida implementação de um algoritmo em hardware, posto que um eventual defeito na implementação pode ser facilmente corrigido sem que o chip tenha que ser fabricado novamente.

Uma forma de programar um FPGA é utilizar uma Linguagem de Descrição de Hardware ( $\mathrm{LDH}$, do inglês, Hardware Description Language, que é uma linguagem criada especificamente para descrição de circuitos digitais. Embora a programação de FPGAs seja menos tortuosa utilizando-se LDH do que com os métodos tradicionais para descrição de circuitos digitais, como Transistor-transistor logic (TTL), tal processo ainda continua bastante complexo e demorado, se comparado às etapas de criação de um programa de computador com LPAN, como $\mathrm{C}$ ou Python. Por isto, é interessante estudar métodos de construção de hardware a partir de LPAN Cardoso \& Neto, 2003; Lopes, 2007; Lopes et al. 2006; Pellerin \& Thibault, 2005. Outra vantagem de se utilizar LPAN para geração de hardware, é que conforme esse paradigma e algumas dessas linguagens são mais difundidas, é possível reutilizar código já existente, além de não ser necessário que pro- 
gramadores dessas linguagens que queiram implementar alguma aplicação em hardware passem por uma grande readaptação.

Alguns FPGAs, ainda, permitem que seus circuitos sejam reconfigurados em tempo de execução. Tal reconfiguração é chamada de Reconfiguração Dinâmica, ou RPD. Reconfiguração Dinâmica implica que uma FPGA pode ser reconfigurado durante sua execução. RPD implica que apenas uma parte de um FPGA pode ser reconfigurado em tempo de execução. Desta forma, apenas parte do FPGA é modificado, enquanto outra parte continua executando, sem que haja perda de dados.

Isto possibilita a criação de ferramentas de compilação que geram hardware dinâmico a partir de algoritmos implementados em uma LPAN. A ferramenta ChipCflow, em desenvolvimento desde o início de 2006, trata-se de um projeto de arquitetura baseada em fluxo de dados dinâmico, implementado em hardware parcialmente reconfigurável. Com o objetivo de acelerar programas escritos na linguagem $\mathrm{C}$, por meio da execução direta em hardware, beneficia-se do paralelismo natural do modelo baseado em fluxo de dados, além do desempenho e versatilidade do hardware parcialmente reconfigurável Silva \& Marques, 2006; Silva, 2006; Lopes et al., 2006; Astolfi \& Silva, 2007; Souza Junior et al. 2010.

Para lidar com os problemas citados em máquinas tradicionais de fluxo de dados, que não apresentaram vantajoso uso prático até hoje [Gajski et al., 1982, a ideia inicial do ChipCflow consiste em descentralizar as unidades de matching (circuitos de máquinas baseadas em fluxo de dados responsáveis pela identificação dos pares de tags), que são responsáveis por grande parte do overhead dessas máquinas. Essa descentralização acontece por meio da "cópia" real do hardware dos nós dos GFD. Desta forma, cada "instância" pode ser responsável por executar apenas um dado por vez.

Para que essa "cópia" de nós dos GFD aconteça dentro do hardware reconfigurável, é necessário definir um modelo de arquitetura que respeite as limitações impostas pela RPD. Esse modelo foi chamado de modelo de partição e protocolo de comunicação.

\subsection{Objetivos}

O objetivo deste projeto é a prova de conceito do processo de partição e do protocolo de comunicação entre as partições definidas a partir de um GFD para a execução direta em hardware parcialmente reconfigurável, tendo como base as plataformas parcialmente reconfiguráveis da Xilinx®, série Virtex. Dadas as características dessa plataforma, é necessário elaborar uma arquitetura de partição e protocolo de comunicação entre essas partições, uma vez que o FPGA possui várias características limitantes inerentes da RPD. Finalmente, serão apresentadas algumas avaliações de desempenho para verificar se o overhead causado pela estrutura de partição e protocolo não comprometem o projeto como um todo. 


\subsection{Organização da Monografia}

A monografia está organizada em 5 capítulos:

No Capítulo 2 é descrita a Computação Reconfigurável. Indo de uma abordagem histórica e teórica, até uma análise da tecnologia FPGA e das arquiteturas reconfiguráveis criadas com essa tecnologia.

O Capítulo 3 contém informações sobre a RPD. Nesse Capítulo são apresentadas tecnologias atuais - científicas e comerciais - de reconfiguração dinâmica e parcial, e será demonstrada a arquitetura da Xilinx@ Virtex II, o dispositivo utilizado neste trabalho para a implementação e validação do modelo.

No Capítulo 4 é abordada a ferramenta ChipCflow de uma forma geral e posteriormente no modelo de partição e protocolo com mais ênfase. Neste Capítulo, também é apresentada a metodologia de validação e implementação do modelo de partição e protocolo.

No Capítulo 5 serão vistos os resultados obtidos com a implementação e com os experimentos propostos no Capítulo 4. Além disso, uma discussão minuciosa dos resultados obtidos é apresentada nesse Capítulo.

Finalmente, no Capítulo 6] são apresentas as conclusões obtidas a partir dos resultados e discussões apresentadas no Capítulo 5. 




Tradicionalmente, existem duas formas de se executar um algoritmo Compton \& Hauck, 2002. A primeira é utilizando tecnologia hardwired, como Application-Specific Integrated Circuit (ASIC), efetuando operações diretamente no hardware. ASIC são desenvolvidos para executar uma tarefa específica em hardware, e por isso, são rápidos e eficientes para desempenhar tal tarefa. Todavia, devido ao fato de utilizar tecnologia hardwired, ele não pode ser alterado, forçando um novo projeto e consequentemente uma nova fabricação caso haja necessidade de se modificar seus circuitos.

A segunda forma, também conhecida como computação de propósito geral (von Neumann), é utilizando microprocessadores que podem ser programados por software. Deste modo, qualquer alteração na lógica do algoritmo pode ser rapidamente incluída no software, posto sua facilidade de modificação. Essa flexibilidade tem um custo no desempenho, dado que um microprocessador baseado na arquitetura de von Neumann ainda precisa ler a instrução na memória, decodificar tal instrução para, então, finalmente executá-la.

Com escopo de execução mais amplo que ASICß, programados por software mas não tão flexíveis quanto microprocessadores de propósito geral, os processadores de domínio específico (Domain-Specific Processor) são construídos para executar uma classe específica de algoritmos. Digital Signal Processor (DSP) é a classe de processadores de domínio específico mais utilizada, e são otimizados para operações de processamento de sinais em que cálculos aritméticos intensivos são necessários. Normalmente, eles possuem rápidos circuitos para a função multiply accumulate (MAC) (executando-as em apenas um ciclo) Bobda, 2007.

Na Figura 2.1 é demonstrado um gráfico sobre a contradição entre flexibilidade e desempenho existente.

A Computação Reconfigurável foi criada com o intuito de se preencher o grande vazio entre essas três classes de processadores, podendo-se conseguir um desempenho mais alto 


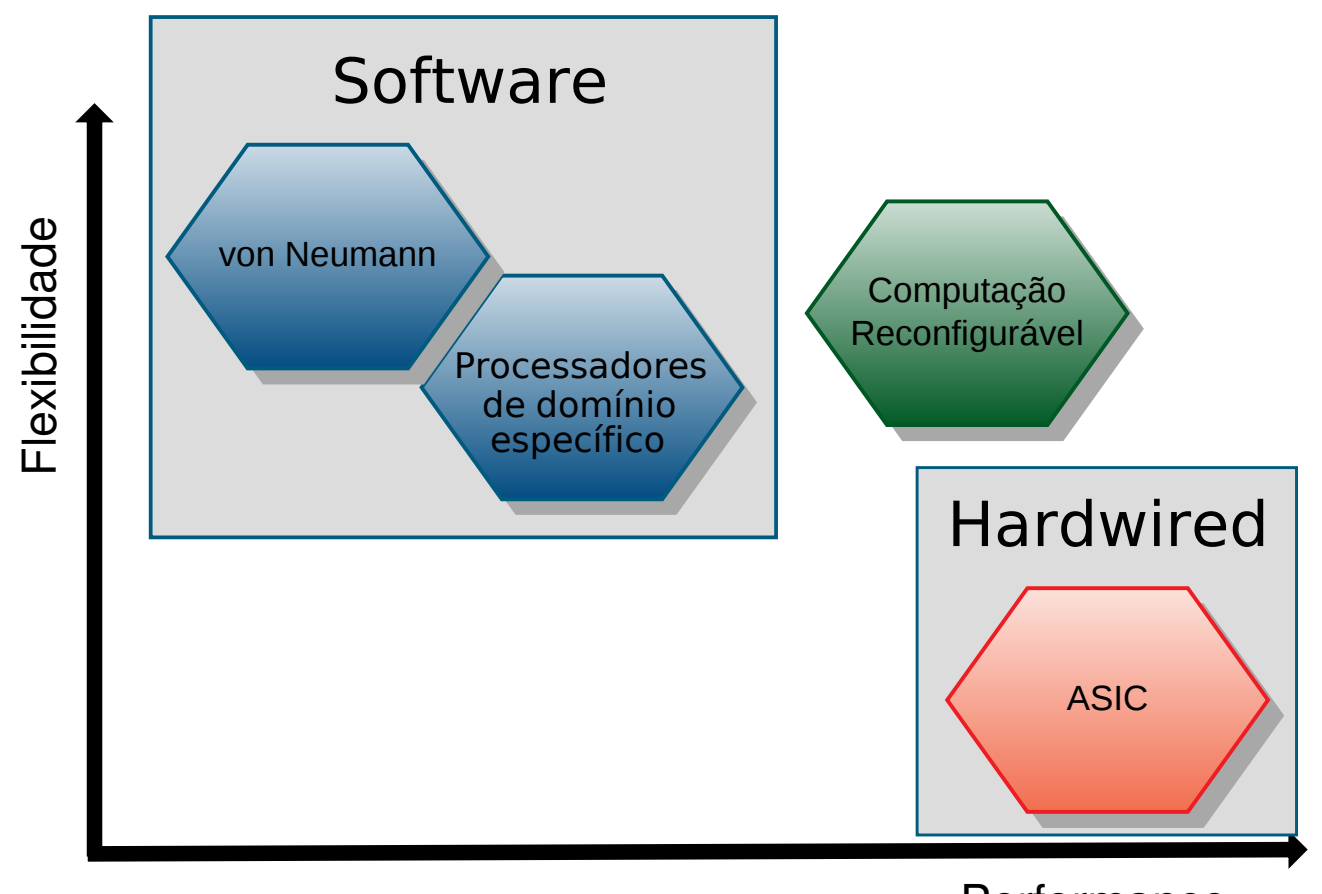

Performance

Figura 2.1: Comparação de Flexibilidade versus Desempenho de classes de processadores. Adaptado de [Bobda, 2007]

que o software (computação de propósito geral) e uma flexibilidade maior que a tecnologia hardwired (Figura 2.1). Sua principal diferença em relação as arquiteturas tradicionais que utilizam tecnologia hardwired é a possibilidade de "programação" de um circuito. Esse processo de programação é comumente referido como reconfiguração. A reconfiguração acontece com bits de configuração que são enviados para o chip. Esses bits de configuração são normalmente chamados de bitstream.

As estruturas reconfiguráveis presentes em computadores reconfiguráveis são chamadas de Reconfigurable Processing Unit ( $\mathrm{RPF}$, ou, estruturas de processamento reconfigurável. Elas normalmente são relativamente simétricas e podem ser divididas em estruturas funcionais menores, em que cada uma pode ser chamada de Processing Element, ou EP. Para implementar uma determinada tarefa, RPF são reconfiguradas por meio de bitstreams de configuração contendo todas as "instruções virtuais" (Virtual Instruction Configuration (VIC) requeridas para que tal tarefa seja corretamente computada Hauck \& DeHon, 2007.

Comumente, RPFs possuem menor frequência de clock do que DSPs ou arquiteturas tradicionais. Sua vantagem, no entanto, se dá na possibilidade de se criar estruturas otimizadas, dedicadas e com um alto grau de paralelismo e pipeline. Devido a isto, geralmente, apenas tarefas de alto custo computacional que podem se beneficiam destas características tem uma implementação vantajosa em $\mathrm{RPF}$.

As arquiteturas das $\mathrm{RPF}$ presentes na computação reconfigurável variam na granularidade de seus elementos. A granularidade varia da fina (fine-grained), onde manipula-se pequenas unidades de processamento, para a grossa (coarse-grained), onde a reconfigura- 


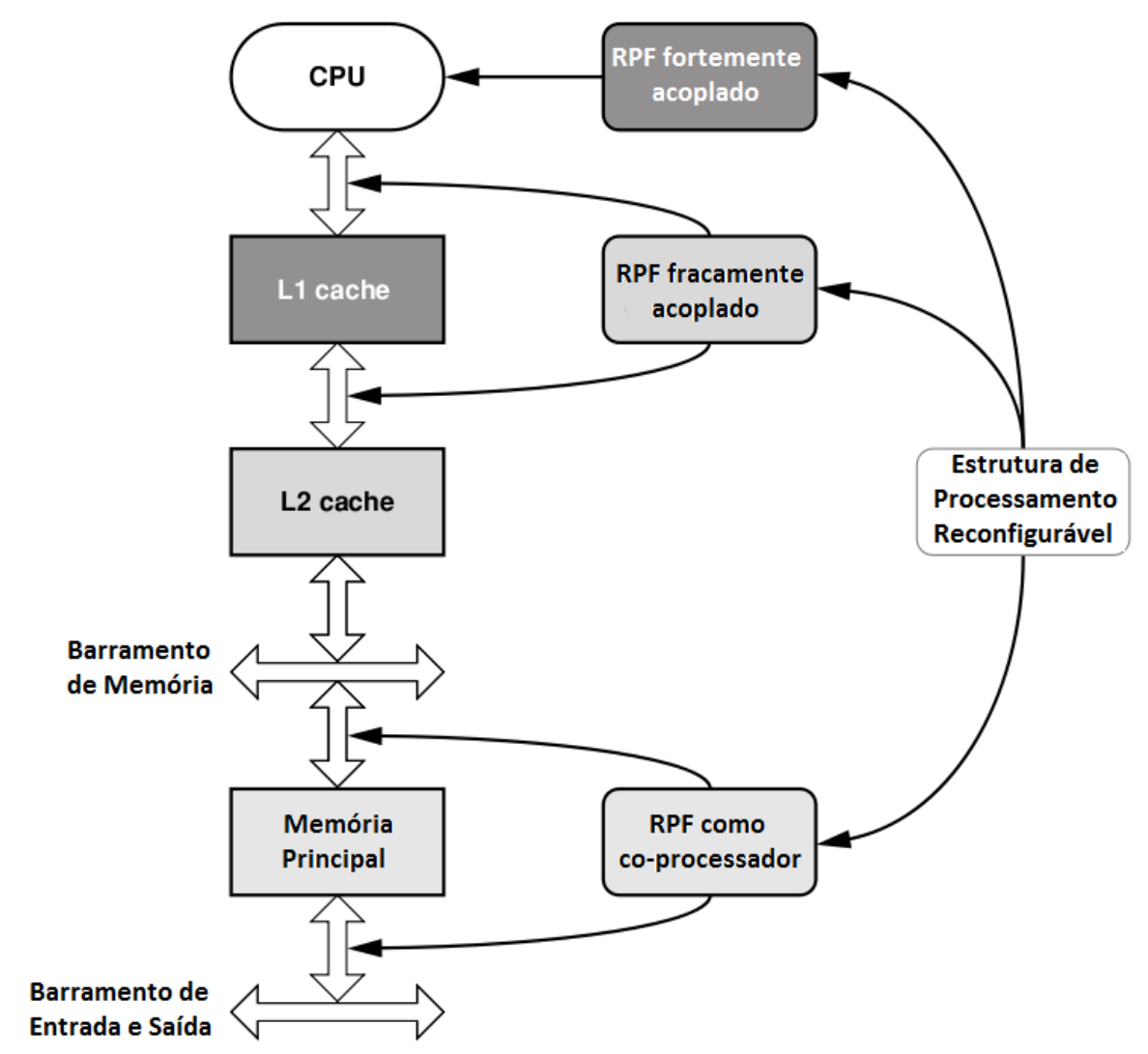

Figura 2.2: Diferentes formas de acoplar um RPF à um CPU host. Adaptado de Hauck \& DeHon, 2007.

ção consiste no roteamento e configuração de unidades complexas, como multiplexadores e Unidade de Lógica e Aritmética (ULA) Hauck \& DeHon, 2007.

Tipicamente, computadores reconfiguráveis consistem na conjunção de RPF;, CPU host, memória e outras estruturas. Esses computadores, então, podem ser catalogados baseados na forma em que as RPF são acoplados a CPU host de acordo com a hierarquia da memória do sistema. Hauck \& DeHon [2007] define três categorias básicas em que uma estrutura reconfigurável pode se acoplar à CPU; acoplamento forte, acoplamento fraco e como um co-processador independente. Alguns diagramas dessa hierarquia podem ser vistos na Figura 2.2. Os retângulos arredondados dizem respeito às $\mathrm{RPF}$, quanto mais escuro é seu preenchimento, mais fortemente acoplado é o RPF ao processador. Os retângulos representam os diferentes tipos de memória do sistema. Quanto mais escuro é seu interior, mais fortemente acoplado é a memória ao CPU.

Várias arquiteturas reconfiguráveis foram propostas desde a invenção do termo, a maioria delas provenientes de trabalhos acadêmicos. Infelizmente, poucos computadores reconfiguráveis conseguiram entrar no mercado atual, dominado por arquiteturas mais tradicionais. Nas próximas Seções, algumas das arquiteturas reconfiguráveis relevantes serão apresentadas. 


\subsection{Pré-FPGA}

Com a chegada dos FPGAs comerciais, a pesquisa em computação reconfigurável cresceu sobremaneira, posto que houve um acesso mais amplo a uma estrutura que possibilitava a reconfiguração. Atualmente, a maior parte das pesquisas em computação reconfigurável são desenvolvidas com a utilização de FPGA computação reconfigurável ocorreu pelo menos vinte anos antes da produção em larga escala dos FPGA tradicionais. Esta Seção fará um breve análise do avanço da pesquisa em computação reconfigurável antes da comercialização dos FPGA;.

\subsubsection{Máquina Fix-plus}

O conceito de computação reconfigurável foi introduzido em 1959 por Gerald Estrin Bobda, 2007. No começo da década seguinte, ele publicou alguns artigos em que apresentava o conceito de computação reconfigurável e implementava sua visão com uma máquina chamada máquina fix-plus Estrin \& Turn, 1963.

A arquitetura deste computador foi dividida em três partes: parte fixa (F), parte variável (V) e parte de controle supervisora (SC) Estrin \& Turn, 1963. As partes (F) e (SC) eram estáticas, sendo que a primeira consistia em um processador e memórias de alta-velocidade e uma memória externa. A segunda controlava as operações entre as outras duas partes. A parte (V) era formada por uma RPF que funcionava como um coprocessador e por memórias de alta velocidade e memória externa. A Figura 2.3 contém um diagrama da organização das partes da máquina.

Sua RPF era composta por blocos modulares que poderiam ser inseridos em qualquer uma de 36 posições da placa mãe. Esses blocos modulares básicos eram inseridos fisicamente na placa mãe e eram modificados manualmente, sendo que poderiam ser substituídos por blocos novos. Dois tipos de blocos básicos estavam disponíveis na máquina fix-plus: o primeiro bloco básico era composto por quatro amplificadores associados à lógica de entrada para inversão de sinal, amplificação ou armazenamento de alta-velocidade. O segundo bloco básico era combinatório e era construído por dez diodos e quatro drivers de saída.

A máquina fix-plus era utilizada para acelerar o cálculo de auto-valores e mostrou um aumento de velocidade de 2,5 a 1000 sobre um IBM7090 Estrin \& Viswanathan, 1962.

\subsubsection{A Máquina de Ramming}

Em 1977, Rammig 1977] apresentou o conceito de um hardware editável sem qualquer interferência mecânica ou manual e, por consequência, seu editor, de uma forma similar as arquiteturas das FPGAs de hoje. Esse editor foi construído a partir de um conjunto de módulos, pinos e de uma função de mapeamento um-para-um sobre esse conjunto de pinos. Poderiam haver dois estados para essa função: $\mathrm{w}=$ wired (ligado) e $\mathrm{u}=$ unwired 


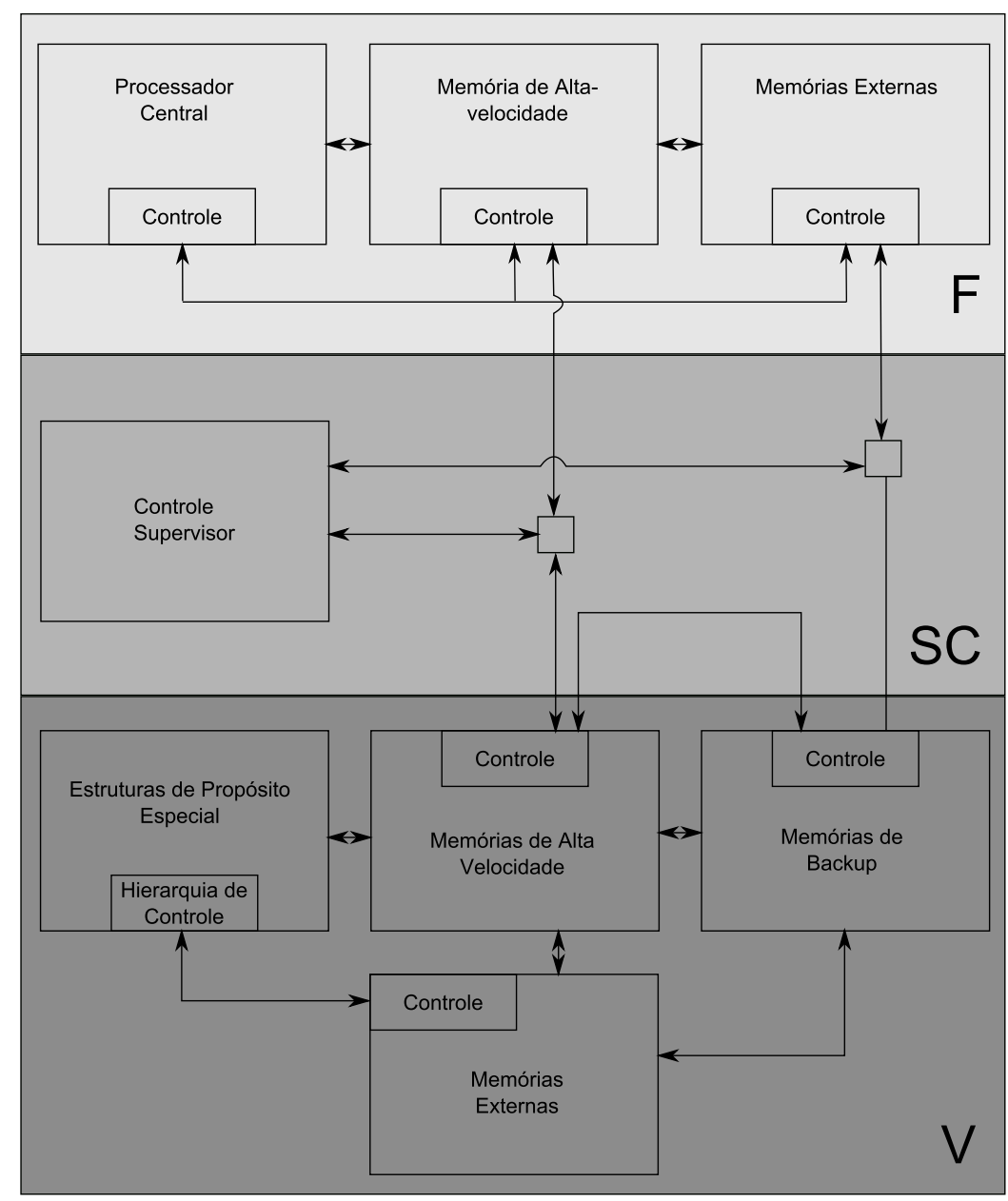

Figura 2.3: Organização da Máquina fix-plus [Bobda, 2007].

(desligado). Com essa função, era criada uma série de bits, capazes de programar os seletores. A Figura 2.4 contém a arquitetura dessa máquina.

Essa propriedade foi implementada com uma crossbar switch, construída sobre um array de seletores. As séries de bits eram fornecidas para gravação do seletor de controle nos registradores, e para fazer desses registradores acessíveis de um computador host. Cada placa poderia ser selecionada pelo software de controle. O mapeamento da entrada e saída do módulo para os pinos foi feita manualmente.

\subsubsection{XPuter}

O conceito do XPuter foi apresentado no começo dos anos oitenta por Reiner Hartenstein Bobda, 2007]. Seu objetivo era conseguir um alto-grau de paralelismo em um hardware reprogramável, a fim de conseguir um desempenho que não é possível com a arquitetura de von Neumann. Ao contrário da arquitetura de von Neumann, o XPuter não sequenciava instruções, fazendo que seu controle fosse feito por meio de fluxo de dados. Um XPuter consistia em três partes principais: o sequenciador de dados, a memória de dados e uma RPF, chamada de Unidade de Lógica e Aritmética reconfigurável (ULAr). A manipulação dos dados era feita pela ULAr que acessava várias scan windows. A parte mais essencial do sequenciador de dados era o Gerador de Endereços Genérico (GEG), que 




Figura 2.4: Estrutura da Máquina de Ramming [Bobda, 2007.

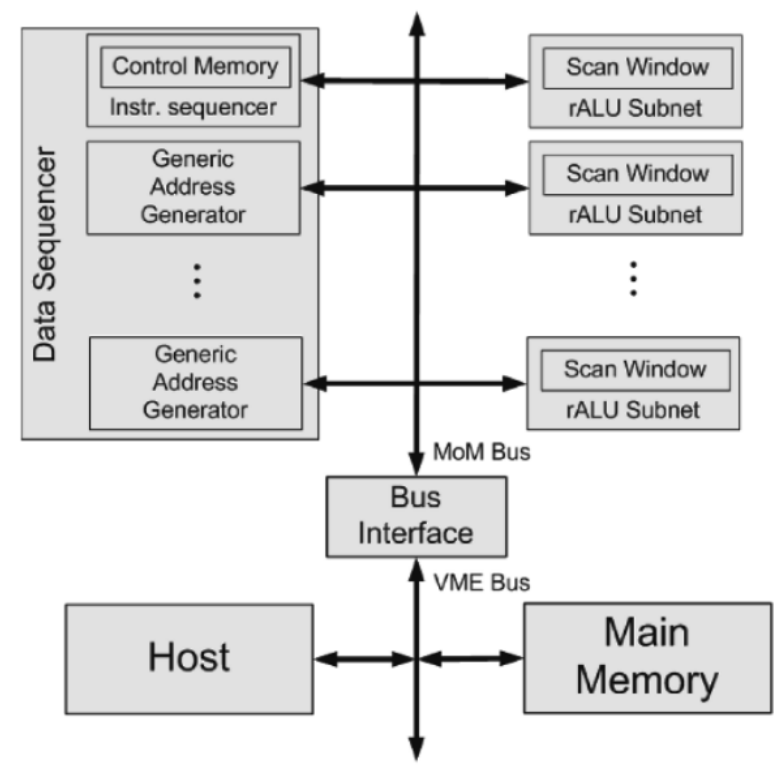

Figura 2.5: Organização do XPuter implementado como uma Map Oriented Machine Bobda, 2007.

era capaz de produzir sequências de endereços correspondentes aos dados das próximas três interações dos laços. A Figura 2.5 contém a organização do XPuter implementado como uma Map Oriented Machine.

A ULAr era composta por vários EPs, chamados de Reconfigurable Data Path Units, ou, unidades reconfiguráveis de fluxo de dados, interligados entre si por meio de várias conexões reprogramáveis (Figura 2.6). Ela, então, permitia a reconfiguração em tempo de execução dos canais dessas conexões. Dentro de um laço, os dados que eram processados eram acessados via estruturas de dados chamadas scan windows. Cada EP possuía duas entradas e duas saídas de 32 bits cada. As entradas eram localizadas no norte e no oeste, enquanto as saídas ficavam localizadas no sul e no leste. Essa forma de organização permitia que as entradas e saídas ficassem ligadas de forma encadeada. Junto com essas 


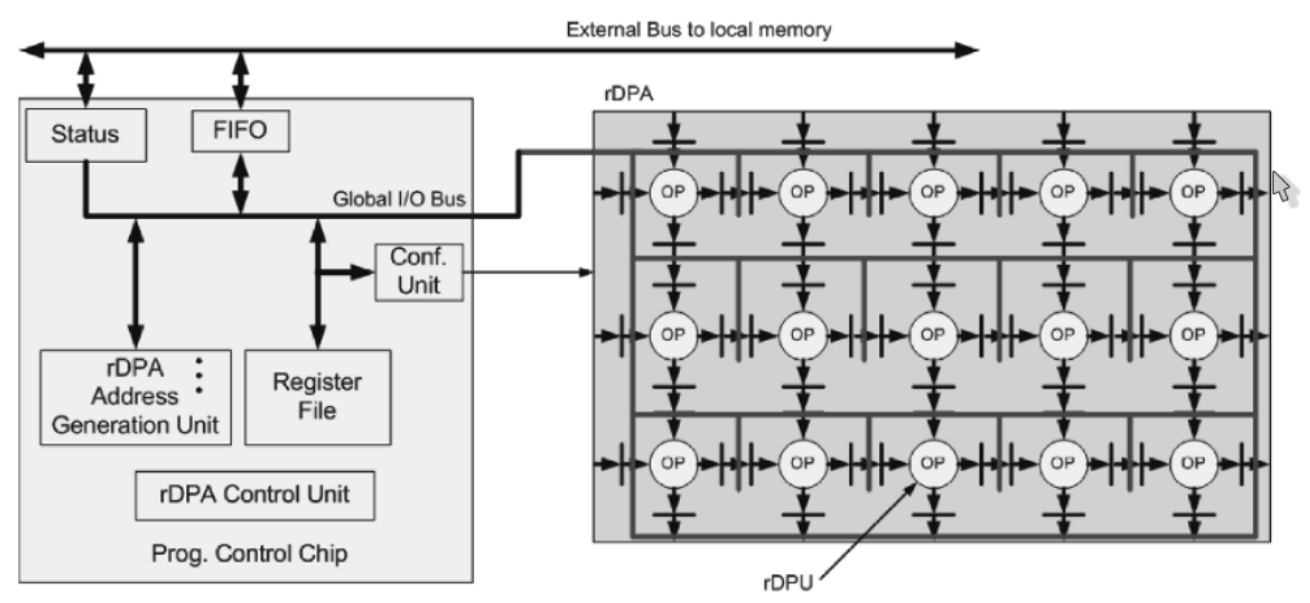

Figura 2.6: Arquitetura da RALU, demonstrando as EPs e uma estrutura de controle [Bobda, 2007].

ligações entre as $\mathrm{EP}$, ainda, havia um barramento de entrada e saída. Esse barramento era utilizado principalmente para acessar as scan windows. Além disso, havia uma unidade de controle que é responsável por interligar a RPF ao resto do sistema. Dentro dela, há a unidade de reconfiguração, responsável por reconfigurar a RPF, além de registradores utilizados para otimizar o acesso à memória pela RPF.

O XPuter tinha como escopo aplicações de processamento de imagens, arrays sistólicos e processamento de sinais.

\subsection{Pós-FPGA}

Com a chegada do FPGA no meio dos ano 80 Vuillemin et al. [1996], a computação reconfigurável ficou mais acessível e popular, ainda que essa popularidade tenha se restringido ao meio acadêmico. Isso se deu devido a existência de ferramentas comerciais que a viabilizaram e baratearam a pesquisa na área.

\subsubsection{FPGA}

FPGAs, possuem arrays de elementos computacionais que podem ser modificados por meio de bits de configuração. Esses elementos são conectados por um conjunto de recursos de roteamento também reprogramáveis. Desta forma, novos circuitos digitais podem ser mapeados dentro dessa organização, aumentando a flexibilidade do hardware, sem perder muito do seu desempenho.

Normalmente, FPGAs apresentam frequências de clock inferiores a processadores de propósito geral e específico. Isso é decorre de diversos fatores, que variam desde o tamanho dos transístores (frutos dos processos de fabricação das empresas), até a própria estrutura destes. Uma porta lógica em um CLB em um FPGA é maior do que a em transistor hardwired. Em termos gerais, pode ser observado uma correlação (sem relação de casualidade) entre paralelismo de operações e a frequência de clock (Figura 2.7). 


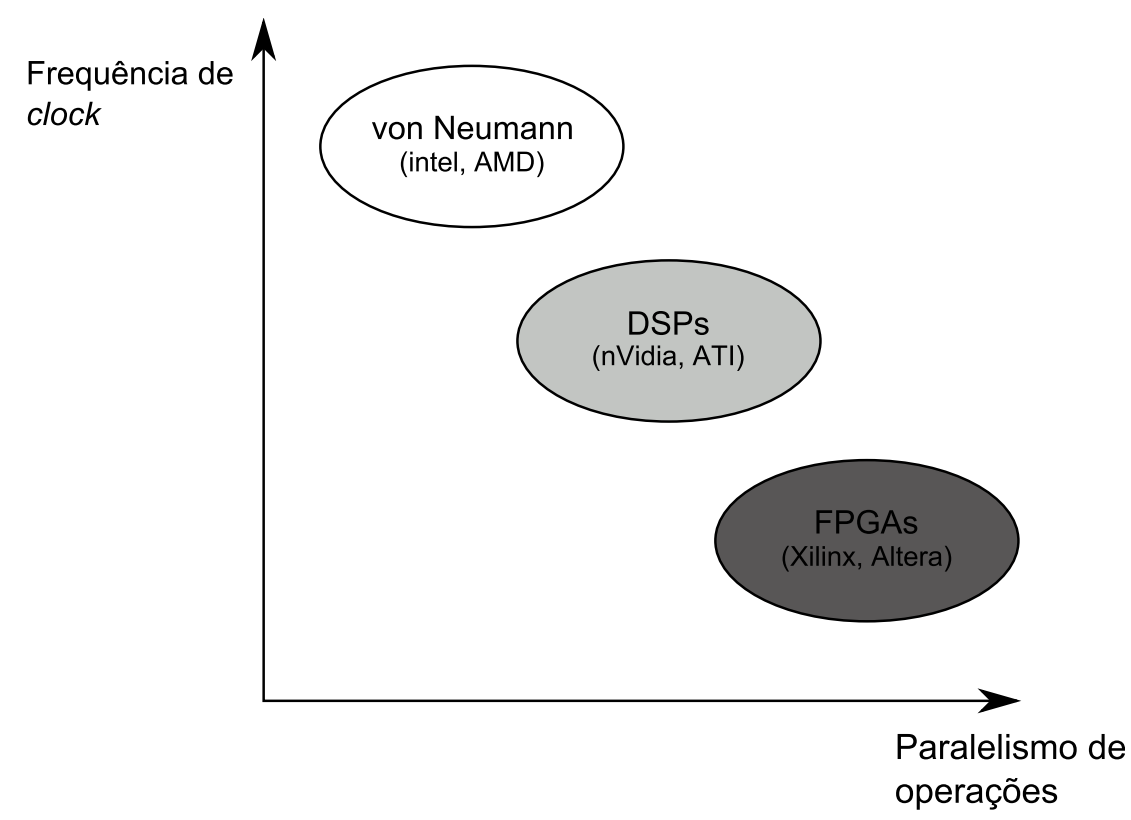

Figura 2.7: Gráfico ilustrativo da correlação entre paralelismo de operações e frequência de clock. Entre parênteses, exemplos de empresas que fabricam tais chips.

Esta correlação pode ser considerada natural, pois o uso vantajoso de arquiteturas com uma frequência de clock menor só pode ser interessante se ela trouxer um ou mais benefícios para a aplicação desejada. Esses benefícios, contudo, não se limitam a capacidade de processamento do dispositivo. A escolha do chip geralmente considera vários fatores, tais como, tamanho, consumo preço, suporte do fabricante etc. Todavia, pelo ponto de vista específico expresso aqui (capacidade de processamento), o benefício dessas arquiteturas (FPGAs e DSPs) se dá por meio do paralelismo que pode ser conseguido com elas.

Essa ideia pode ser validada por meio de alguns trabalhos realizados, com implementações de aplicações com dispositivos reconfiguráveis. Com essas implementações, é possível obter aumentos significativos no desempenho, se comparados a computadores de propósito geral, principalmente quando essas aplicações apresentam um alto grau de paralelismo Compton \& Hauck, 2002.

Elbirt \& Paar 2000] demonstrou uma implementação em FPGA do algoritmo Serpent de criptografia em blocos de chave simétrica, finalista do "Advanced Encryptation Standard process" Bulman, 1999. Essa implementação, feita em um FPGA Xilinx@ Virtex XCV1000, demonstrou um aumento de troughtput com um fator de dezoito em relação a um Pentium Pro $200 \mathrm{MHz}$.

Outro trabalho demonstra uma implementação um sistema de processamento de imagens em FPGA em que o aumento de desempenho com uma FPGA Xilinx@ XCV2000E rodando à $50 \mathrm{MHz}$ em relação a um software rodando em um microprocessador de $266 \mathrm{MHz}$ foi do fator de 2,5 McBader \& Lee, 2003.

Ainda que esses trabalhos tenham se limitado a analisar microprocessadores bastante lentos para os padrões de mercado da época, alguns outros trabalhos mostram a comparação com processadores mais atuais, tal como Lee et al. [2006], que realizou um estudo 
em que construiu em um FPGA Xilinx@ Virtex-II Pro XC2VP100-7 rodando a $95 \mathrm{MHz}$ um gerador de ruídos utilizando o método Box-Muller. O aumento de desempenho sobre um software que executou o mesmo algoritmo em um computador Pentium-4 $3 \mathrm{GHz}$ foi de duzentas vezes. Este aumento foi obtido devido ao alto grau de paralelismo do algoritmo utilizado.

Vários outros trabalhos mais recentes que demonstraram algum ganho de desempenho com utilização de FPGAs podem ainda ser encontrados, algumas referências interessantes são: [Asano et al., 2009], [Bonato et al., 2007], GholamHosseini \& Hu, 2008] e outros.

\subsubsection{Estrutura}

Um FPGA é um chip semi-condutor normalmente formado por um arranjo de células ou blocos configuráveis (CLB), uma rede que interconecta esses blocos reconfiguráveis, células de entrada e saída que também são reconfiguráveis e eventualmente outros blocos de diferentes tipos. As arquiteturas dos FPGAs variam de fabricante e modelo. Algumas arquiteturas, mais simples, possuem apenas blocos lógicos e de entrada e saída que são interligados entre si, semelhante a estrutura mostrada na Figura 2.8. Outras arquiteturas mais complexas, apresentam, além dessas estruturas, outras diferentes, como Block Random Access Memory (BRAM) e até processadores Power PC (PPC). A Figura 2.9 contém um diagrama da estrutura do FPGA Xilinx@ Virtex 2-Pro, modelo XV2P30. Neste modelo, além das estruturas básicas já citadas, há diversas colunas de BRAM;, multiplicadores e dois processadores $\mathrm{PPC}$. Neste diagrama, as estruturas de comunicação não são mostradas.

Essas estruturas são reconfiguradas por meio de uma memória, presente no chip, anexada a elas. Os FPGAs podem ser baseados em SRAM, Erasable Programmable Read-Only Memory (EPROM), Electrically Erasable Programmable Read-Only Memory (EEPROM), dentre outros tipos de memória. A primeira, SRAM, é uma memória volátil, ou seja, sempre que o FPGA for desligado, toda sua configuração é perdida. Desta forma, é necessário que o FPGA seja conectado a uma memória não-volátil, para que sempre que ele seja ligado, a configuração seja transferida para o chip. FPGAs baseados em memórias EPROM e EEPROM conseguem manter sua configuração mesmo depois de desligados.

Como benefícios dos FPGA baseados em SRAM, existem: (1) capacidade de programação rápida, o que não acontece com as FPGA baseadas nas tecnologias alternativas citadas; (2) necessidade apenas de tecnologia padrão para fabricação. Sua desvantagem é o elevado tamanho do circuito, ocupando bastante espaço no chip.

As funções lógicas (circuitos combinacionais simulados) são implementadas nos FPGAs por meio dos geradores de função (function generators). Um gerador de função pode ser visto como a unidade básica de computação do FPGA, e pode ser tanto um multiplexador quanto uma Look-up Table (LUT). Uma LUT é uma tabela de pesquisa, formada por um grupo de células de memória que armazenam todos os possíveis resultados de uma dada função lógica de um número $n$ de entradas e um número $m$ de saídas. 


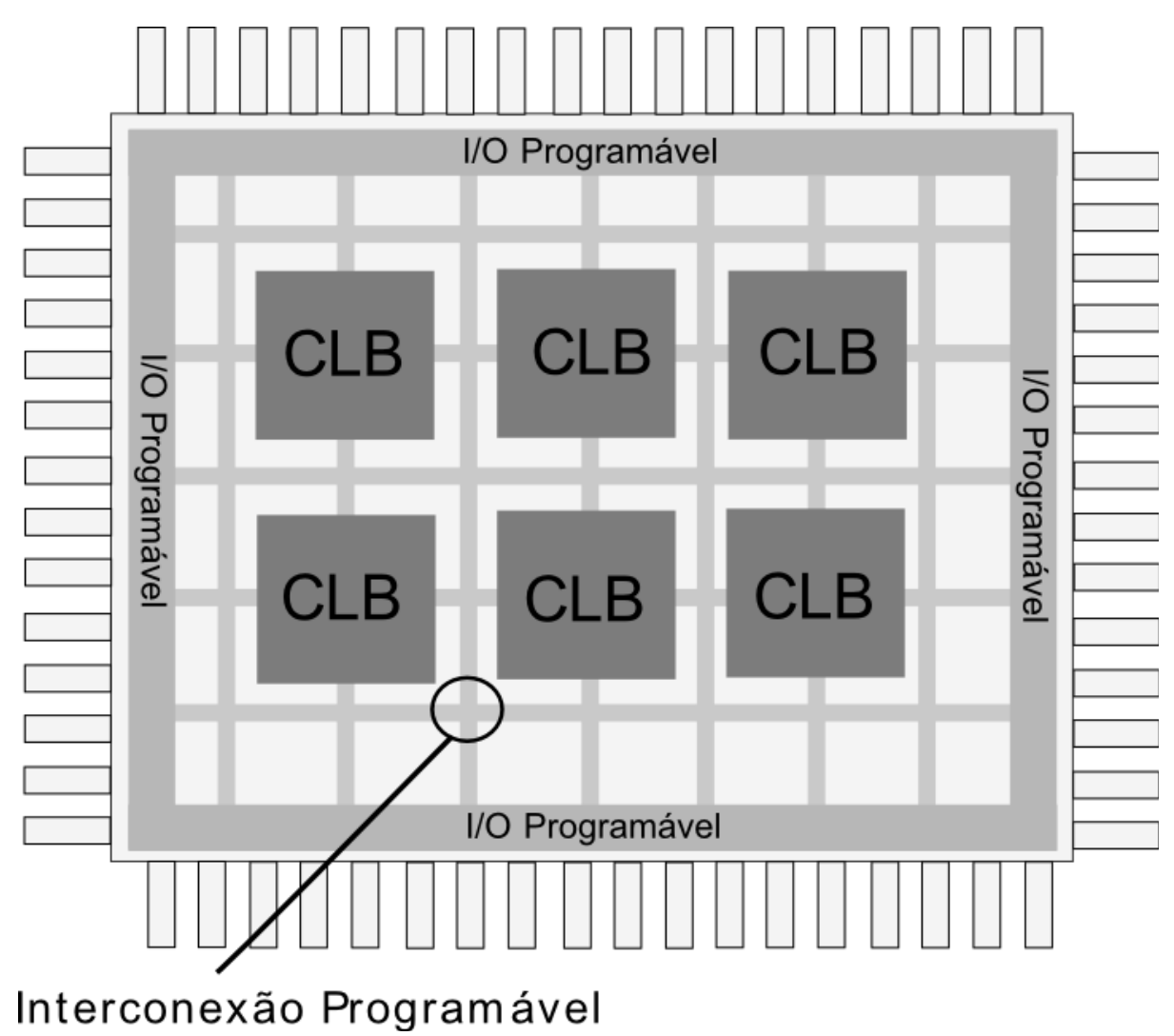

Figura 2.8: Diagrama da estrutura de um FPGA.

Com a chegada dos FPGAs comerciais em 1986 pela Xilinx®, o interesse em computação reconfigurável aumentou. Desde então, várias arquiteturas reconfiguráveis foram criadas sobre FPGAs. Nesta seção, serão apresentadas algumas arquiteturas reconfiguráveis relevantes, que variam desde a fina-granularidade até a grossa-granularidade.

\subsubsection{Arquiteturas clássicas}

Conforme já mencionado, com a invenção dos FPGA;, a computação reconfigurável foi mais investigada por meio dessa tecnologia. Nesta sub-seção, serão apresentadas algumas das arquiteturas consideradas "clássicas" da computação reconfigurável.

\subsubsection{Programmable Active Memory (PAM)}

PAM Vuillemin et al. 1996] foi uma das primeiras arquiteturas a utilizar FPGAs. Sua idéia principal baseava-se em acoplar uma $\mathrm{RPF}$ como co-processador de fina-granularidade à um processador de propósito geral de alto desempenho.

Sua RPF era composta por EPs, também chamados de PAB, que eram conectados de uma forma regular. Cada EP consistia em um flip-flop e um elemento combinacional com quatro entradas e quatro saídas, bastante parecido com um bloco lógico de um FPGA atual. Tal elemento possuía cinco tabelas look-up, sendo que cada uma implementava uma função de cinco entradas e uma saída Vuillemin et al. 1996. A Figura 2.10 contém o diagrama de uma RPF com um arranjo de 5x5 EPs. 


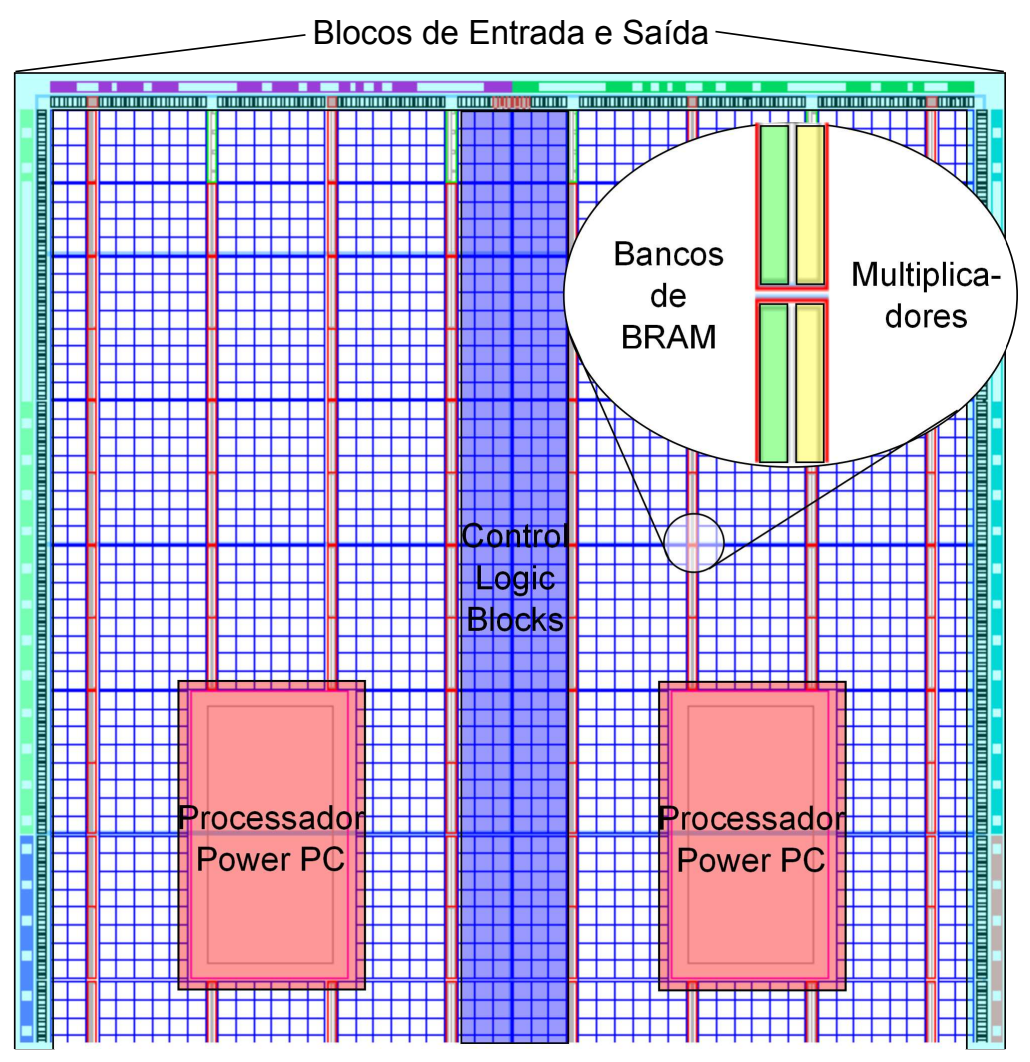

Figura 2.9: Diagrama da estrutura de um FPGA Xilinx@ Virtex 2 modelo XV2P30, adaptado de uma captura de tela do software Xilinx@ PlanAhead.

DECPeRLe-1 foi uma implementação experimental da arquitetura PAM (Figura 2.11), construída em 1992 pela Digital's Paris Research Laboratory. Ele possuía vinte e três FPGAs Xilinx@ XC3090, denotados pelos quadrados na Figura 2.11, e 4 memórias com $1 \mathrm{MB}$ de SRAM, indicadas na ilustração pelos retângulos com a letra $R$. Seu núcleo de processamento continha uma matriz de 4x4 FPGAs denotados pelos quadrados com a letra $M$. Cara FPGA possuía um barramento de 32 bits que o inter-conectava com seu vizinho. Cada linha, também, representa um barramento de 32 bits.

\subsubsection{DISC}

Dynamic Instruction Set Computer (DISC) Wirthlin \& Hutchings, 1995 era uma arquitetura de computação dinâmica e parcialmente reconfigurável baseada na arquitetura de von Neumann. Ela permitia que seu conjunto de instruções fosse modificado dinamicamente, em tempo de execução, conforme a necessidade do programa que estivesse sendo executado. Assim, era possível que um programa que tenha um gargalo de desempenho em certo trecho do algoritmo pudesse criar um hardware específico para tal trecho, aumentando seu desempenho.

Ela possibilitava que o hardware fosse realocado utilizando o modelo de hardware vertical linear, gerando, assim, um formato unidimensional para posicionamento de hardware. A Figura 2.12 contém um diagrama desse modelo, denotado pelas linhas verticais. Cada espaço dentre essas linhas, então, poderia conter uma instrução (ou parte de uma instru- 


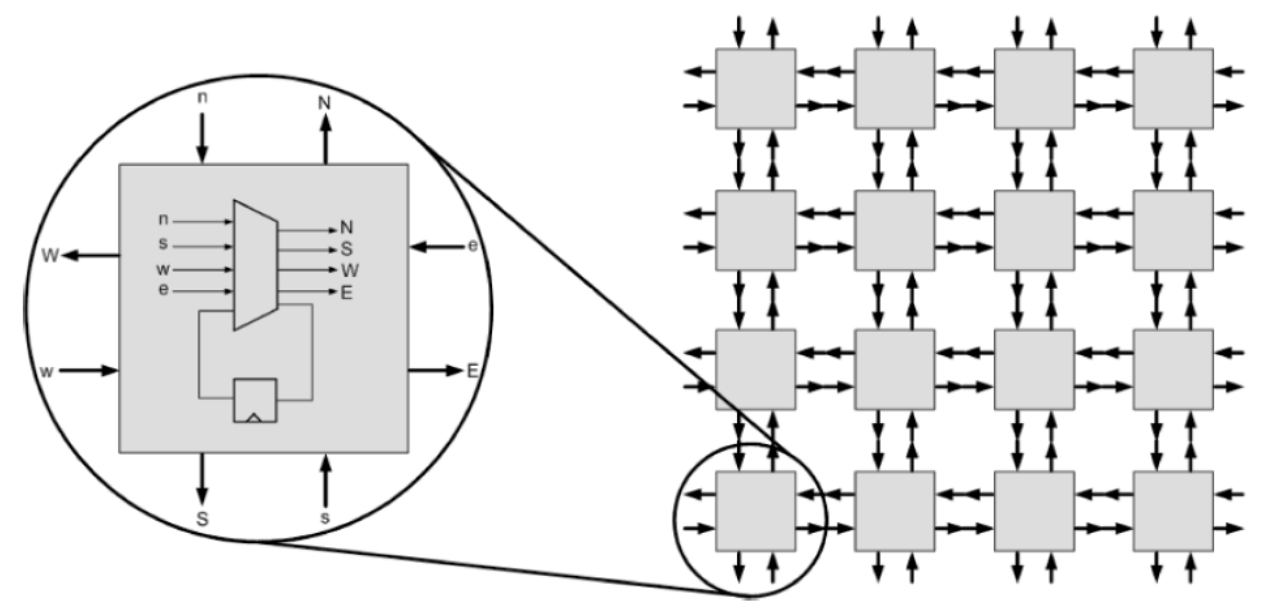

Figura 2.10: Arquitetura de uma hipotética máquina $\mathrm{PAM}$ de $4 \times 4$ PAB. Bobda, 2007.

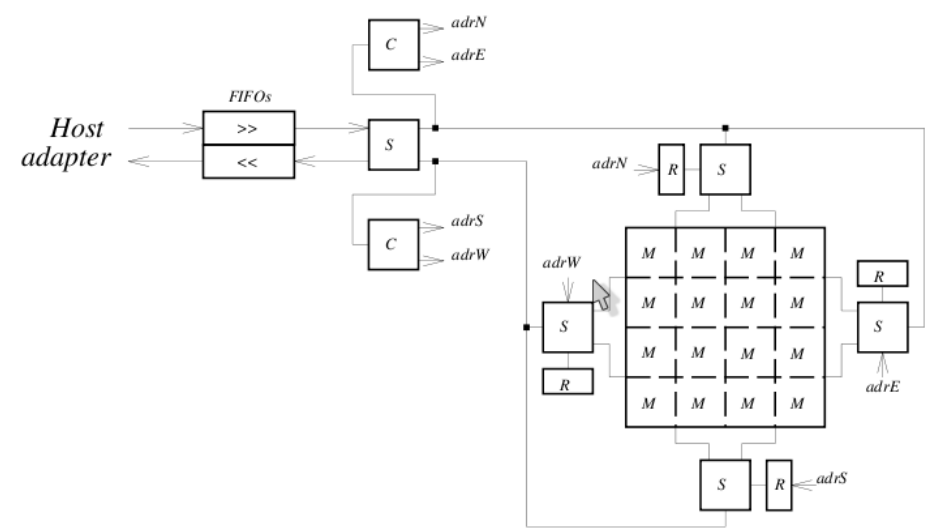

Figura 2.11: Arquitetura da máquina DECPeRLe-1 Vuillemin et al., 1996.

ção maior). Sua arquitetura consistia em manter uma pequena área do chip fixa, chamada Controlador Global, que era responsável pela comunicação com a memória Random Access Memory ( $\mathrm{RAM}$, entrada e saída, comunicação interna e estado global. A arquitetura foi construída de modo que haja 56 colunas para reconfiguração, sendo que 10 colunas eram utilizadas pelo Controlador Global.

Um diagrama da estrutura do Controlador Global pode ser visto na Figura 2.13. Alguns sub-módulos que podem ser observados são:

- Registradores de dados (Data Registers): responsáveis por armazenar resultados intermediários, buffering de comunicação entre os módulos e ajudar na geração de endereços complexos (8 bits);

- Registradores de endereçamento (Address Registers): endereçamento padrão de acesso à memória (16 bits);

- Registradores de estado (Status Registers): armazenava o estado atual do processador;

- Unidade de Controle Global (Global Control Unit): contém o circuito necessário 


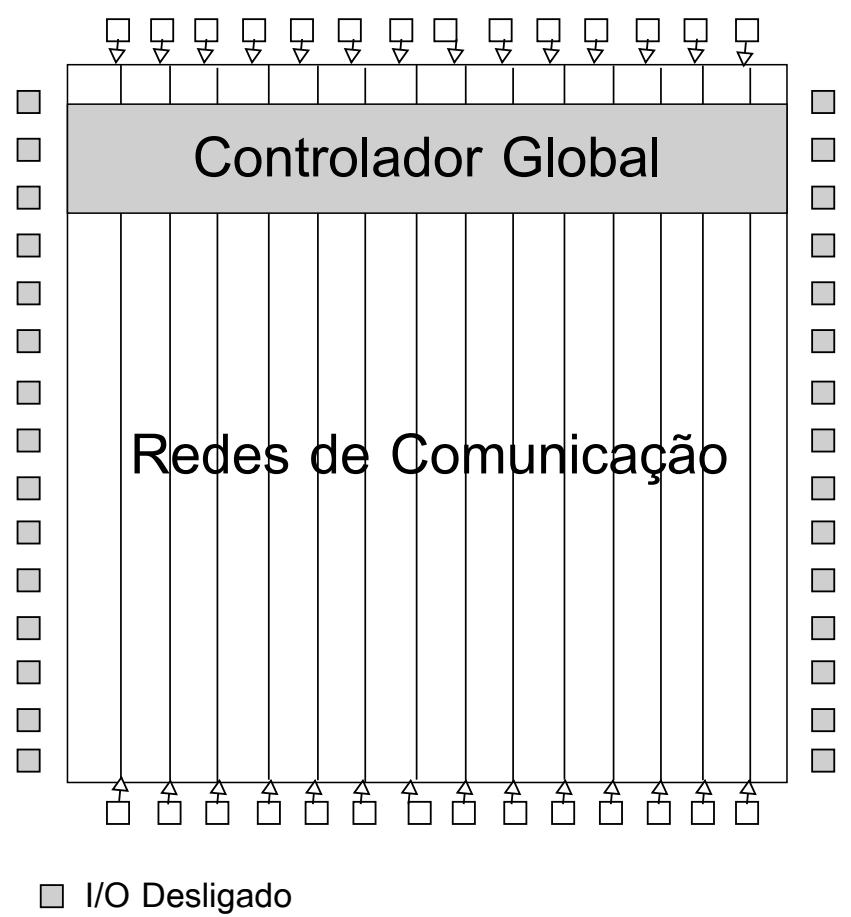

Figura 2.12: Arquitetura da máquina DISC. Adaptado de Wirthlin \& Hutchings, 1995.

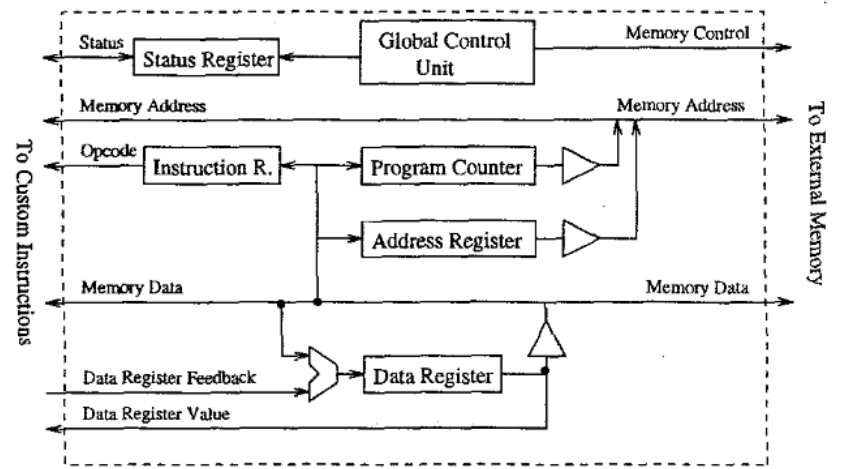

Figura 2.13: Estrutura do Controlador Global da arquitetura DISC Wirthlin \& Hutchings, 1995].

para preservar o protocolo de comunicação, sequência de estados do processador, e a interface de entrada e saída;

- Registrador de instrução (Instruction Register): onde a instrução que seria executada ficava armazenada;

- Contador de Programa (Program Counter): assim como na arquitetura de von Neumann, existe um contador de programa para endereçar a próxima instrução que será executada.

Desta forma, o Controlador Global era capaz de se comunicar com qualquer instrução em qualquer parte vertical do $\mathrm{RPF}$. As instruções, por sua vez, podiam ser alocadas em qualquer uma das linhas restantes. Cada instrução, também, podia ter qualquer tamanho, desde que coubesse dentro do RPF. O Controlador Global também era responsável por 


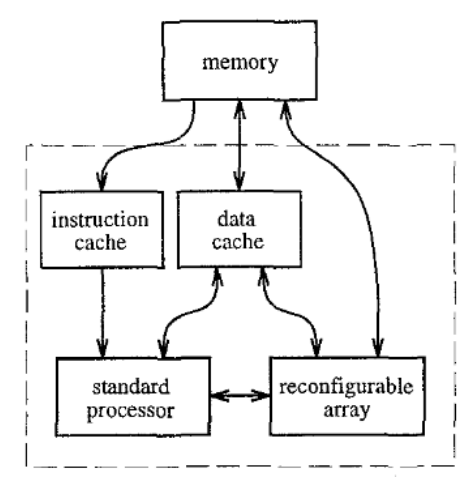

Figura 2.14: Organização da arquitetura Garp. O retângulo tracejado indica a área da pastilha de silício [Hauser \& Wawrzynek, 1997].

alocar e desalocar as instruções no RPF. Caso uma instrução precisasse ser colocada e não houvesse espaço disponível livre, o Controlador Global retirava as instruções mais antigas do RPF, até que o espaço necessário fosse liberado. Caso houvesse espaço suficiente livre e fragmentado, o Controlador Global também era responsável por realocar as instruções dentro do RPF para que uma nova instrução fosse inserida.

\subsubsection{Garp}

Garp [Hauser \& Wawrzynek, 1997] era uma tecnologia que une uma RPF com EPs de baixa granularidade a um processador Microprocessor Without Interlocked Pipeline Stages (MIPS) na mesma pastilha de silício. Ele foi criado de forma que sua RPF compartilhava o acesso à memória externa e interna (cache) com o processador host, o que garante a consistência dos dados compartilhados entre eles. O processador host, por sua vez, também podia se comunicar diretamente com a RPF (Figura 2.14). Desta forma, o gargalo de comunicação entre a $\mathrm{RPF}$ e o microprocessador host era diminuído.

Sua RPF, ilustrada na Figura 2.15, era composta por dois tipos de EPs: um tipo utilizado apenas para controle (denotados como quadrados cinzas), que era capaz de se comunicar com recursos externos à RPF $\mathrm{O}$ outro tipo (expressos como quadrados brancos), de baixa granularidade, conseguia efetuar operações atômicas em 2 bits de dados. Para reduzir o tempo de reconfiguração do RPF pela metade, foram utilizadas EP 2 bits, e não de apenas um. A $\mathrm{RPF}$ continha uma matriz de EPs, com colunas de 24 unidades e linhas de tamanho variável, com mínimo de 32 linhas Hauser \& Wawrzynek, 1997]. A primeira coluna da matriz continha $\mathrm{EP} \beta$ de controle, os $16 \mathrm{EP}$ s centrais eram fixados para operações lógicas, enquanto os $4 \mathrm{EP}$ restantes a esquerda e os 3 a direita, eram utilizados para outras tarefas, como checagem de overflow, cálculo com carry ou alguma outra operação. Era possível, então, utilizar os 16 EP s centrais para cálculos de 32 bits de dados.

Existiam, também, quatro barramentos de memória que atravessam verticalmente todo RPF, que serviam apenas para transferir dados entre o RPF memória externa e o processador. Essas transferências de memória limitavam-se a utilizar os 16 EP 


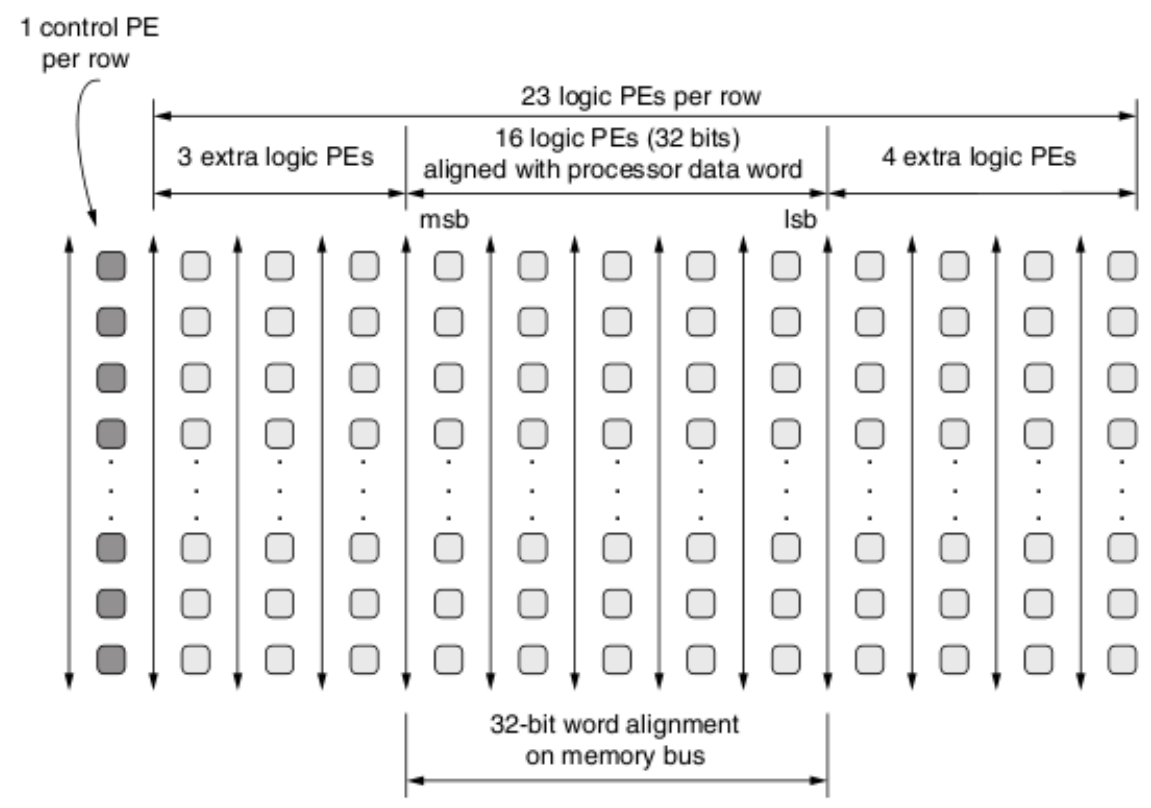

Figura 2.15: Arquitetura da RPF da arquitetura Garp Hauck \& DeHon, 2007].

Foram criados também fios que ligavam os EPs tanto verticalmente, quanto horizontalmente, de tamanhos variados. Esses fios permitiam a comunicação por meio de linhas e colunas no RPF. Todavia, não havia conexões entres fios, senão através de um EP. Para que fios diferentes fossem interconectados, um EP fora utilizado para fazer essa ligação.

Sua reconfiguração total era uma operação lenta, posto que eram necessários 64 bits para cada EP, sendo que, em um $\mathrm{RPF}$ com 32 linhas, resultaria em 6144 bytes. Considerando que esses dados deveriam ser transmitidos durante uma troca de contexto, isto poderia gerar um gargalo na execução. Essa arquitetura, no entanto, permitia reconfiguração parcial e dinâmica. Enquanto uma parte do RPF estava em operação, outra parte podia ser reconfigurada pelo processador host, sem que houvesse necessidade de reiniciar o RPF. Outro ponto é que a reconfiguração parcial permitia que um arquivo de configuração menor fosse enviado para o $\mathrm{RPF}$, na medida que se necessitasse de uma lógica menor para ser modificada. Isso, então, diminuía seu tempo de reconfiguração.

Alguns testes realizados com algumas aplicações utilizando a arquitetura Garp com o sistema configurado à $133 \mathrm{MHz}$ demonstraram aumento de desempenho em relação à um processador UltraSPARC rodando à $167 \mathrm{MHz}$ de 2,1 à 24 vezes.

\subsubsection{PipeRench}

PiPeRench era um co-processador de alta-granularidade criado para otimizar cálculos simples de grandes quantidades de dados de larguras diferentes Goldstein et al. 1999. Segundo Goldstein et al. [1999], o aumento de desempenho nos testes realizados variam de 11,3 até 189,7 vezes com uma arquitetura com EP de 8 bits e um stripe de 128 bits com clock de $33 \mathrm{MHz}$ em relação à um UltraSPARC-II com clock de $300 \mathrm{MHz}$.

Sua ideia principal era dividir os algoritmos em estágios virtuais de pipeline, que por sua vez eram mapeados em estágios físicos de pipeline. Desta forma, era possível que o 


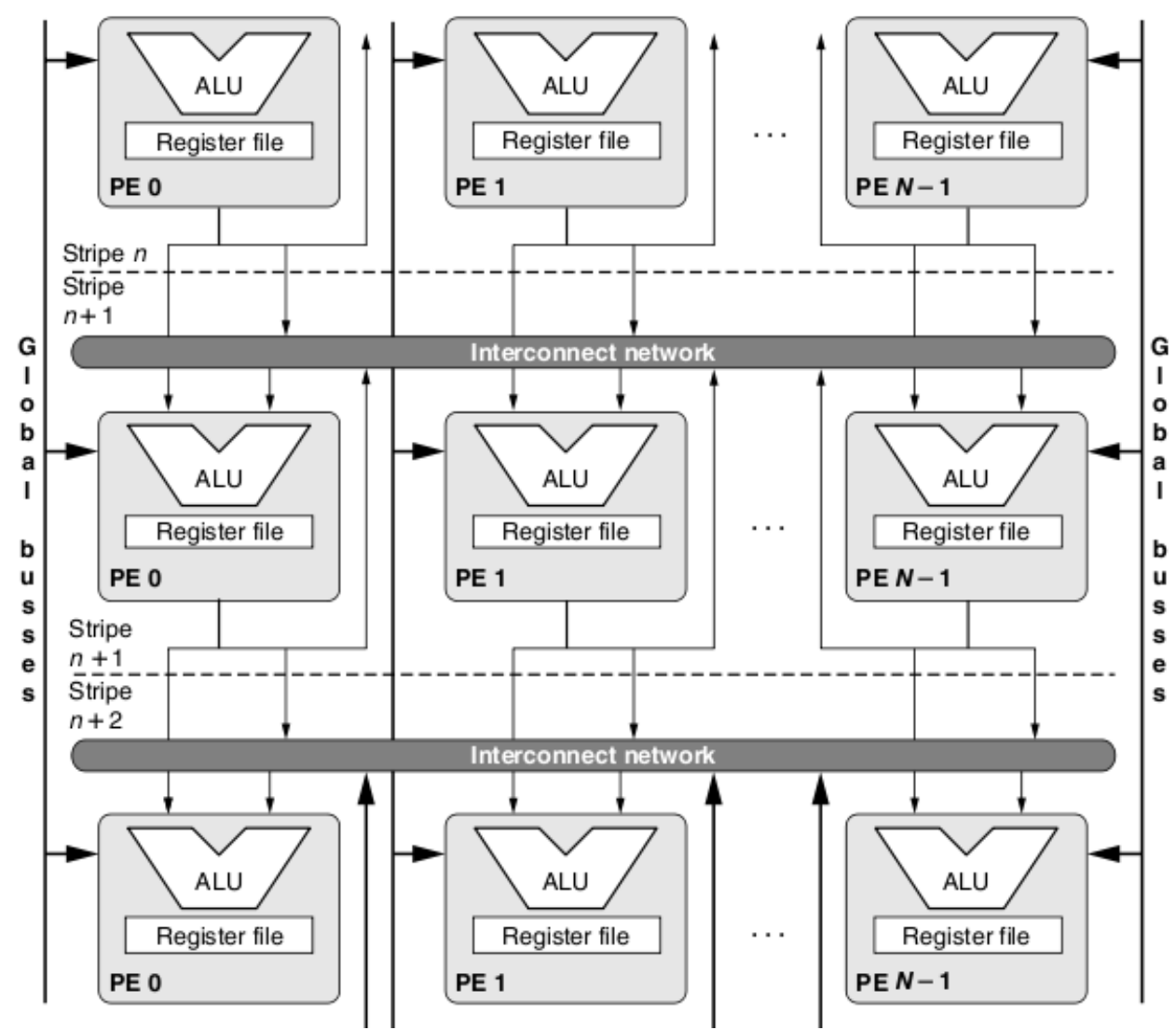

Figura 2.16: Arquitetura da RPF da arquitetura PiPeRench Hauck \& DeHon, 2007.

número de estágios virtuais ultrapassasse o número de estágios físicos. Um estágio de pipeline podia ser reconfigurado no hardware em apenas um ciclo de clock.

A arquitetura do PipeRench, demonstrada no diagrama da Figura 2.16 era composta por um arranjo bidimensional de $\mathrm{EP}$ s, sendo que cada um correspondia a uma ULA e um banco de registradores de transmissão. Cada linha do arranjo era referente a um stripe. Cada configuração do VIC continha um roteamento e operação dos EPs de uma stripe. Cada stripe era conectada por uma full crossbar, que também era reconfigurável.

Foram criadas também algumas ferramentas Computer-Aided Design (CAD) para auxiliar a geração da configuração da arquitetura. Elas baseavam-se nos parâmetros da arquitetura definidos previamente: tamanho do stripe (em EPs), largura de cada EP, e o número de registradores no banco de registradores. Segundo Hauck \& DeHon [2007], essa ferramenta é capaz de gerar satisfatoriamente a localização dos stripes, embora falhe na criação de bons canais de roteamento, que precisam ser modificados manualmente.

\subsubsection{Arquiteturas atuais}

Atualmente, são inumeráveis as arquiteturas reconfiguráveis que são criadas a cada ano, posto os resultados já conseguidos com a área de pesquisa. Não obstante, FPGA também têm sido utilizados para criação de arquiteturas para aplicações específicas, como as apresentadas em Bonato 2008; GholamHosseini \& Hu 2008; Asano et al. 2009. Conforme não é o foco deste trabalho, elas não serão apresentadas em detalhes aqui. 


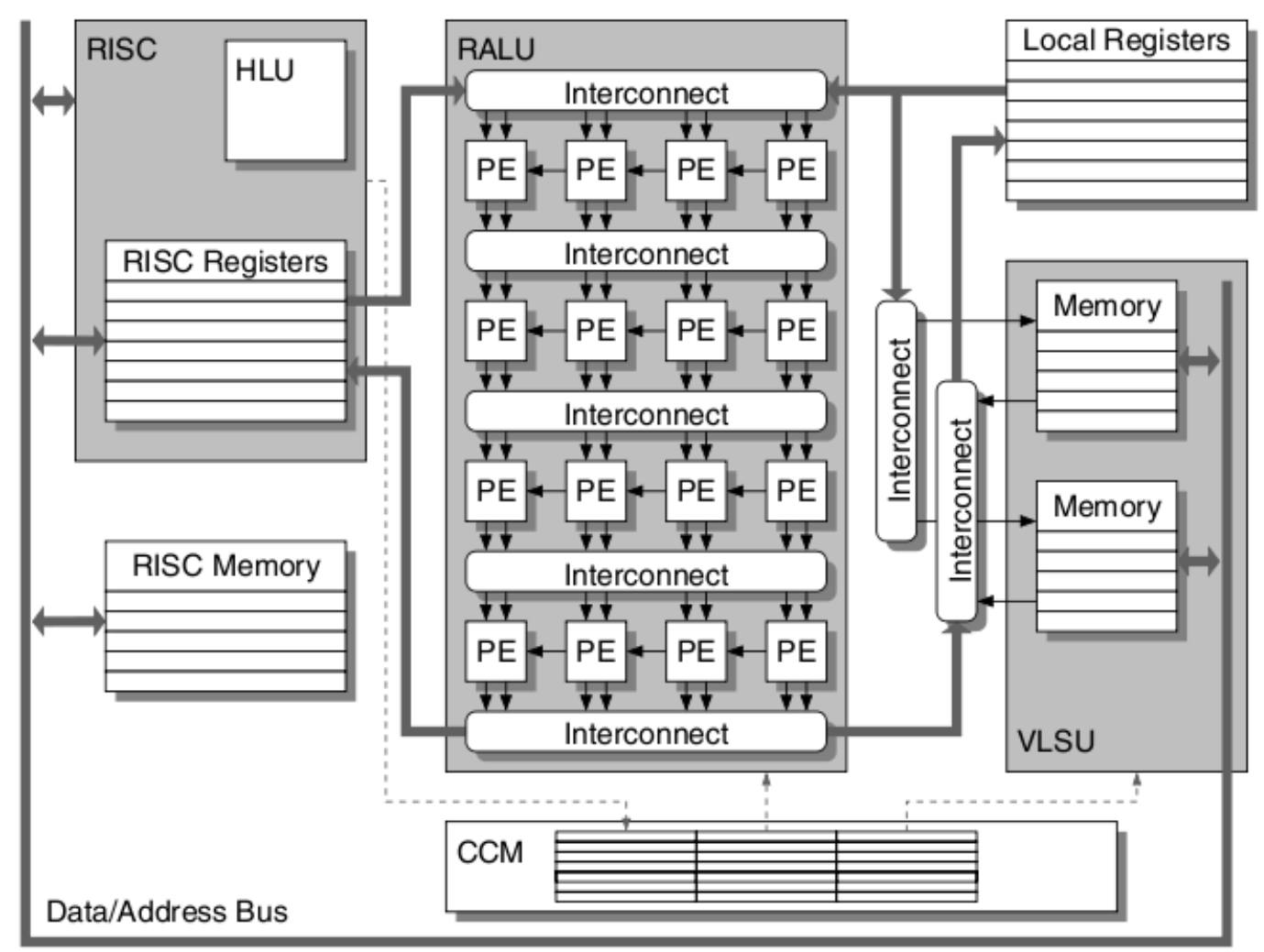

Figura 2.17: Diagrama da arquitetura ARRIVE Kohler et al. 2008.

Seria inviável citar aqui todas as arquiteturas de computadores reconfiguráveis atuais. Deste modo, nesta sub-seção, apenas algumas arquiteturas mais interessantes serão apresentadas.

\subsubsection{ARRIVE}

ARRIVE [Kohler et al., 2008] é uma extensão datapath de grossa granularidade para microprocessadores Reduced Instruction Set Computer (RISC). Essa arquitetura é otimizada para aplicações DSP, posto que implementa apenas instruções Single Instruction, Multiple Data SIMD.

Como pode ser visto na Figura 2.17, a extensão consiste em duas unidades: RALU e Vector Load/Store Unit (VLSU). O primeiro, RALU, é um RPF que consiste em EPs de grossa granularidade organizados em linhas que podem ser controlados por 32 contextos reconfiguráveis. Cada linha de $\mathrm{EP}$ s é conectada diretamente à linha anterior através de switches reconfiguráveis ou bancos de registradores. O roteamento através de colunas acontece apenas sobre os EPs. Cada $\mathrm{EP}$ pode ser reconfigurado para 48 diferentes tipos de instruções. Todavia, os recursos disponíveis não são totalmente uniformes, posto que apenas a primeira linha contém multiplicadores. Não existe um tamanho fixo para o número de $\mathrm{EP}$ no $\mathrm{RPF}$, embora o escolhido seja de 4x4 EPs de 16 bits cada, escolhido apenas por ser mais viável para os benchmarks criados.

A segunda unidade, VLSU, é formada por um conjunto de memórias que pode ser acessada paralelamente e guardar dados dos bancos de registradores do processador RISC, 
tanto quanto dos registradores locais do RALU. Seus registradores suportam operações típicas de transferência de memória para DSP. Ela, também, apresenta 32 contextos de configurações independentes dos contextos de configuração do RPF.

Essas duas unidades são controladas pelo Context Configuration Manager (CCM), que ativa as configurações das duas unidades conforme elas forem requisitadas. Existem 64 entradas do processador RISC que são relacionadas aos contextos de configuração das duas unidades. A cada ciclo de clock, o registrador que contém a instrução que será executada no processador RISC é então comparada com todas as 64 entradas do CCM, caso haja uma igualdade, o contexto então é carregado através dos barramentos de configuração nas unidades reconfiguráveis.

Essa arquitetura apresentou um aumento de desempenho, área do chip gasta e de consumo de energia, se comparados à um processador RISC ARM922T.

\subsubsection{Arquiteturas baseadas em fluxo de dados}

Embora as arquiteturas reconfiguráveis baseadas em fluxo de dados pudessem ser encaixadas nas outras seções deste capítulo, elas foram separadas já que são especialmente de interesse para este trabalho. Nesta sub-seção, serão apresentas algumas arquiteturas reconfiguráveis baseadas em fluxo de dados.

\subsubsection{WASMII}

What A Steap Machine Is It (WASMII é uma arquitetura baseada em fluxo de dados que utiliza o conceito de hardware virtual [Ling \& Amano, 1993]. Tal nome é utilizado em uma maneira semelhante ao conceito de memória virtual: conforme os FPGA eram bastante restritos e apenas alguns nós do GFD podiam ser implementados em um FPGA inteiro, haviam instâncias de configuração do FPGA contendo outros subgrafos de execução que seriam trocados com a configuração atual conforme necessitassem ser executados.

A arquitetura WASMII foi criada de forma que seja possível uma execução com apenas um $\mathrm{RPF}$ ou vários: nela, era possível que vários FPGAs executassem simultaneamente subgrafos do GFD, alcançando assim o paralelismo máximo de máquinas baseadas em fluxo de dados.

Todavia, na época, ainda, não estavam disponíveis as FPGAs que permitiam reconfiguração dinâmica Ling \& Amano, 1993, apenas FPGA de reconfiguração estática, gerando duas dificuldades: (1) todo RPF precisava ser reconfigurado sempre que necessário, (2) devido a isto, também, todos os dados presentes no RPF eram perdidos durante a reconfiguração. Para solucionar o segundo problema, foram criados buffers externos capazes de armazenar os tokens que seriam executados pelos outros nós.

Os tokens gerados pelos subgrafos ficavam armazenados em buffers. Cada instância de subgrafo só era executada se todos os tokens de entrada estivessem disponíveis para 
ela. Na medida em que os tokens estivessem disponíveis, o hardware virtual era trocado pela nova instância.

Para evitar deadlocks decorrentes de reentrância nos grafos, o método implementado consistia em fazer com que a reentrância de dados nos grafos não ocorresse internamente e sim externamente: dessa forma, caso um nó externe um token que será utilizado por um outro nó na mesma instância do subgrafo, tal token não será diretamente direcionado para dentro da instância e sim para a estrutura de buffers externa.

Posteriormente, houve alguma evolução sobre o WASMII. Takayama et al. 1999. implementou e validou um compilador de linguagem de alto-nível para a arquitetura. Takayama et al. [2000], também, criou algoritmos de particionamento e escalonamento para a máquina, que previne a geração de GFD com possibilidade de deadlock. Além disso, esses algoritmos obitveram de $13 \%$ à $39 \%$ de melhorias no desempenho.

\subsection{Considerações Finais}

Neste capítulo foram apresentados aspectos técnicos básicos da Computação Reconfigurável, além de uma introdução sobre algumas arquiteturas reconfiguráveis desenvolvidas.

Alguns dos sistemas apresentados fazem uso de RPD. Com ele é possível que em tempo de execução, parte do hardware reconfigurável seja reconfigurado, aumentando o dinamismo do sistema e diminuindo assim o tempo de reconfiguração.

No próximo capítulo será analisada a RPD, abordando os aspectos teóricos e o estado da arte em esforços acadêmicos e comerciais em tecnologia parcialmente reconfigurável. 


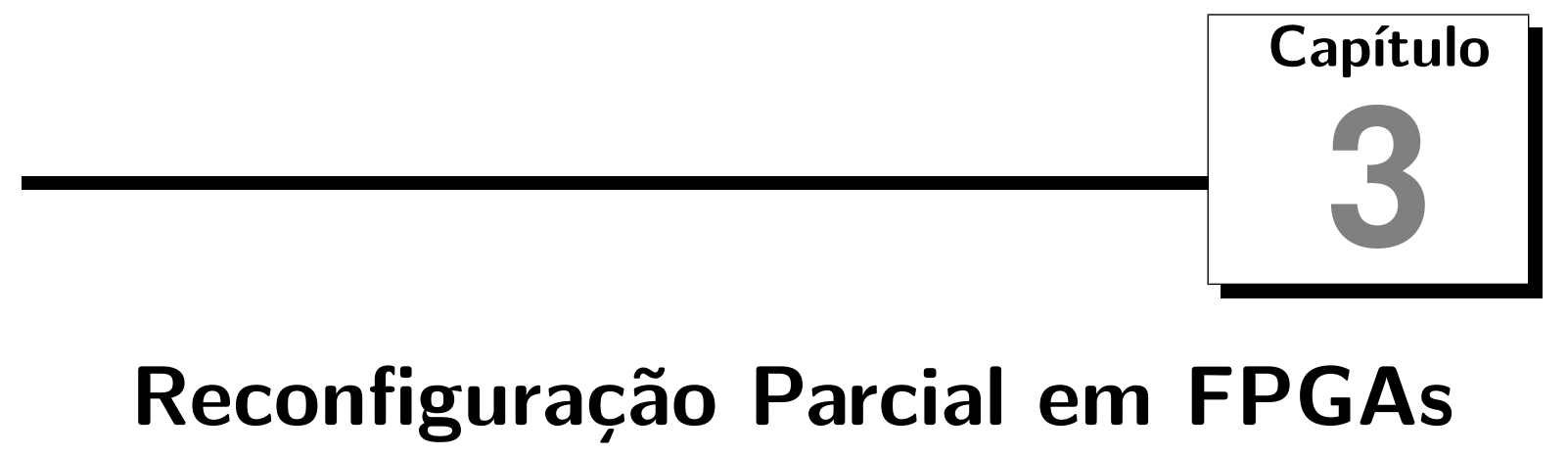

A ideia de executar algoritmos diretamente em hardware não é nova. Várias ferramentas comerciais já fazem a tradução de LPAN para hardware. Todavia, da mesma forma que para um processador comum a memória em que os algoritmos ficam armazenados é um fator limitante, um algoritmo convertido para hardware também tem como limite o tamanho do FPGA de destino para tal hardware.

A solução, muitas vezes, não pode passar pela compra de um chip maior ou o reprojeto do hardware com o intuito de diminuir o seu tamanho. Para esses casos, alguns FPGAs permitem que sua configuração seja alterada dinamicamente. Ou seja, em tempo de execução é possível você modificar hardware configurado no FPGA. Desta forma, fica então possível que um determinado hardware seja dividido em várias partes e então essas partes sejam escalonadas no FPGA em função de sua necessidade.

Esse processo é chamado de Reconfiguração Dinâmica (RD) ou Run-Time Reconfiguration (RTR Hauck \& DeHon, 2007, Bobda, 2007, Compton \& Hauck, 2002, 1999. Alguns autores se referem a RD como hardware virtual Compton \& Hauck, 2002, Ling \& Amano, 1993, de uma maneira semelhante à memória virtual: uma configuração fica fora do FPGA do mesmo jeito que uma página ou segmento de memória fica fora da memória principal de um computador. E, também como ela, é enviada para o FPGA na medida em que ela é necessária.

Desta forma, é possível definir que um determinado hardware $H$ pode ser dividido em partes $h_{1}, h_{2}, h_{3}, \ldots h_{n}$ sendo que $H=\sum h_{i}$ e que $n$ é o número total de partes. Assim, uma determinada parte do hardware $h_{i}$ que pode ser necessário em um instante $t$ pode ser dado por meio de uma função de mapeamento $f(t)$, sendo que $f(t)=h_{i}^{t}$. Na Figura 3.1, é possível observar um exemplo de execução da RD. Nela, há um FPGA em um determinado tempo $t_{0}$ com uma parte de hardware $h_{1}$ configurado. Neste tempo, é feita uma reconfiguração dinâmica do FPGA e uma nova parte do hardware é enviada para o 

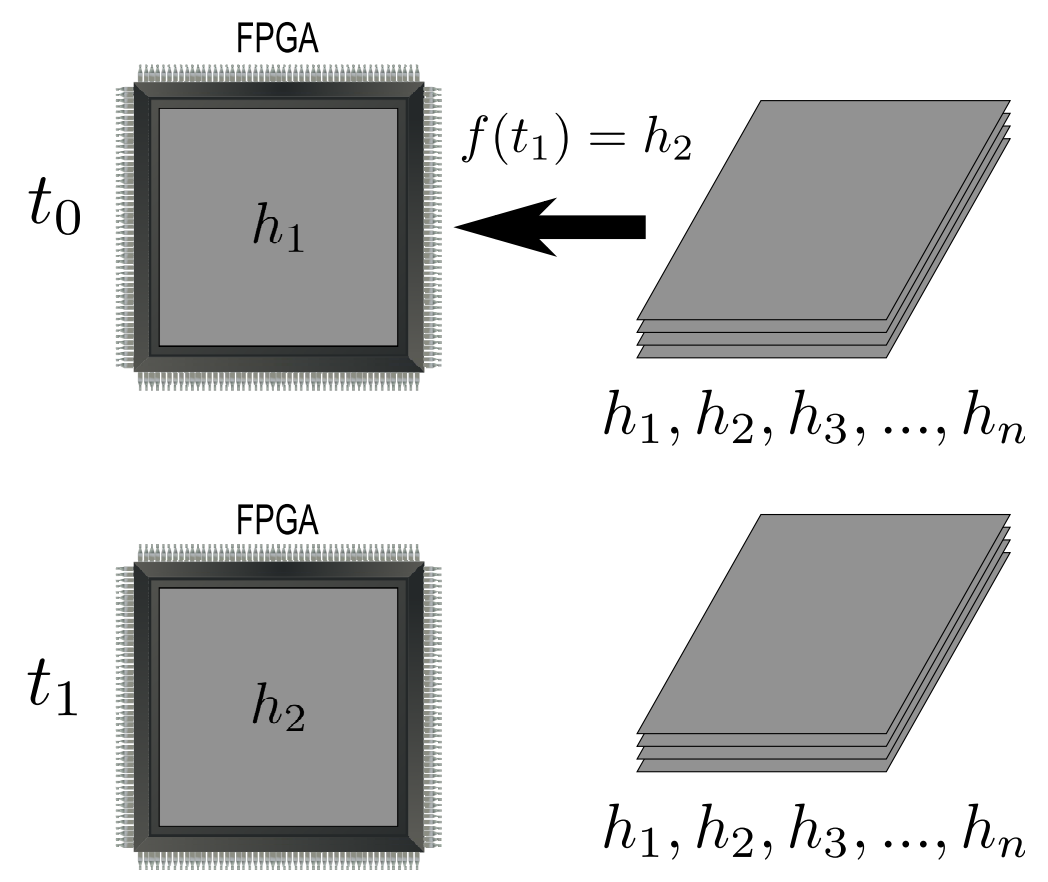

Figura 3.1: Ilustração da reconfiguração dinâmica.

\section{FPGA,}

Para a maioria dos FPGAs, o tempo de reconfiguração de todo dispositivo é muito grande. Também, nem todas as aplicações necessitam de uma reconfiguração total do FPGA. Não obstante, a reconfiguração de apenas parte do FPGA enquanto outra parte se mantém executando, pode aumentar o desempenho do sistema como um todo, posto que aumenta o paralelismo. Conceitualmente, permitir que apenas uma determinada parte do hardware seja reconfigurado enquanto outra continua executando, é chamado de reconfiguração parcial ou RPD Hauck \& DeHon, 2007, Bobda, 2007; Compton \& Hauck, 2002, 1999.

A Figura 3.2 contém uma ilustração da dinâmica desse processo. Nela, uma determinada parte de hardware $h_{4}$ é enviada para o FPGA no tempo $t_{0}$ para que no tempo $t_{1}$ ela então esteja disponível para executar.

A ferramenta ChipCflow utiliza o conceito de RPD para tentar solucionar diversos problemas. Além do já citado problema com o espaço de alocação do hardware no chip, o ChipCflow tenta solucionar o problema de matching de dados usuais das arquiteturas baseadas em fluxo de dados dinâmico. Uma explicação detalhada sobre os mecanismos utilizados pode ser encontrado no Capítulo 4

Na Seção 3.1, algumas das arquiteturas de FPGA que permitem RD e RPD são apresentadas. 


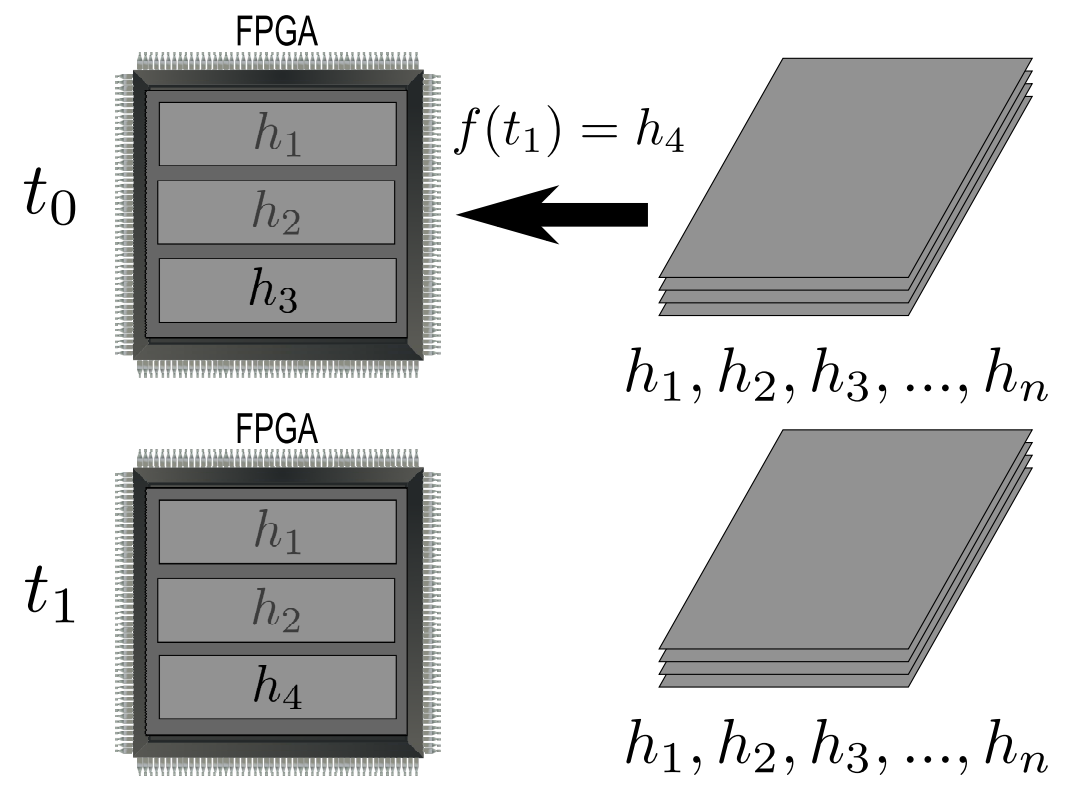

Figura 3.2: Ilustração da reconfiguração parcial dinâmica.

\subsection{Arquiteturas de FPGAs com reconfiguração dinâmi- cas}

Uma arquitetura de FPGA é o circuito físico básico que permite que os bitstreams sejam reconfigurados no chip. Os circuitos que possibilitam a reconfiguração dos FPGAs podem variar desde simples correntes de shifts até estruturas mais complexas capazes de manipular as configurações mesmo depois delas carregadas no chip Hauck \& DeHon, 2007.

\subsubsection{Contexto único}

Os FPGA de contexto único são os tipos mais comuns de FPGAs comerciais. Nesse tipo de FPGA, os dados são carregados para o chip através de correntes de shifts (Figura 3.3p. Nelas, o bitstream é enviado sequencialmente, bit-a-bit, fazendo com que a saída de um bloco de SRAM seja enviada para o próximo bloco. Apenas no final do processo de reconfiguração, então, o bitstream estará corretamente configurado e o FPGA poderá ser utilizado.

Algumas arquiteturas de contexto único possuem estruturas que podem ser endereçáveis, similares à um dispositivo de memória RAM. Isto possibilita a RPD, permitindo que partes específicas do hardware sejam enviadas em uma posição adequada do FPGA. A série Xilinx@ Virtex possui essa característica. Ele é um chip de contexto único que permite que determinadas partes do FPGA sejam endereçadas diretamente. Esse tipo de estrutura faz com que alguns transistores sejam economizados dentro do chip, embora force a criação de mais pinos para o endereçamento dos blocos [Hauck \& DeHon, 2007].

Alguns FPGAs conseguem enviar mais de um bit por clock para os registradores,

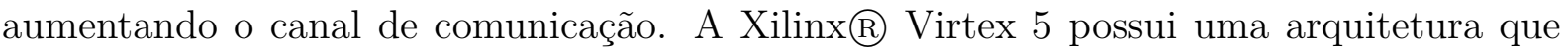




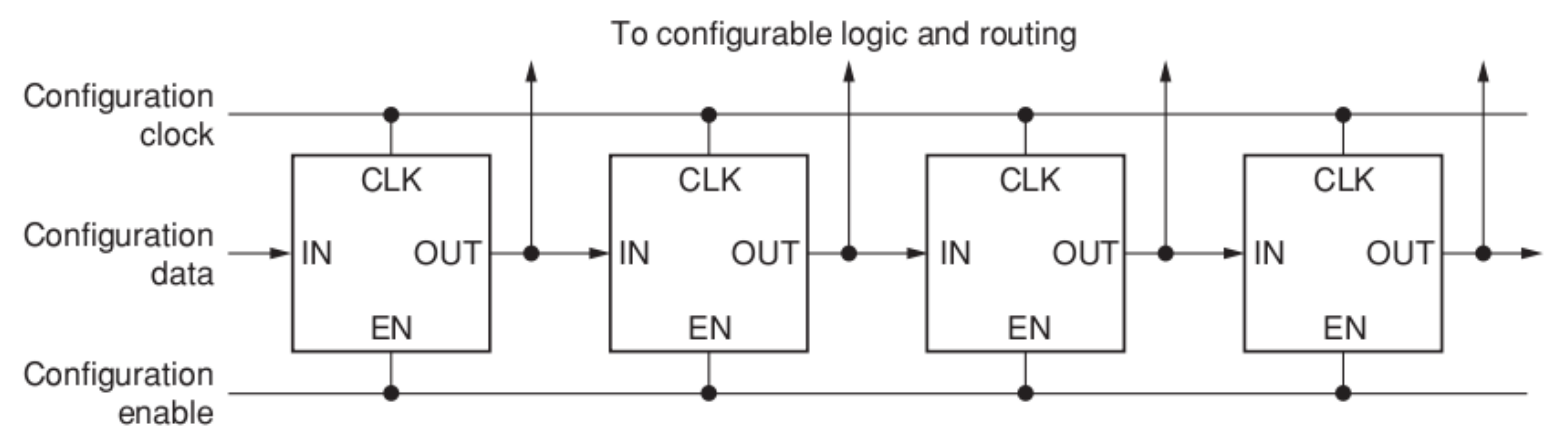

Figura 3.3: Cadeia de shifts utilizados para programação do FPGA. Cada quadrado representa um bit em SRAM Hauck \& DeHon, 2007.

permite que 32 bits sejam enviados a cada sinal de clock [Hauck \& DeHon, 2007]. Levando em consideração que bitstreams de configuração de FPGAs atuais ocupem alguns MBs, dividir esse número por 32 pode auxiliar consideravelmente no tempo de reconfiguração.

\subsubsection{Múltiplos contextos}

O primeiro FPGA de múltiplos contextos foi descrito por Motomura et al. 1997, chamado Dynamic-progammable Gate Array (DPGA), e consiste em substituir a usual estrutura com memórias SRAM por memórias Dynamic Random Access Memory (DRAM). Desta forma, vários bitstreams podem ser armazenados de uma única vez no FPGA e, sempre que necessário, uma rápida troca de contextos (em um ciclo de clock, ) pode ser efetuada. Isso acontece porque a arquitetura do FPGA consiste em diversos planos de memória (contextos) DRAM, conforme pode ser visto na Figura 3.4 .

Outras arquiteturas de múltiplos contextos foram desenvolvidas apresentando a mesma idéia básica demonstrada no DPGA. Uma outra arquitetura que dispõe desse mecanismo para FPGAs de fina-granularidade é a Time Multiplexed [Trimberger et al., 1997], que adiciona bits de SRAM aos CLBs de um FPGA Xilinx@ XC4000E. Essa arquitetura consegue realizar a troca de contextos em 30 ns.

O principal benefício dessa abordagem é que a troca de contextos acontece rapidamente, algumas, conforme já citado, em apenas um ciclo de clock. Todavia, isso só acontece quando a configuração que precisa ser utilizada está presente em algum outro contexto dentro do chip. Caso isso não aconteça, o FPGA precisa ser reconfigurado da mesma maneira que aconteceria em FPGAs de contexto único.

Um problema dessa arquitetura é que o hardware necessário para os novos contextos ocupa um grande espaço físico dentro do chip [Hauck \& DeHon, 2007). Desta maneira, recursos que poderiam ser utilizados para criar novas estruturas lógicas no FPGA, como CLB; , multiplicadores etc, precisam dar lugar à memória adicional para os contextos. Outro eventualmente problema é que a troca de contextos de todo chip eleva demasiadamente o consumo de energia, que pode violar as restrições do projeto. 


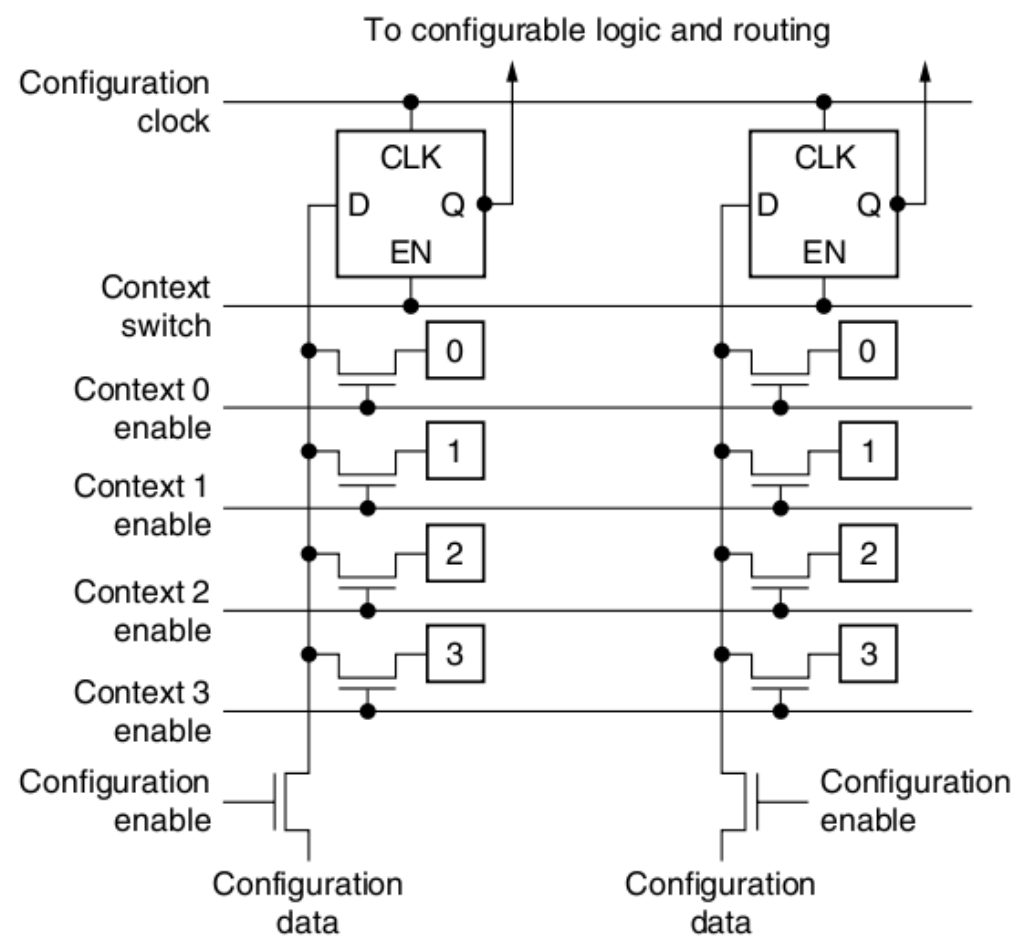

Figura 3.4: 2 bits de configuração em uma FPGA de 4 contextos. Cada contexto representa um plano de memória. Hauck \& DeHon, 2007.

\subsection{Reconfiguração Parcial Dinâmica}

FPGAs que permitem reconfiguração parcial se caracterizam por permitir que sua estrutura interna seja diretamente endereçada. Dado que um endereçamento total em cada bit possa gerar um número elevado de pinos no chip ou uma velocidade de reconfiguração total lenta, a maioria dos FPGAs comerciais atuais que permitem RPD, implementam apenas o endereçamento de blocos de recursos. Desta forma, um melhor custo-benefício pode ser alcançado [Hauck \& DeHon, 2007]. O primeiro FPGA que possibilitou essa característica foi o Xilinx@ XC6200 [Hauck \& DeHon, 2007; Xilinx, 1997]. Sua arquitetura permitia que um CLB fosse individualmente reconfigurado em tempo de execução.

Embora alguns FPGAs que podem ser encontrados na literatura permitam uma rápida reconfiguração em tempo de execução, a maior parte dos FPGAs comerciais demora milissegundos para ser reconfigurada. Isso se dá devido ao fato dos FPGAs modernos terem atualmente milhões de estruturas de fina-granularidade e o processo de reconfiguração ser de poucos bits por clock. Alguns estudos estimaram que o tempo de reconfiguração pode variar de $25 \%$ à $75 \%$ do tempo total de computação de uma aplicação Hauck \& DeHon, 2007, Resano et al., 2005, 2003, Wirthlin \& Hutchings, 1995.

Compton \& Hauck 1999 cita três técnicas para se reduzir esse overhead gerado: (1) diminuir o tamanho do bitstream, (2) antecipar a utilização do hardware e configuralo antes dele ser necessário e (3) otimizar o hardware de modo que o número de vezes que a troca de hardwares seja diminuído. Taher [2005], também, apresenta uma técnica chamada Gerenciamento de Configuração Virtual, que gera um cache de configurações em 


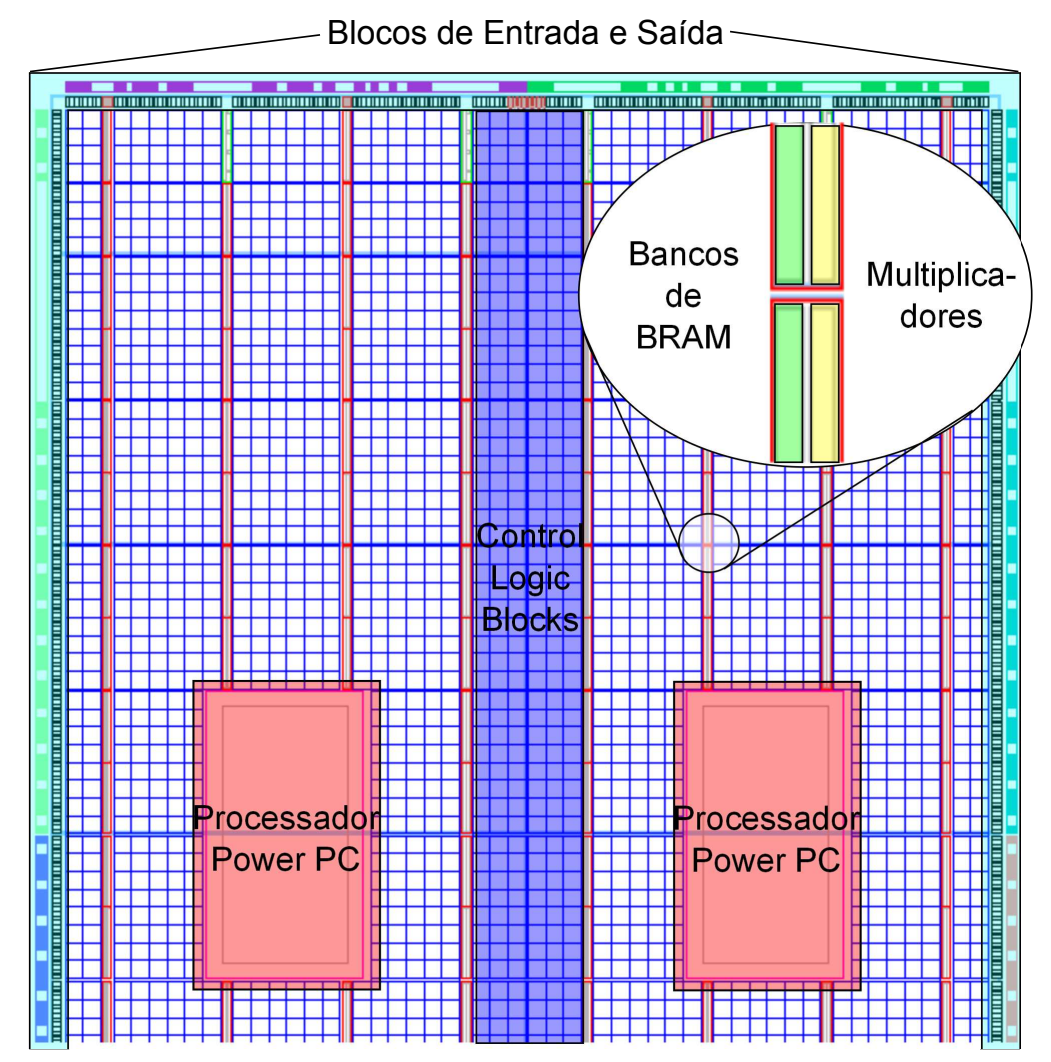

Figura 3.5: Diagrama da estrutura de um FPGA Xilinx $\AA$ Virtex 2 modelo XV2P30, adaptado de uma captura de tela do software Xilinx® PlanAhead.

que o overhead de aplicações não-determinísticas - gerado por dificuldade em se prever a próxima configuração que será utilizada - pode ser diminuído.

\subsubsection{Reconfiguração Parcial nos dispositivos Virtex}

O modelo de partição e de memória do ChipCflow foi criado baseando-se nos FPGAs Virtex, da Xilinx®, que permitem RPD. Por este motivo, uma análise mais aprofundada sobre esses dispositivos serão apresentados nesta sub-seção. O estudo apresentado se baseia no sistema de reconfiguração das Virtex II e II Pro. Todavia, não há grandes diferentes entre esses dispositivos e dispositivos mais novos, como Virtex 4 e Virtex 5. As informações encontradas neste subseção foram retiradas de Xilinx 2007b c.

Os FPGAs Xilinx@ Virtex II/Pro são formados por blocos de diferentes tipos de recursos, que são interconectados por estruturas de comunicação. Os tipos de recursos presentes nos FPGAs Xilinx@ Virtex II/Pro são: CLBs, BRAMs, multiplicadores, blocos de entrada e saída e, eventualmente, processadores PPC. A Figura 3.5 contém um Diagrama da estrutura básica de uma Virtex II Pro modelo XVP30. Nela, é possível ver uma fatia de todos os recursos disponíveis no dispositivo.

Nos FPGA $\$$ Xilinx@ Virtex II/II Pro, um CLB é formado por 4 slices, sendo que cada slice possui duas células lógicas. Uma célula lógica é formada por uma tabela [LUT de 4 entradas e uma saída, carry logic e um flip-flop de 1 bit. Uma tabela LUT] é uma tabela que pode implementar qualquer função de $\mathrm{N}$ entradas e 1 saída. Um bloco 


\section{Array de CLBs}

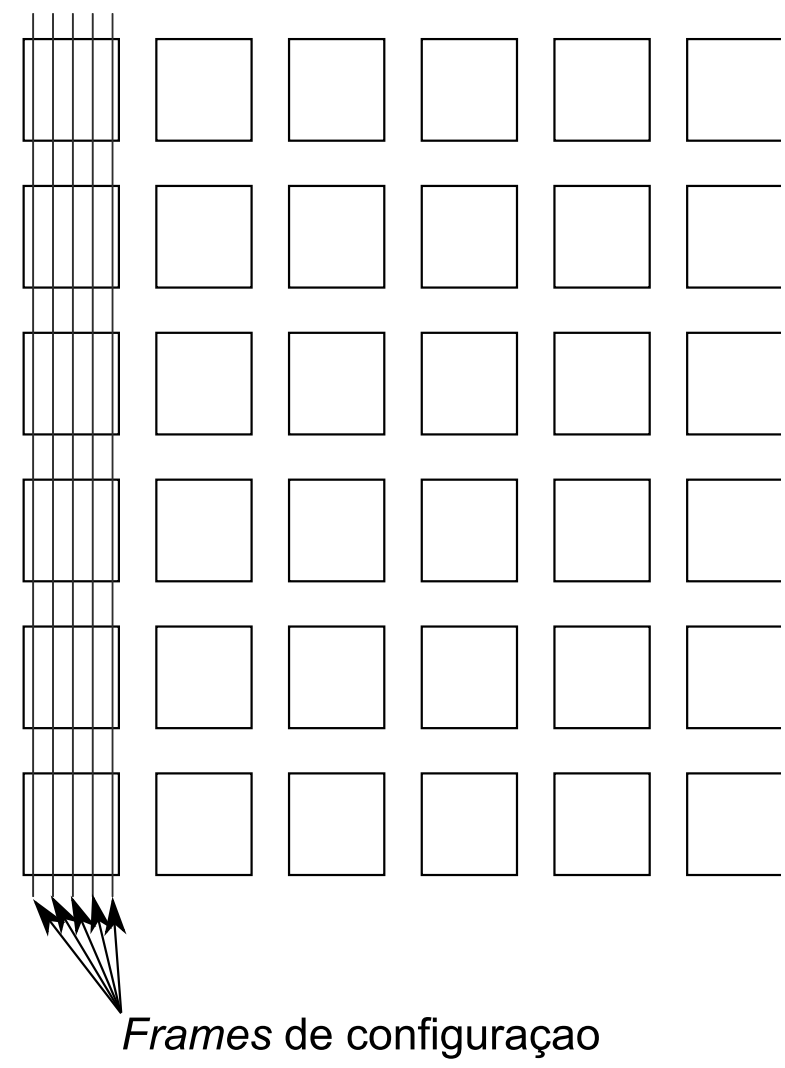

Figura 3.6: Demonstração da disposição de frames de configuração através dos blocos CLB.

BRAM é composto de $18 \mathrm{~Kb}$ de memória RAM. Um multiplicador é é capaz de realizar multiplicações com operandos de 18 bits e saída de 36 bits. Esses multiplicadores podem ter saída combinatória ou registrada Xilinx, 2007c.

Os FPGA $\$$ Virtex possuem sua memória de configuração baseadas em frames. Um frame é a menor unidade de reconfiguração de um FPGA Virtex . A cada coluna de CLBs, existem um ou mais frames. Nos chips do Virtex II/II Pro, por exemplo, uma coluna de CLB possui 22 frames, enquanto uma coluna de BRAM possui 64 frames. Um frame pode ocupar também uma coluna inteira do chip ou apenas parte dela. No FPGA Virtex II, por exemplo, um frame ocupa toda altura do chip. No FPGA Virtex 4, ao contrário, um frame ocupa apenas metade da altura do chip. Na Figura 3.6 é possível ver uma ilustração sobre a disposição dos frames por meio de arrays de CLB:

Para manipulação dos frames, existem três interfaces que permitem os bitstreams sejam enviados a eles, são elas: Internal Configuration Access Port (ICAP), SelectMAP e Joint Test Action Group (JTAG).

A interface SelectMAP (Figura 3.7) provê um barramento bidirecional para a lógica de configuração da Virtex. Seu tamanho varia conforme o modelo do dispositivo muda. Em uma Virtex II, por exemplo, ele possui 8 bits de memória. Essa interface tem dois modos de programação: Master e Slave. No modo Master, o sinal CCLK (clock) é uma saída do FPGA. Ele é utilizado para conectar uma única FPGA à um ou mais PROMs 


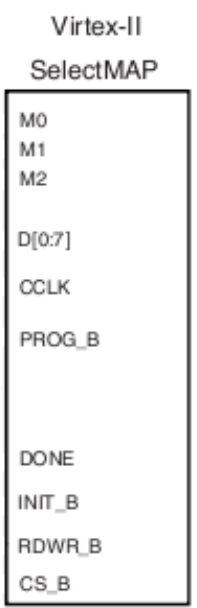

Figura 3.7: Interface SelectMAP. Adaptado de Xilinx, 2007b.

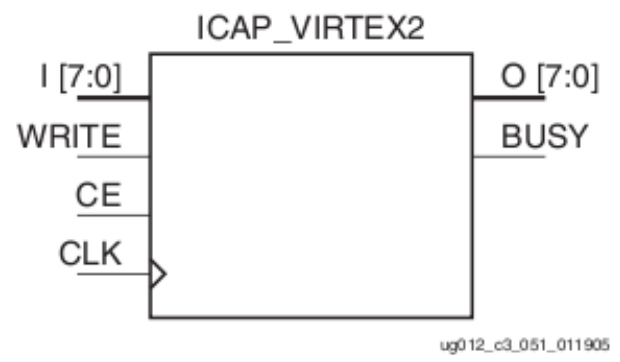

(a) Interface ICAP Xilinx, 2007b.

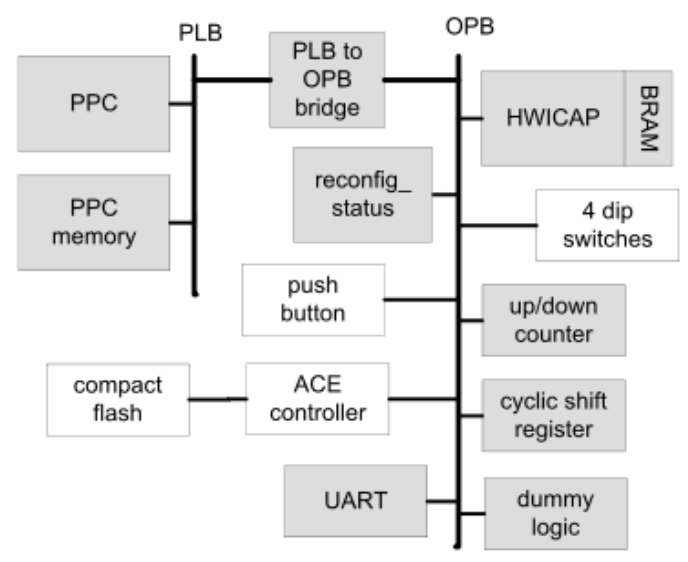

(b) Caixas cinzas representam componentes internos. Componentes brancos são partes da plataforma XUP que está conectado ao FPGA Papadimitriou et al. 2007.

Figura 3.8: Interface e Estrutura da porta ICAP

de configuração. No modo Slave, tal sinal entra no FPGA. Nesse modo, os sinais D [0:7], CCLK, RDWR_B, BUSY, PROG_B, DONE e INIT_B são distribuídos por meio de um único barramento que passa por todo dispositivo. O clock máximo que essa interface suporta sem que o sinal BUSY seja ligado é de $66 \mathrm{MHz}$.

A interface ICAP é um subconjunto da interface SelectMAP, operando como a segunda no modo Slave. Ela pode ser acessada por meio da lógica interna do FPGA. Assim como a interface SelectMAP, o clock máximo que a interface pode receber sem que o sinal BUSY seja verificado é de $66 \mathrm{MHz}$. A Figura 3.8a demonstra o diagrama da interface ICAP. A forma com que a ICAP é interligada no FPGA pode ser visto na Figura 3.8b.

O bitstream de configuração de um FPGAVirtex é enviado ao chip por meio de uma dessas interfaces de configuração citadas. A velocidade de reconfiguração dessas interfaces pode ser dada pela Equação 3.1 Souza Junior et al., 2010]:

$$
T_{\text {conf }}=T_{p p c \rightarrow \text { hwicap }}\left\lceil\frac{S}{512}\right\rceil+T_{\text {hwicap } \rightarrow c m}\left\lceil\frac{S}{2048}\right\rceil
$$


Tabela 3.3: Lista parcial de endereços de registradores do hardware de reconfiguração.

\begin{tabular}{c|c|c|c} 
Sigla & Escrita/Leitura & Endereço & Nome \\
\hline \hline FAR & $\mathrm{E} / \mathrm{L}$ & $0 \times 1$ & Frame Address Register \\
\hline FDRI & $\mathrm{E}$ & $0 \times 2$ & Frame Data Register Input \\
\hline FDRO & $\mathrm{L}$ & $0 \times 3$ & Frame Data Register Output \\
\hline CMD & $\mathrm{E} / \mathrm{L}$ & $0 \times 4$ & Command Register \\
\hline MFWR & $\mathrm{E}$ & $0 \times \mathrm{A}$ & Multiple Frame Write Register \\
\hline FLR & $\mathrm{E} / \mathrm{L}$ & $0 \times \mathrm{B}$ & Frame Length Register
\end{tabular}

Tabela 3.4: Composição do endereço de um frame.

\begin{tabular}{|c|c|c|c|c|c|c|c|c|c|c|c|c|c|c|c|c|c|c|c|c|c|c|c|c|c|c|c|c|c|c|}
\hline & & & & & B & & & & & MJ & & & & & & & & MN & & & & & & & Byte & $\mathrm{Nul}$ & Imbes & & & \\
\hline 31 & 30 & 29 & 28 & 27 & 26 & 25 & \begin{tabular}{|l|}
24 \\
\end{tabular} & \begin{tabular}{|l|l|}
23 \\
\end{tabular} & $2 \mid$ & 21 & 20 & 19 & 18 & 17 & \begin{tabular}{|l|l|}
16 \\
\end{tabular} & 15 & 14 & 13 & \begin{tabular}{|l|l|}
12 \\
\end{tabular} & \begin{tabular}{|l|l|}
11 \\
\end{tabular} & 10 & \begin{tabular}{|l|}
9 \\
\end{tabular} & \begin{tabular}{|l|}
8 \\
\end{tabular} & 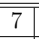 & \begin{tabular}{l|l}
6 & 5 \\
\end{tabular} & 44 & 3 & 2 & 1 & 0 \\
\hline 0 & 0 & 0 & 0 & 0 & $\mathrm{x}$ & $\mathrm{x}$ & \begin{tabular}{|c|}
$x$ \\
\end{tabular} & $\mathrm{x}$ & $\mathrm{x}$ & $\mathrm{x}$ & $\mathrm{x}$ & $\mathrm{x}$ & $\mathrm{x}$ & $\mathrm{x}$ & $\mathrm{x}$ & $\mathrm{x}$ & $\mathrm{x}$ & $\mathrm{x}$ & $\mathrm{x}$ & $\mathrm{x}$ & $\mathrm{x}$ & $|x|$ & \begin{tabular}{|l|}
0 \\
\end{tabular} & 0 & \begin{tabular}{l|l}
0 & 0
\end{tabular} & 0 & \begin{tabular}{|l|}
0 \\
\end{tabular} & & 0 & \\
\hline
\end{tabular}

O valor do campo "Endereço do Registrador" contém o endereço do registrador que será lido ou gravado no dispositivo. É possível endereçar vários registradores presentes no hardware de reconfiguração do FPGA. Para o envio de bitstreams propriamente dito, os registradores relacionados são listados na Tabela 3.3. Nela, é possível ver seis registradores:

- Frame Address Register (Registrador de Endereço de Frame). Esse registrador armazena o endereço onde os próximos bitstreams serão enviados. O endereço de um frame tem 32 bits de tamanho e é composto por 4 campos: Block Address (BA), MJA (Major Address), MNA (Minor Address) e um número de byte (Tabela 3.4). Esse número, segundo o fabricante, não deve ser acessado pelo usuário, sendo utilizado apenas pela lógica interna do dispositivo.

- Frame Data Register Input (Registrador de Entrada de Dados de Frame). Os dados de configuração das unidades reconfiguráveis (CLBs, BRAMs etc) deverão ser enviados para este registrador, depois que o dispositivo foi corretamente iniciado através do Command Register, Frame Length Register e eventualmente o Multiple Frame Write Register e o(s) endereço(s) do(s) frame(s) foi(ram) corretamente definidos através do Frame Address Register.

- Frame Data Register Output (Registrador de Saída de Dados de Frame). É por meio deste registador que um determinado bitstream que já foi devidamente reconfigurado na memória de configuração pode ser lido.

- Command Register (Registrador de Comando) . Este registrador tem vários usos; a partir dele é possível enviar inúmeros comandos para o FPGA, que não serão citados aqui. Para a reconfiguração parcial, os comandos relacionados são: Write Configuration Data (Gravar Dados de Configuração) e Multiple Frame Write Register (Registrador de Escrita de Múltiplos Frames), que, respectivamente, servem para informar o FPGA que dados de configuração serão enviados para o registrador FDRI e para se gravar um frame em vários endereços de frames. 


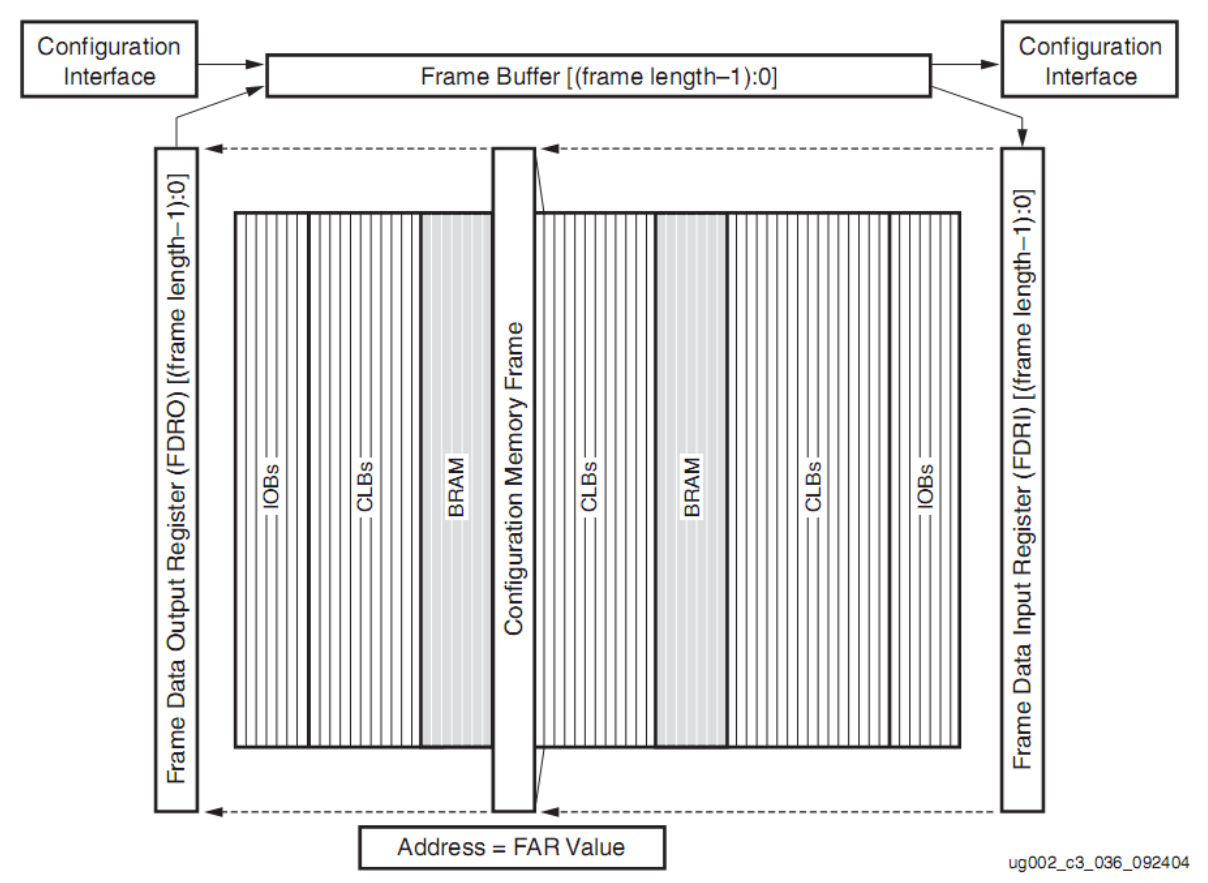

Figura 3.9: Caminho de dados do frame Xilinx, 2007c.

- Multiple Frame Write Register (Registrador de Escrita de Múltiplos Frames). Este registrador é utilizado para que vários frames de configuração sejam escritos simultaneamente. Com ele, é possível gravar diversos endereços no registrador FAR com apenas um frame enviado ao FDRI, que o hardware de reconfiguração se encarregará de enviar os dados para os endereços especificados. Essa possibilidade de se enviar um frame de configuração para diversos endereços só é possível - para o caso se utilize a ferramente bitgen - se a opção -g Compress:yes for definida.

- Frame Length Register (Registrador de Tamanho de Frame). Este registrador armazena o tamanho em palavras do frame. Ele é necessário posto que os dispositivos Virtex não possuem o valor do tamanho do frame gravados diretamente em seu hardware, sendo necessário ser reconfigurado a cada vez que o chip é ligado. Isso acontece porque a mesma lógica de reconfiguração é utilizada para dispositivos de diversos tamanhos.

Por meio da Figura 3.9 é possível ver o caminho de dados que um frame de configuração faz. Primeiro, o frame é enviado pela interface de configuração. Ele, então, é colocado em um frame buffer. A partir daí, ele é enviado para o registrador FDRI que grava o frame na memória de configuração, de acordo com o endereço estipulado no registrador FAR. Da mesma forma, para leitura, o frame é lido para o registrador FDRO, enviado para o frame buffer e, então, é finalmente direcionado para a interface de configuração.

\subsubsection{Reconfiguração Sem Ruídos}

Uma das características da RPD no Virtex II/II Pro é a possibilidade de que, caso um bitstream reconfigurado possua partes iguais as anteriores, os da lógica reconfigurada 


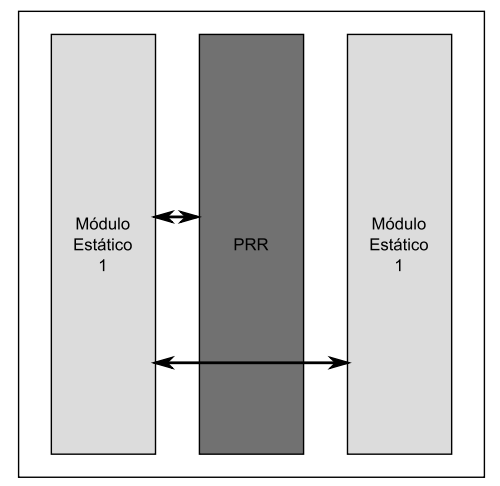

FPGA

Figura 3.10: Exemplo de roteamento possível.

idêntica não sofra "ruídos" Blodget et al. 2003. Ou seja, dessa forma, um roteamento fixo pode ser definido dentro de uma área reconfigurável e, desde que o bitstream reconfigurado possua os mesmo bits de configuração para o roteamento definido, esse roteamento não sofrerá ruídos para os sinais trafegados.

A Figura 3.10 contém um diagrama de uma possível configuração de área devido ao fato da reconfiguração parcial não ter ruídos. Nela, é possível ver duas áreas estáticas e uma PRR. O roteamento estático passa dentro da PRR sem, contudo, ser afetado pela $\mathrm{RPD}$.

\subsubsection{Fluxos de Desenvolvimento}

Existem diversos fluxos de desenvolvimento para criação de projetos que utilizam a reconfiguração parcial, alguns da própria Xilinx® e outros de terceiros, como o ReCoBus Koch et al. 2008. Contudo, a maioria deles está em desuso. Devido o maior suporte e a maior documentação, neste trabalho o fluxo de desenvolvimento escolhido foi o EAPR Xilinx, 2008, que é da própria Xilinxß.

Esse fluxo de desenvolvimento se assemelha ao fluxo de desenvolvimento padrão de um hardware em um FPGA sem reconfiguração parcial. A Figura 3.11 contém um fluxograma do fluxo de desenvolvimento. Nele, é possível ver que ainda há um fluxo de desenvolvimento padrão (denotado por "design não parcialmente reconfigurável") em adição do fluxo de desenvolvimento específico (denotado por "design parcialmente reconfigurável").

\section{Desenvolvimento Estático}

Inicialmente, o fluxo de desenvolvimento deve passar pelo desenvolvimento dos módulos de hardware estáticos, da mesma maneira que seria feito em um projeto estático. Contudo, esse desenvolvimento deve ser feito levando em consideração alguns critérios específicos da reconfiguração parcial.

\section{1) Descrição de hardWare}

Nesta etapa, todo o hardware é descrito com alguma [LDH ou alguma linguagem esquemática. O projetista deve particionar o hardware em módulos estáticos e módulos reconfiguráveis (Partially Reconfigurable Module ( $\overline{\mathrm{PRM}}$ ), ainda que não haja implemen- 


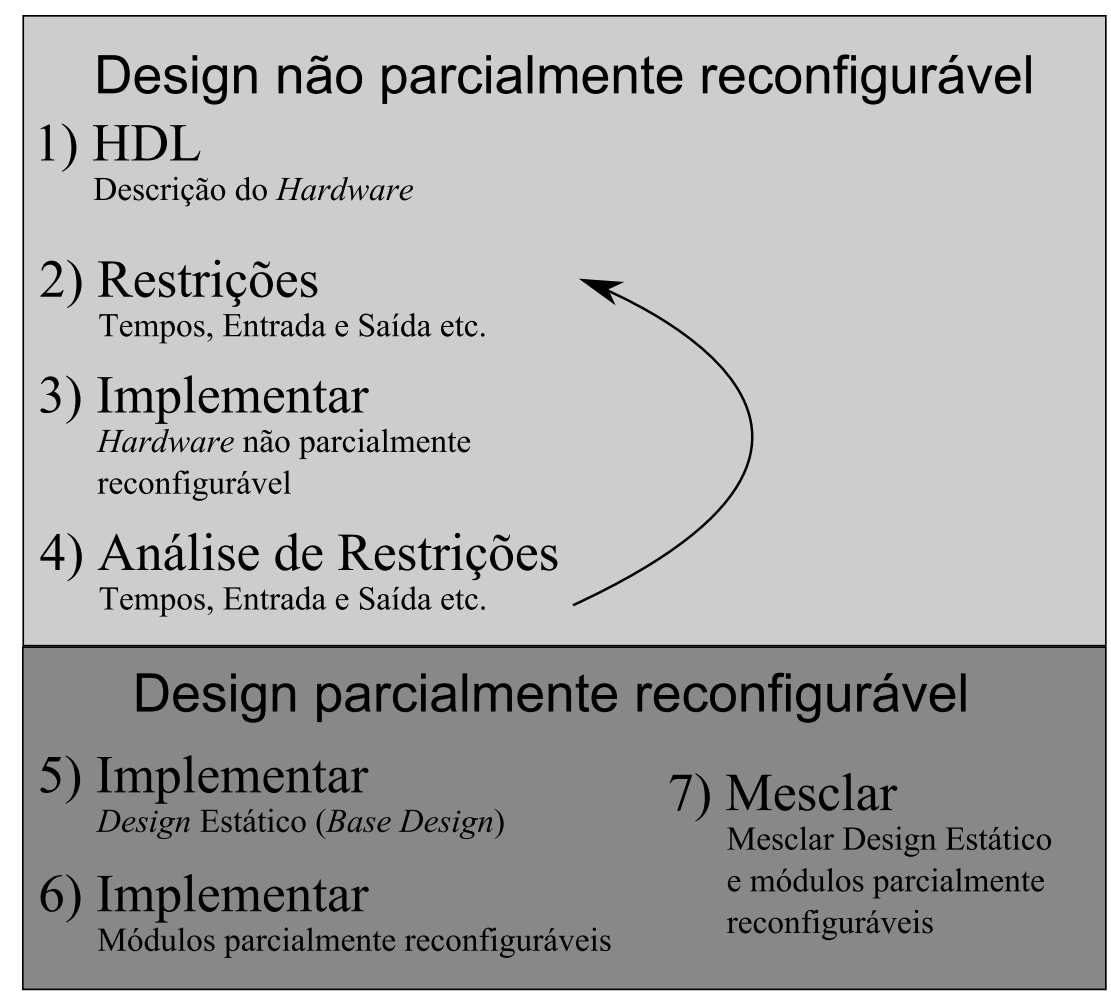

Figura 3.11: Fluxo de desenvolvimento do EAPR, Adaptado de Xilinx, 2008.

tação direta disso ainda. Esta etapa é importante para análise dos simuladores e para a geração e análise de restrições das próximas etapas.

\section{2) GeraÇÃo DE RESTRIÇÕES}

Aqui, o projetista deve gerar todas as restrições de tempo, pinos e voltagem de entrada e saída etc. A diferença básica deste processo para os fluxos de desenvolvimento para projetos inteiramente estáticos é que o projetista deve ter em mente as restrições de espaço dos módulos estáticos e reconfiguráveis. Nesta etapa do projeto, as áreas dos módulos reconfiguráveis $(\mathrm{PRR})$ devem ser definidas dentro das restrições que a plataforma tem. As restrições de espaço são:

1. Uma $\overline{\mathrm{PRR}}$ pode ser utilizada para um ou mais $\overline{\mathrm{PRM}}$ s. A restrição aqui é que a $\mathrm{PRR}$ deve ter recursos suficientes para o maior PRM a ser roteado.

2. A PRR deve ocupar blocos de recursos completos. Não é possível, por exemplo, que parte do conjunto de 4 slices de um CLB fique para uma área reconfigurável. Assim, todo CLB deve ser parte de uma área.

3. As $\overline{P R R}$ e as áreas estáticas devem ser interconectadas por meio de hard macros. Hard macros são estruturas previamente e estaticamente definidas pelo usuário. Essa forma de interconexão é feita assim devido o fato de que a ferramenta de Place and Route da Xilinx $(\mathbb{R}$ não conseguir inferir automaticamente esses fios de interconexão. Sem o uso de hard macros, uma possível estrutura de roteamento entre as PRRs e áreas estáticas poderia ser definida para um PRM por meio da ferramenta e depois outra estrutura poderia ser definida para outro PRM. 


\section{FPGA}

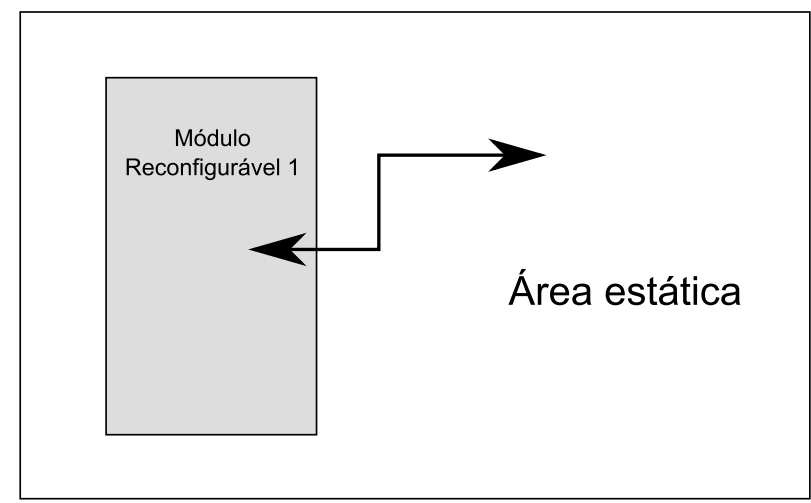

FPGA

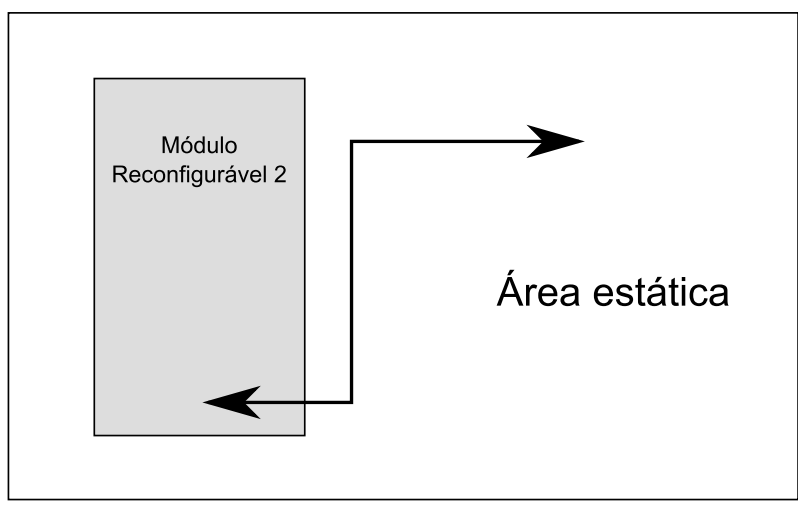

Figura 3.12: Diagrama exemplificando dois roteamentos distintos para dois módulos reconfiguráveis diferentes para uma mesma área reconfigurável.

Na Figura 3.12, é possível notar dois roteamentos distintos para uma mesma PRR e dois $\underline{\mathrm{PRM}}$ s diferentes. Dessa forma, posto que a área estática não será reconfigurada, se a PRR for reconfigurada, não haverá ligação entre a área estática e a PRR.

A Xilinx® disponibiliza um conjunto de hard macros para o roteamento entre as partes estáticas e $\mathrm{PRR}$ p para o EAPR. Essas estruturas são chamadas de bus macros. As bus macros são hard macros que definem 8 pontos de interconexão fixos entre dois (bus macro "estreita") ou quatro (bus macro"larga") CLB:. Elas devem ser ligadas nas bordas das PRRs, ficando um ponto de interconexão dentro da PRR e outro ponto de interconexão dentro da área estática. Dessa forma, uma área estática que precisa ser ligada a uma $\mathrm{PRR}$, deve ser ligada diretamente a uma bus macro e, essa, deve ser ligada diretamente na lógica interna da $\mathrm{PRR}$.

A Figura 3.13 mostra um exemplo de bus macro ligando uma PRR a uma área estática. Nela, é possível notar que bus macros são fixadas em uma determinada localidade do FPGA. Assim, os fios de interconexão são ligados às bus macros e, por meio delas, os sinais trafegam entre as PRRs e as áreas estáticas. É interessante notar que, para a Virtex II/II Pro, as bus macros tem tem apenas uma direção (horizontal) e dois sentidos possíveis: da esquerda para a direita e da direita para a esquerda. Ou seja, não há uma bus macro responsável por ligar verticalmente uma área estática com uma PRR e, também, uma bus macro única não pode ser responsável por transferir sinais de entrada e saída ao 


\section{FPGA}

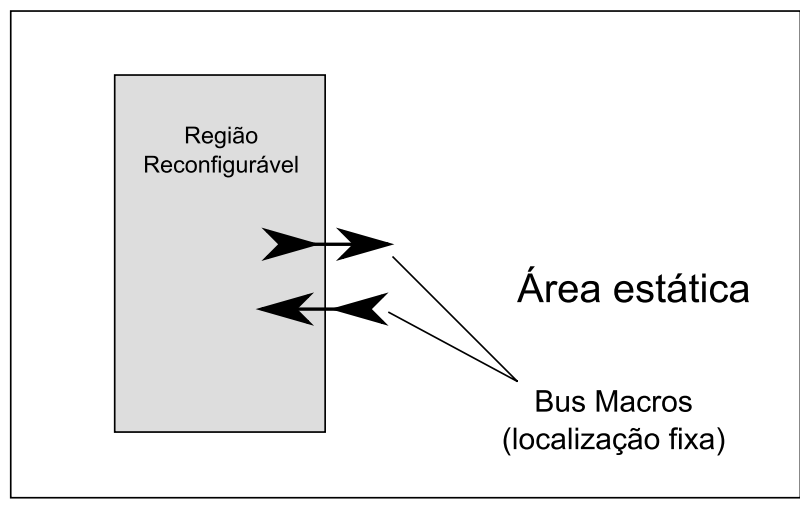

Figura 3.13: Diagrama exemplificando a utilização de bus macros.

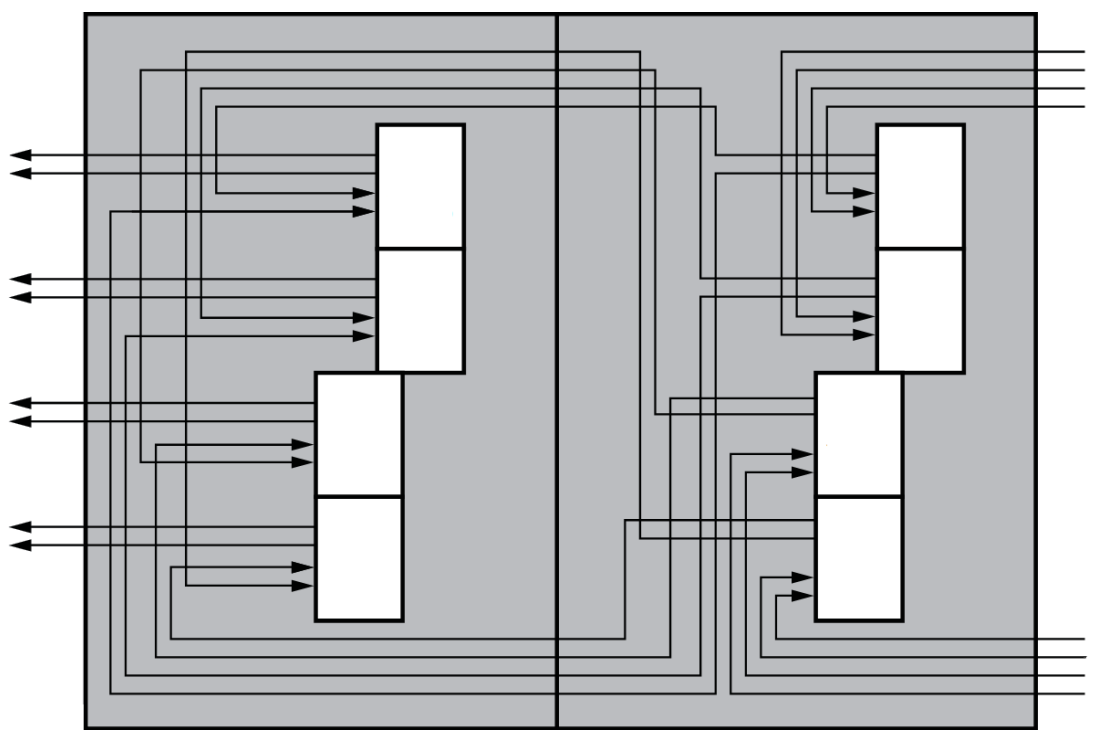

Figura 3.14: Desenho de uma bus macro assíncrona do tipo "direita para a esquerda". Adaptado de Xilinx 2006.

mesmo tampo da PRR

Na Figura 3.14, é possível ver a forma de uma bus macro assíncrona estreita, que leva sinais da direita para a esquerda. Os retângulos cinzas da imagem representam os dois CLB $\$$, os brancos representam slices do CLB. Também, é possível ver que 8 fios vem da direita, passam pelos dois CLBs e chegam a esquerda. A linha preta vertical central delimita também a divisão da área reconfigurável da área estática, sendo que qualquer uma das duas podem estar em qualquer lado da bus macro.

3) IMPLEMENTAR

Nesta etapa, o hardware descrito é simulado e implementado diretamente em hardware de forma estática. Os $\mathrm{PRM}$ s devem ser implementados como módulos estáticos com o intuito de validar a descrição anteriormente feita.

4) AnÁlise de RestriçÕes

Nesta etapa, a implementação é utilizada para análise de restrições previamente descrita. Caso as restrições não sejam atendidas, deve-se voltar para as etapas anteriores para modificar as restrições ou a descrição previamente feita, com o intuito de adequar o 
projeto às restrições existentes.

\section{Desenvolvimento Reconfigurável}

Com o hardware funcionando de forma puramente estática, cabe implementar o hardware parcialmente reconfigurável. As etapas 5, 6 e 7 podem ser feitas por meio da ferramenta PlanAhead, desenvolvida pela Xilinx®. Essa ferramenta, além de ajudar no floorplanning dos designs, auxilia no fluxo de desenvolvimento. Desta forma, essas etapas são feitas automaticamente pela ferramenta.

\section{5 e 6) Implementar Design Base e Reconfigurável}

Nesta etapa, as partes estática e os $\overline{\mathrm{PRM}}$ s do projeto reconfigurável são sintetizadas.

7) Mesclar Módulos ReCONfiguráveis E ESTÁticos

Finalmente, os bitstreams dos $\mathrm{PRM}$ s e estático são gerados e em seguida mesclados. Essa mescla tem como objetivo criar um bitstreams que podem efetivamente ser enviados para o FPGA.

A RPD é utilizada em diversos projetos de hardware na literatura acadêmica. Na próxima Seção, alguns trabalhos que utilizam RPD serão citados.

\subsection{Trabalhos Relacionados}

Desde a criação do conceito de RD e RPD, alguns trabalhos foram propostos explorando essas características. Ultimamente, é possível notar um certo crescimento de publicações de trabalhos que utilizam RD. Algumas das áreas que se beneficiam dessa tecnologia são: Network on Chip (NoC) e System on Programmable Chip (SoPC) Matos et al., 2009; Hur et al., 2007; Kalte et al., 2002; Moraes et al., 2005, Computação de Alto Desempenho El-Araby et al., 2009, Computação Bioinspirada [Upegui \& Sanchez, 2005. Sidhu et al., 1999, Tyrrell et al., 2003, Computação Reconfigurável Alle et al., 2009. Kohler et al., 2008; Goldstein et al., 1999; Hauser \& Wawrzynek, 1997; Ling \& Amano, 1993; Wirthlin \& Hutchings, 1995. Além da rápida implementação de diversos algoritmos computacionais diretamente em hardware.

\subsubsection{Computação Bioinspirada}

Upegui \& Sanchez 2005 cita três modelos de evolução de hardware utilizando a família de FPGA Xilinx@ Virtex. Estes modelos são: (1) baseados em módulos, (2) em diferenças de hard-macros e (3) manipulação de bitstream. O primeiro modelo constitui em uma abordagem de grossa-granularidade, evoluindo o hardware através da combinação de módulos. Os outros dois modelos, no entanto, são de fina-granularidade: o segundo se baseia no modelo de desenvolvimento baseado em diferenças Xilinx, 2007a, e através dela modifica os conteúdos das hard-macros até conseguir um resultado desejável. O terceiro, utiliza a manipulação direta do bitstream já gerado para evoluir o hardware, esse método consiste em deixar o roteamento fixo através de hard-macros para que o dispositivo não seja danificado, e evoluir unidades lógicas, como multiplexadores. 
Sidhu et al. [1999 propôs um método de programação genética utilizando FPGAs Xilinx® XC6264. Esse método, assim como na programação genética tradicional, consiste em três fases: inicialização, validação do fitness e evolução. A população é criada em forma de configuração no hardware cujo cada elemento é separadamente executado para que o fitness seja avaliado. Assim, então, na última fase, a configuração é modificada com o intuito de evoluir a população.

\subsubsection{NoCs e SoCs}

System on Chip (SoC)s consistem sistemas inteiros, como memória, processador, controlador de vídeo, etc, dentro de um único chip. SoPCs implementam esses recursos dentro de um chip reprogramável. NoCs são plataformas que implementam conceitos conhecidos em redes de computadores em chips que apresentem vários recursos como processadores, para que eles possam se comunicar.

O primeiro SoPC que suportava RPD foi criado por Kalte et al. 2002]. Ele utiliza um FPGA Xilinx $\AA$ Virtex II, e é composto por IP-sockets reprogramáveis no FPGA. Ou seja, módulos do SoC poderiam ser reprogramados em tempo de execução dentro desses sockets criados anteriormente, aumentando assim a flexibilidade do SoC.

Hur et al. 2007] propôs um NoCem uma Xilinx@ Virtex II em que utilizava reconfiguração parcial dinâmica para escolher a melhor arquitetura de roteamento em decorrência do padrão de comunicação que acontecia em um determinado momento. O aumento de desempenho, comparado à uma rede 2D-mesh Packet Switched Network (PSN) foi de duas vezes. Além de uma economia de espaço no chip de $70 \%$.

Matos et al. 2009 propôs um roteador dinamicamente reconfigurável para um NoC, que muda o tamanho do buffer conforme o padrão de comunicação do canal. Assim, se um canal de comunicação não está usando completamente seus buffers, ele pode permitir que seus vizinhos da esquerda e da direita utilizem-nos caso eles necessitem. A Figura 3.15 demonstra o diagrama esquemático da arquitetura proposta e da arquitetura anterior. Na Figura 3.15b, é possível perceber que a nova metodologia faz com que o buffer de comunicação seja dividido entre as entradas de três canais de comunicação.

\subsection{Considerações Finais}

Este Capítulo conteve uma abordagem sobre a RPD, abordando as arquiteturas presentes na literatura (contexto único, múltiplos contextos, parcialmente reconfigurável etc), citando alguns trabalhos relacionados à utilização e criação desses conceitos e, por fim, apresentando a estrutura interna da Xilinx $®$ Virtex II, o FPGA que será utilizado neste trabalho, tal como o fluxo de desenvolvimento para criação de um projeto com hardware parcialmente reconfigurável.

No próximo Capítulo a proposta deste trabalho será detalhada. Tal como o Estado da Arte atual de todo projeto. 


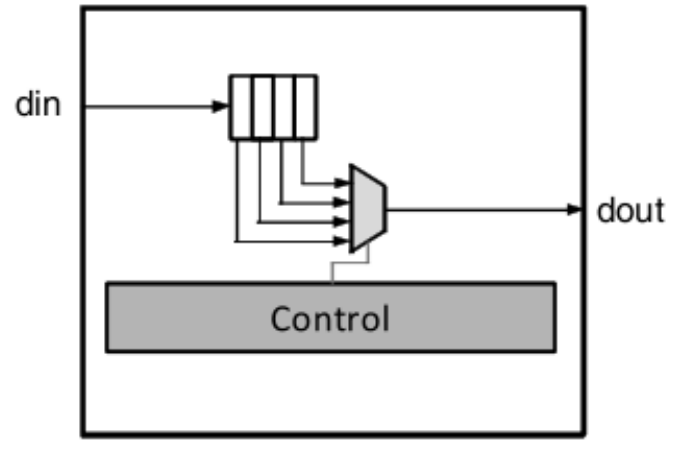

(a) Arquitetura padrão.

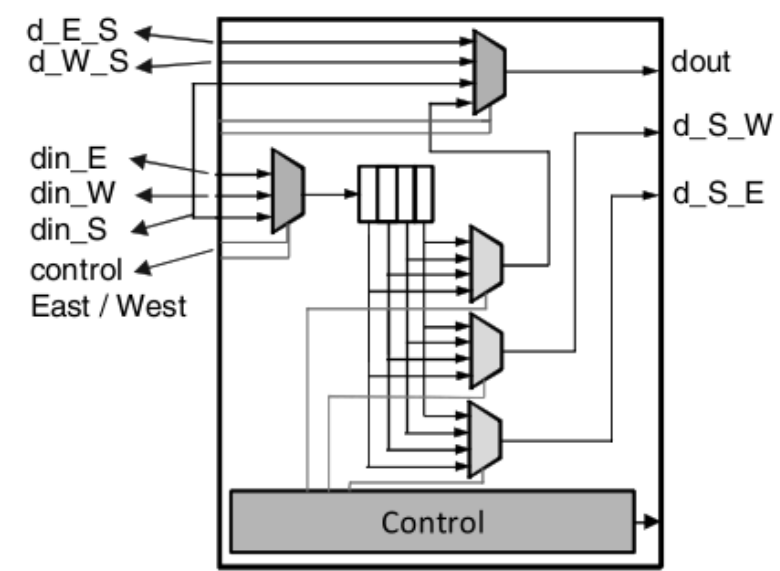

(b) Arquitetura proposta.

Figura 3.15: Filas de entrada Matos et al. 2009 


\section{Capítulo}

\section{ChipCflow: Proposta de Partição e Protocolo}

A ferramenta ChipCflow vem sendo desenvolvida nos últimos quatro anos, inicialmente a partir de um projeto de arquitetura a fluxo de dados dinâmico em hardware reconfigurável, mas agora como uma ferramenta de compilação. Ela tem como objetivo a execução de algoritmos por meio do modelo de arquitetura a fluxo de dados associado ao conceito de dispositivos parcialmente reconfiguráveis. Sua característica principal é acelerar o tempo de execução de programas escritos em LPAN, do inglês, High Level Languages, em particular nas partes mais intensas de processamento. Isso é feito por meio da implementação dessas partes de código diretamente em hardware reconfigurável - utilizando a tecnologia FPGA- aproveitando ao máximo o paralelismo considerado natural do modelo a fluxo de dados e as características do hardware parcialmente reconfigurável Souza Junior et al. 2010, Astolfi \& Silva, 2007; Silva \& Marques, 2006, Silva, 2006].

\subsection{Fluxo de Desenvolvimento}

A Figura 4.1 contém o diagrama de fluxo do desenvolvimento de uma aplicação por meio da ferramenta ChipCflow. Inicialmente, o programa é escrito em C. A partir dele, um GFD equivalente é gerado. Neste ponto, o GFD é dividido em partições, isto é, subgrafos do grafo original. Essa divisão é feita com o intuito de futuramente se criar configurações distintas que serão reconfiguradas no FPGA. Para isto, as partições são convertidas para a linguagem de descrição de hardware VHSIC Hardware Description Language (VHDL), com o auxílio de bibliotecas contendo código em comum dos GFDs, com o intuito de se criar PRMs. 


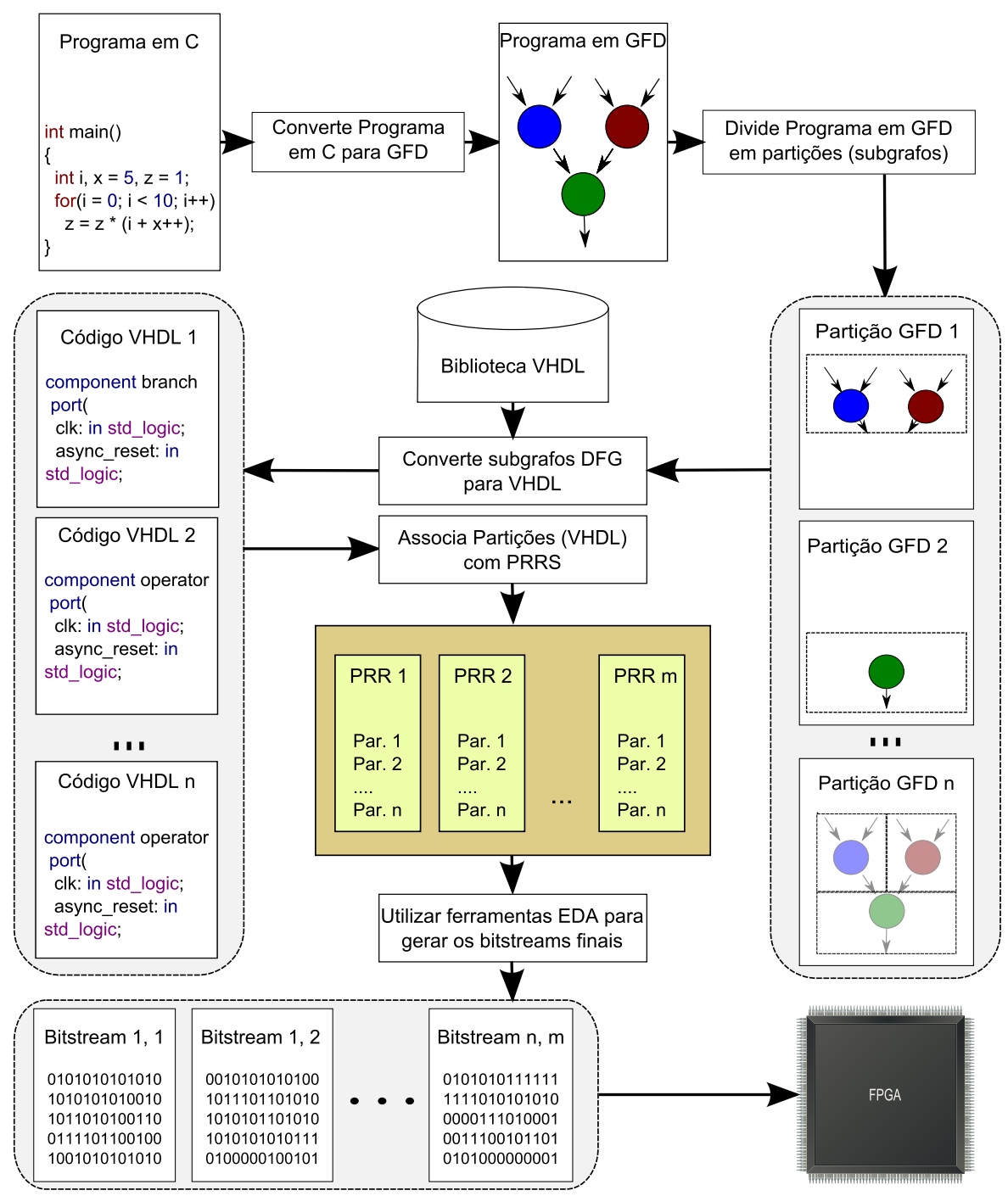

Figura 4.1: Diagrama de Fluxo de desenvolvimento da ferramenta ChipCflow. Adaptado de Souza Junior et al., 2010].

Com os PRMs gerados, o próximo passo consiste em associa-los a PRRs. Essa associação é explicada com detalhes na Seção 4.3. Finalmente, com os PRM a PRRs, deve-se utilizar ferramentas Eletronic Design Automation (EDA para geração final dos bitstreams de configuração.

Alguns trabalhos foram realizados agregando ao projeto ChipCflow. da Costa 2009], por exemplo, fez um compilador de C para GFD em VHDL. Todavia, este trabalho não lida com o modelo de partições com RPD. Astolfi [2009] propôs a utilização de hardware reconfigurável e desenvolveu um fluxo de desenvolvimento para utilização dele. Infelizmente, conforme esse trabalho foi desenvolvido após a realização deste, o fluxo de desenvolvimento proposto ali não foi aproveitado para este trabalho.

Sanches 2010 propôs um modelo de partição e protocolo. Devido a atrasos nesse projeto, o trabalho proposto aqui não pode simplesmente implementar o modelo proposto, conforme o cronograma inicial. Destarte, o modelo de partição e protocolo descrito em [Sanches, 2010 também foi desenvolvido pelo aluno que realizou este trabalho, Francisco de Souza Junior. 


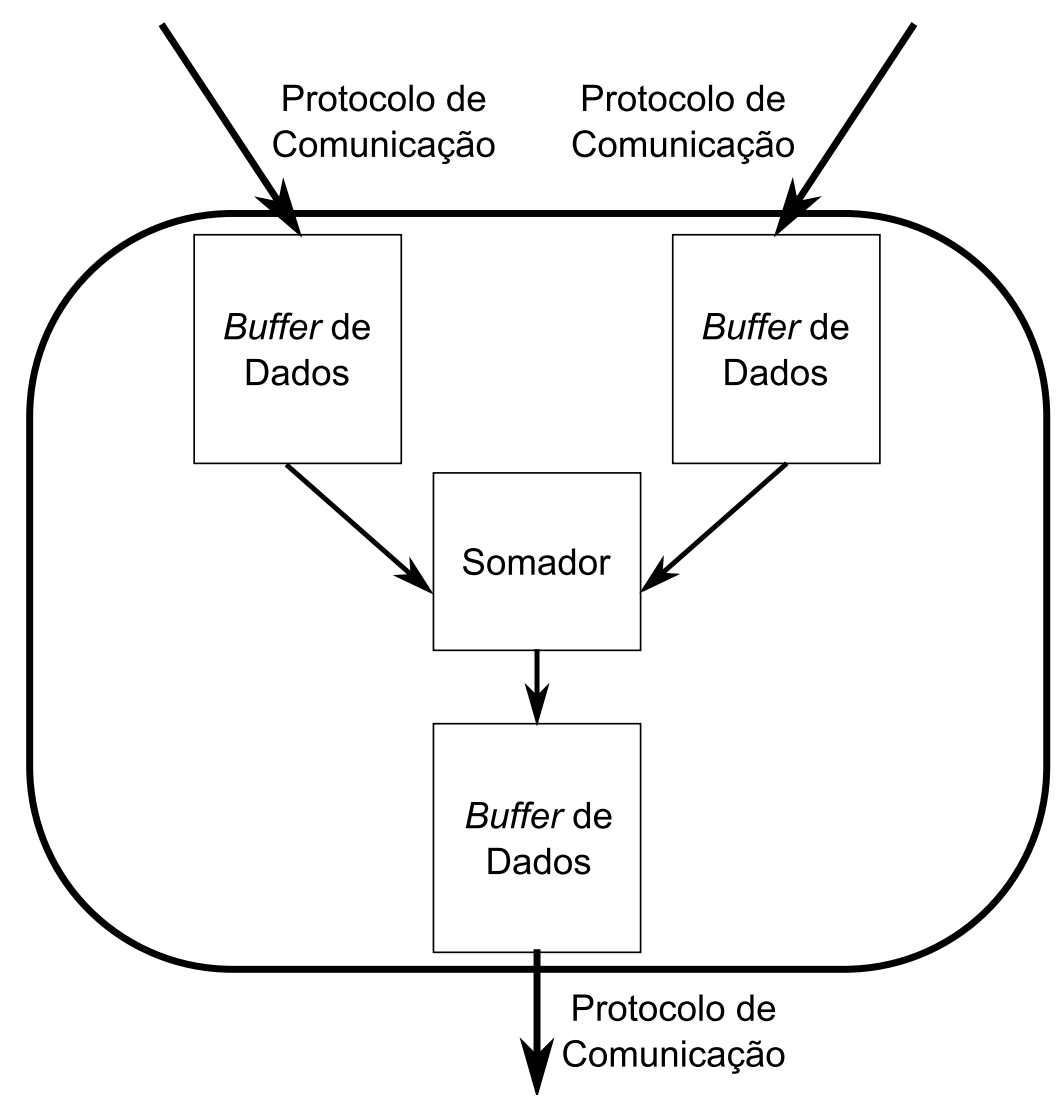

Figura 4.2: Diagrama da arquitetura do circuito de um operador de soma.

\subsection{Fluxo de Execução}

O conceito básico do ChipCflow consiste em utilizar o recurso de RPD em GFDs dinâmicos com o intuito de reduzir o tempo de tag matching de arquiteturas convencionais baseadas em fluxo de dados. Destarte, conforme há reentrância dentro do GFD dinâmico, uma cópia da área de reentrância é criada e inserida dentro do GFD [Silva \& Marques, 2006, Silva, 2006. Para que isso ocorra, os GFDs precisam ser divididos em subgrafos a partir do grafo original.

\subsubsection{Nós do GFD}

No contexto da Computação Reconfigurável, os subgrafos são implementados diretamente em um FPGA. Ou seja, cada nó do GFD possui seu próprio circuito e as interconexões entre outros nós seguem o mesmo fluxo do GFD. Por exemplo, um operador de soma possui buffers para entrada e saída dos tokens, lógica para o protocolo de comunicação entre os nós e um circuito somador interno (Figura 4.2.

Desta forma, os nós do modelo baseado em fluxo de dados podem ser conectados conforme estão dispostos em um GFD qualquer. Dentro do projeto ChipCflow, o primeiro protocolo de comunicação para o envio e recebimento de tokens entre os nós foi proposto por Astolfi \& Silva 2007. O protocolo de comunicação entre nós criado consiste em um barramento de dados para o token, um sinal para strobe e outro sinal para 


\section{Envio de token}

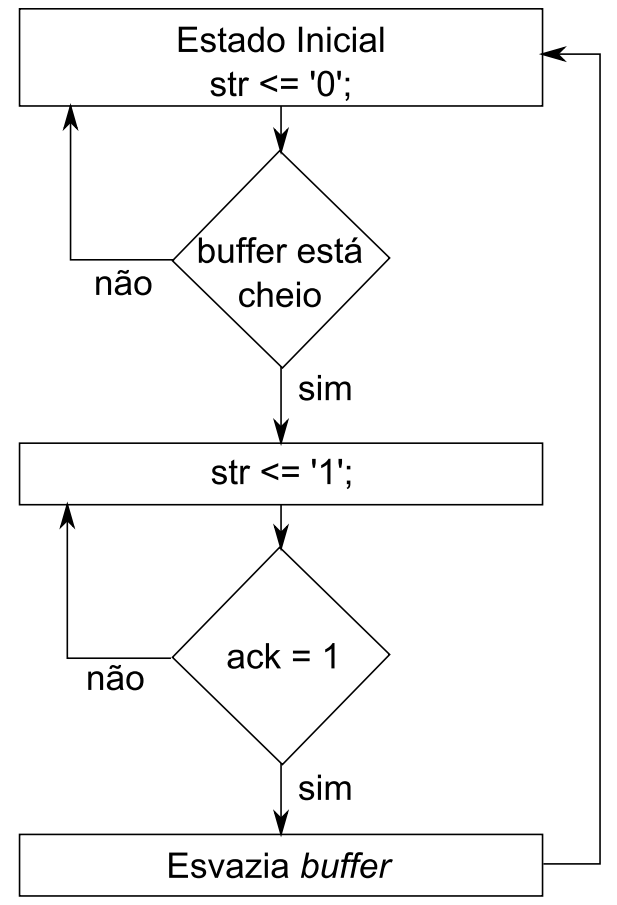

\section{Recebimento de token}

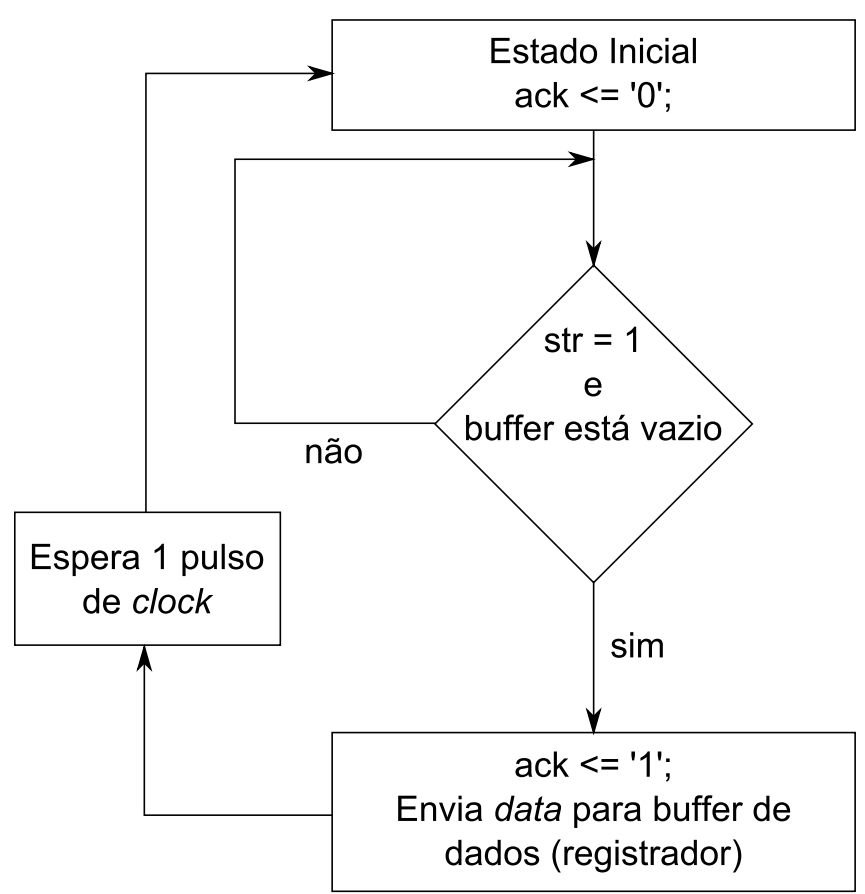

Figura 4.3: Diagrama de estados do protocolo de comunicação entre nós do GFD.

\section{ACKNOWLEDGMENT.}

A Figura 4.3 contém dois diagramas de estados do protocolo de comunicação dos nós do ChipCflow. Um diagrama de estados é responsável pelo envio de token para o próximo nó e outro é responsável pelo recebimento deste token. Para o envio de token, o circuito deve inicialmente o sinal de strobe como "0". Caso o buffer de dados contenha um token, o sinal strobe é definido como "1" e os seus dados são diretamente disponibilizados para o circuito que recebe o token por meio de um barramento de dados. A partir daí, o circuito de envio de token espera que o sinal de acknowledgment seja "1". Quando isso acontecer, o buffer é esvaziado e o sinal de strobe passa a ser "0" novamente.

Para o recebimento de token, o circuito deve inicialmente colocar o sinal de acknowledgment em "0". Quando o sinal de strobe for igual a "1" e o buffer de recebimento estiver vazio, o sinal de acknowledgment deve ir para "1" e os dados do barramento devem ser enviados para o buffer. Finalmente, após 1 pulso de clock, o sinal de acknowledgment volta para "0". Astolfi \& Silva 2007] contém um exemplo de código em VHDL de um operador de soma, contendo toda lógica de comunicação entre nós.

Cabe ressaltar, todavia, que esse protocolo proposto por Astolfi \& Silva [2007] não está preparado para o modelo de fluxo de dados dinâmico com tagged-token e nem ao modelo de partição e protocolo, embora no próprio trabalho introduza alguns mecanismos preliminares para adequação ao tagged-token. 


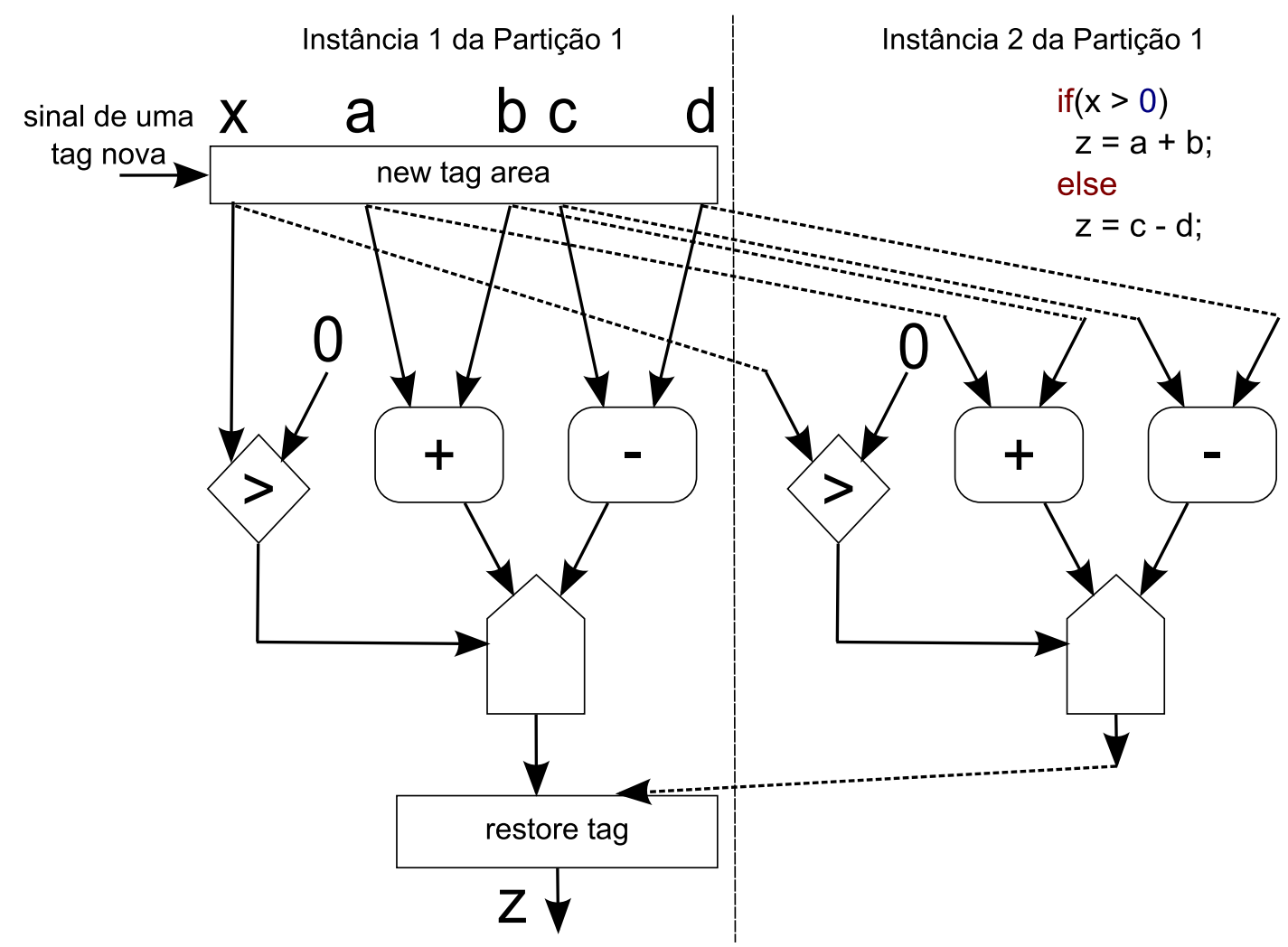

Figura 4.4: Duas instâncias de uma mesma partição. Adaptado de Souza Junior et al., 2010.

\subsubsection{Subgrafos do GFD e Reconfiguração Parcial Dinâmica}

Com o intuito de diminuir o problema de tag matching de máquinas de fluxo de dados dinâmico, o ChipCflow tem como proposta dividir GFD em subgrafos e reconfigura-los no FPGA na medida em que novos tags forem criados e esses subgrafos sejam necessários. Na terminologia utilizada no ChipCflow, um subgrafo é chamado de "partição". O processo de reconfiguração do hardware desta partição no FPGA é chamado de "instanciação". Finalmente, cada partição reconfigurada dentro de uma PRR do FPGA é chamada de "instância" da partição. A Figura 4.4 contém um exemplo de criação de duas instâncias para uma mesma partição em duas PRRs diferentes.

Na Figura 4.4, ainda, é possível ver nós dos GFD responsáveis pela manipulação de tags, o new tag area e o restore tag Veen [1986]. Esses nós tem como objetivo manipular a criação, manutenção e destruição de tags, com o intuito de fazer com que instâncias das partições operem corretamente. Essas estruturas são necessárias para manipulação dos dados e broadcast dos tokens para todas as instâncias das partições conectadas a esses nós. Assim, cada vez que um novo tag for gerado, esse token com o novo tag será enviado para todas as instâncias daquela partição.

Com cada nó recebendo os tokens corretos (dada a ligação direta entre os nós), cabe ao nó, então, apenas a comparação entre os tokens recebidos, para testar se possuem o mesmo tag. Caso os tags sejam iguais, o nó executa os dados e envia os dados para o(s) próximo(s) nó(s). Caso os tags sejam diferentes, os dados são simplesmente descartados. 
Dessa forma, cada nó é responsável por determinar se o dado que chega em suas entradas tem tags iguais, gerando um mecanismo paralelo e natural de tag matching.

Embora seja este o modelo de manipulação de tags que será utilizado neste trabalho, cabe ressaltar que ele ainda é preliminar e bastante simplificado. Um de seus problemas é a sincronização entre instâncias para novos tags, que foi preliminarmente resolvido neste trabalho. Outro modelo está sendo desenvolvido pelo aluno de doutorado Joelmir José Lopes e pelo aluno de mestrado Bruno de Abreu Silva. Todavia, esse novo modelo ainda se encontra em fase inicial de desenvolvimento, sem qualquer implementação ou adequação ao modelo de partição proposto neste trabalho.

Na próxima Seção, esse modelo de partição e protocolo será apresentado detalhadamente.

\subsection{Proposta de Partição}

Dividir GFD em partições e reconfigura-los diretamente em um FPGA através da RPD não é uma tarefa trivial. A grande dificuldade desta tarefa acontece devido as limitações encontradas na ferramenta utilizada. Embora, intuitivamente, pareça simples dividir GFDs em partições e reconfigura-los no FPGA, algumas limitações da plataforma utilizada devem ser levadas em consideração:

- A definição de uma PRR é limitada a um tamanho fixo, definido no projeto;

- A comunicação da $\overline{\mathrm{PRR}}$ e da área estática é limitada pela utilização de hard macros (bus macros);

- A geração de bitstreams só é possível ser feita em tempo de projeto;

- Não é uma tarefa simples determinar qual PRM está reconfigurado em um PRR qualquer;

- O tempo necessário para reconfiguração de módulos pode ser proibitivo para o projeto Souza Junior et al., 2010].

Essas características impossibilitam a utilização do protocolo descrito na Seção 4.2.1 para comunicação dos nós entre instâncias das partições. Isso se dá devido ao fato do protocolo assumir que o dado disponibilizado na entrada do nó, já é o dado correspondente para esse nó (ainda que eventualmente seja de uma tag diferente). Outra empecilho para se implementar esse modelo é que a quantidade de sinais necessários para comunicação entre os nós é estritamente relativa a quantidade de nós.

Devido a essas dificuldades, uma estrutura especial deve ser criada de modo que seja possível de que os GFD sejam executados corretamente e com desempenho adequado dentro do FPGA. Ou seja, o resultado final da execução do GFD deve ser o mesmo que 
FPGA

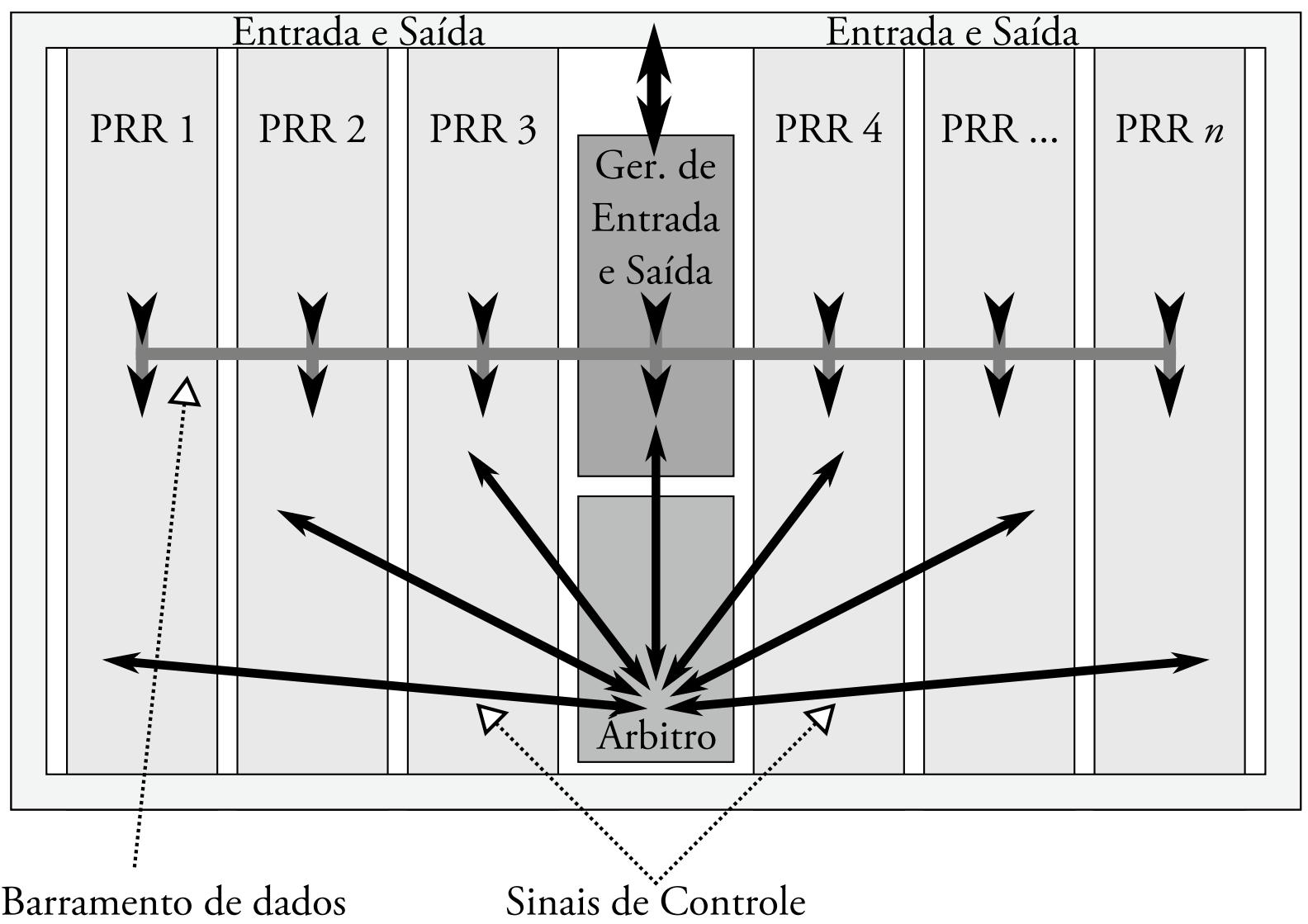

Figura 4.5: Diagrama simplificado da arquitetura proposta do modelo de partição da ferramenta ChipCflow para uma Virtex II/II Pro.

seria sem essa estrutura e tal estrutura não pode afetar significativamente o desempenho da execução do GFD.

Para isso, uma arquitetura para as partições e um protocolo de comunicação dessas partições foi proposta, chamada de "modelo de partição e protocolo". A primeira publicação desse modelo pode ser encontrada em Sanches [2010. Todavia, devido a atrasos desse projeto, neste trabalho um esforço foi feito na concepção desse modelo também. Não obstante, neste trabalho serão encontradas algumas modificações em relação ao modelo proposto por Sanches 2010]. Isso acontece devido a algumas dificuldades encontradas na implementação do mesmo.

A Figura 4.5 contém um diagrama da arquitetura proposta para o modelo de partição do ChipCflow. Nesse diagrama é possível ver uma quantidade $n$ de PRRs, um Árbitro, um Gerenciador de Entrada e Saída (GES), um Barramento de dados e Sinais de Controle. Essas estruturas serão abordadas nas próximas Sub-Seções.

\subsubsection{Partial Reconfigurable Regions}

As PRRs são as áreas em que as partições do GFD serão instanciadas. O modelo proposto permite uma quantidade arbitrária de PRRs, desde que o FPGA utilizado seja capaz de comporta-las. 
Tabela 4.1: Resultados dos testes experimentais da relação entre número de operadores por coluna. Adaptado de [Souza Junior et al., 2010].

\begin{tabular}{c|c|c} 
Área da PRR & Número de operadores & Número de operadores por coluna \\
\hline \hline 1 & 6 & 6 \\
\hline 2 & 29 & 14,5 \\
\hline 3 & 45 & 15 \\
\hline 4 & 61 & 15,250 \\
\hline 5 & 70 & 14 \\
\hline 6 & 84 & 14 \\
\hline 7 & 98 & 14 \\
\hline 8 & 113 & 14,125 \\
\hline
\end{tabular}

Um estudo foi feito com o intuito de dimensionar de modo ótimo o tamanho das PRR 3 Souza Junior et al., 2010]. Os aspectos considerados foram tamanho da área, tempo de reconfiguração e quantidade de lógica reconfigurada. Para maximizar a área reconfigurável sem aumentar o tempo de reconfiguração, partiu-se do principio de que o tempo de reconfiguração era relacionado a quantidade de frames reconfigurados. Utilizouse então a Equação 3.1 para fazer o cálculo de tempo de reconfiguração.

Conforme esse estudo se baseou nos FPGA $\$$ Virtex II/II Pro (modelo xv2p30), uma PRR ocupou uma coluna completa do FPGA. Isso se dá porque um frame de configuração ocupa toda coluna nesses FPGAs, o que já foi largamente abordado no Capítulo 3.

Para se verificar a quantidade de lógica reconfigurada naquela área, uma série de operadores de soma foram criados e conectados em cascata (o primeiro se conecta no segundo, que se conecta no terceiro etc). Essa verificação foi feita para validar as afirmações da documentação da Xilinx® Xilinx, 2008, que afirma que uma área reconfigurável maior torna mais fácil que a ferramenta de roteamento encontre rotas possíveis.

Dessa forma, esperava-se que áreas reconfiguráveis menores não pudessem ser totalmente utilizadas pela ferramenta de roteamento. Isso geraria um desperdício de recursos e dificultaria a definição de $\overline{\mathrm{PRR}}$ s, posto que, embora uma área maior utilizaria melhor os recursos físicos, isso aumentaria o tempo de reconfiguração.

A Tabela 4.1 contém os resultados dos testes realizados por Souza Junior et al. [2010]. Nela, é possível ver que a quantidade de operadores por coluna mantém-se relativamente estável entre 2 e 8 colunas e deve-se manter assim para mais colunas. Com apenas uma coluna, a ferramenta encontrou dificuldades em rotear mais que 6 operadores. Destarte, não há uma tendência clara para o número de colunas, desde que não seja apenas uma, com relação ao desperdício de lógica, ao contrário do que os manuais afirmam.

A Tabela 4.2 contém resultados dos cálculos de tempo de reconfiguração utilizando a Equação 3.1. Nela, é possível ver que há uma relação linear entre a quantidade de colunas e o tempo necessário para reconfiguração. Dessa forma, o tempo de reconfiguração não pode ser otimizado por meio da área utilizada. 
Tabela 4.2: Tempo de reconfiguração para áreas das PRRs testadas. Adaptado de [Souza Junior et al. 2010.

\begin{tabular}{|c|c|}
\hline Tamanho da PRR & Tempo de reconfiguração (em milisegundos) \\
\hline 1 & 16,51654 \\
\hline 2 & 31,75674 \\
\hline 3 & 46,57992 \\
\hline 4 & 61,40310 \\
\hline 5 & 76,64330 \\
\hline 6 & 91,44122 \\
\hline 7 & 106,68143 \\
\hline 8 & 121,50461 \\
\hline
\end{tabular}

Esse cálculo teórico foi realizado por meio de uma análise aos bitstreams gerados nos testes anteriores. Para isso, um programa que decodificava os bitstreams e retornava a quantidade de bytes presentes neles foi criado.

Esse programa era responsável por ignorar todo cabeçalho presente nos bitstreams que não eram enviados ao FPGA, como também foi configurado para ignorar a reconfiguração de recursos do FPGA que não eram CLBs. Isso se deu devido ao fato de que é possível encontrar apenas 6 colunas consecutivas de CLBs. Destarte, colunas de BRAM e multiplicadores foram ignoradas, para focar o teste apenas no tempo de reconfiguração da lógica programável.

Finalmente, pelos testes pode-se concluir que a variação do número de colunas de uma PRR tem uma relação linear entre a lógica reconfigurada e o tempo de reconfiguração. Devido a este motivo, optou-se por manter o tamanho de uma PRR como parâmetro de configuração, já que não há uma clara relação de custo/benefício, sendo que a altura da PRR deve ocupar um frame inteiro do dispositivo.

Conforme o objetivo deste trabalho é uma prova de conceitos e esta baseia-se na utilização de FPGAs Virtex II/II Pro, o diagrama da Figura 4.5 contém PRRs ocupando a altura de todo chip, posto que um frame nesses dispositivos ocupam toda coluna de algum recurso do FPGA.

Com a geometria da PRR decidida, resta determinar sua forma de comunicação com o resto do chip. Para isso, foram definidos dois barramentos, um de controle e um de dados. Para o barramento de controle, foram utilizadas duas bus macros. Uma para saída dos sinais e outra para a entrada deles. O barramento de dados tem largura dinâmica, tendo no mínimo 8 linhas e máximo de 64 , variando em múltiplos de 8 . Com o intuito de prova de conceitos, o circuito implementado utilizou 8 linhas no barramento, conectando as PRRs à área estática, também, por meio de duas bus macros (uma de entrada e outra de saída). 


\section{Barramento de Dados}

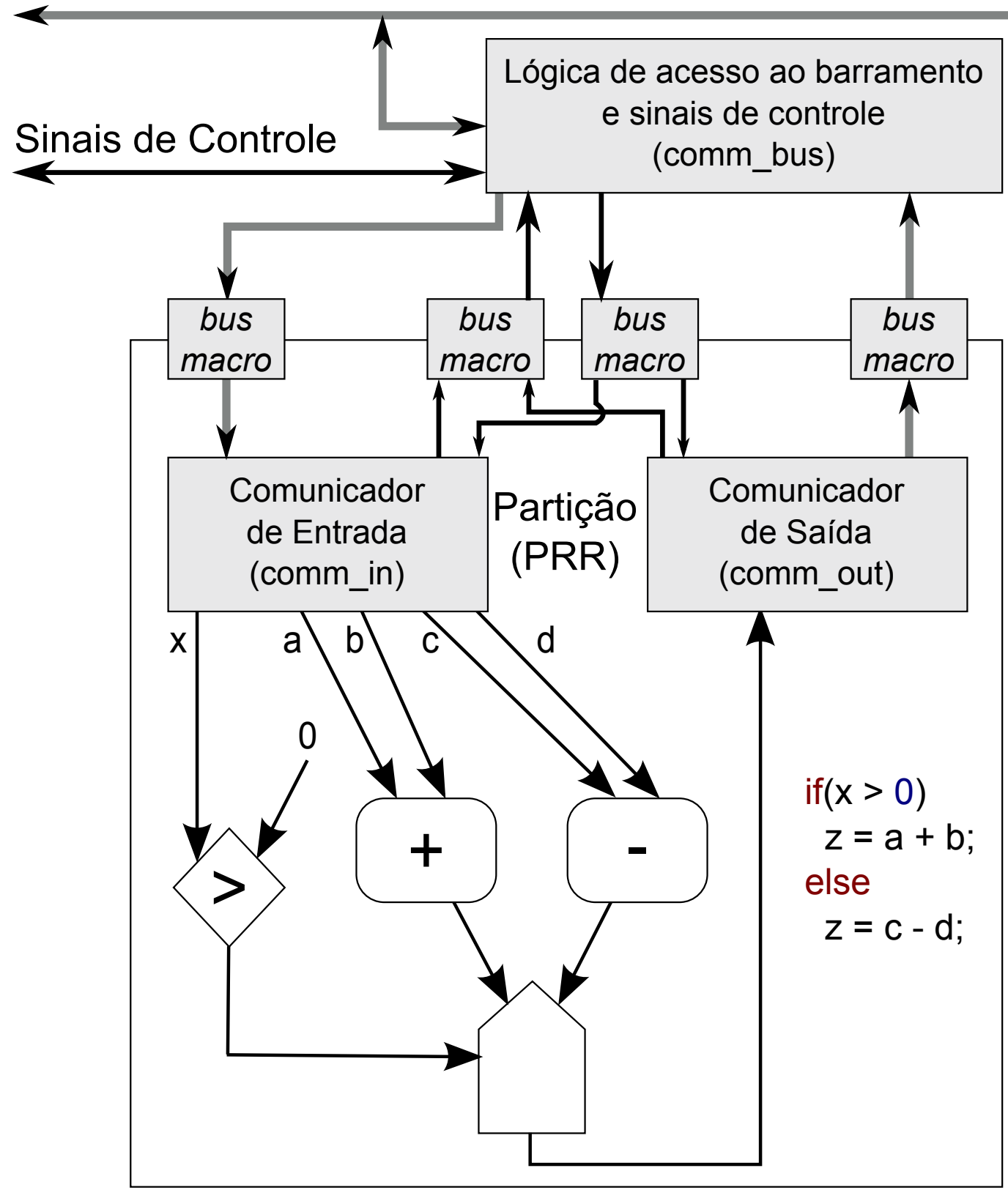

Figura 4.6: Exemplo de um GFD na arquitetura proposta de uma Partição.

\subsubsection{Partições}

As partições propostas nesse modelo seguem a lógica do modelo de particionamento de GFDs descrito na Seção 4.2.2. Os nós tem representações físicas em hardware e são interligados via sinais dedicados para cada interligação presente no GFD. Os GFDs presentes nas partições são considerados GFDs estáticos. Ou seja, a geração de novos tags só pode ser feita entre as partições, não podendo assim ocorrer internamente nelas.

A Figura 4.6 contém um desenho demonstrativo da arquitetura de uma partição. Nela, é possível ver um GFD demonstrativo e o código C utilizado para sua criação. Nela, é possível ver comunicadores de entrada e saída ligados ao barramento de dados. Para essa ligação, os sinais passam por meio de bus macros e acessam uma estrutura que controla o acesso ao barramento, com o intuito de evitar colisão de dados. 


\section{Barramento de Dados}

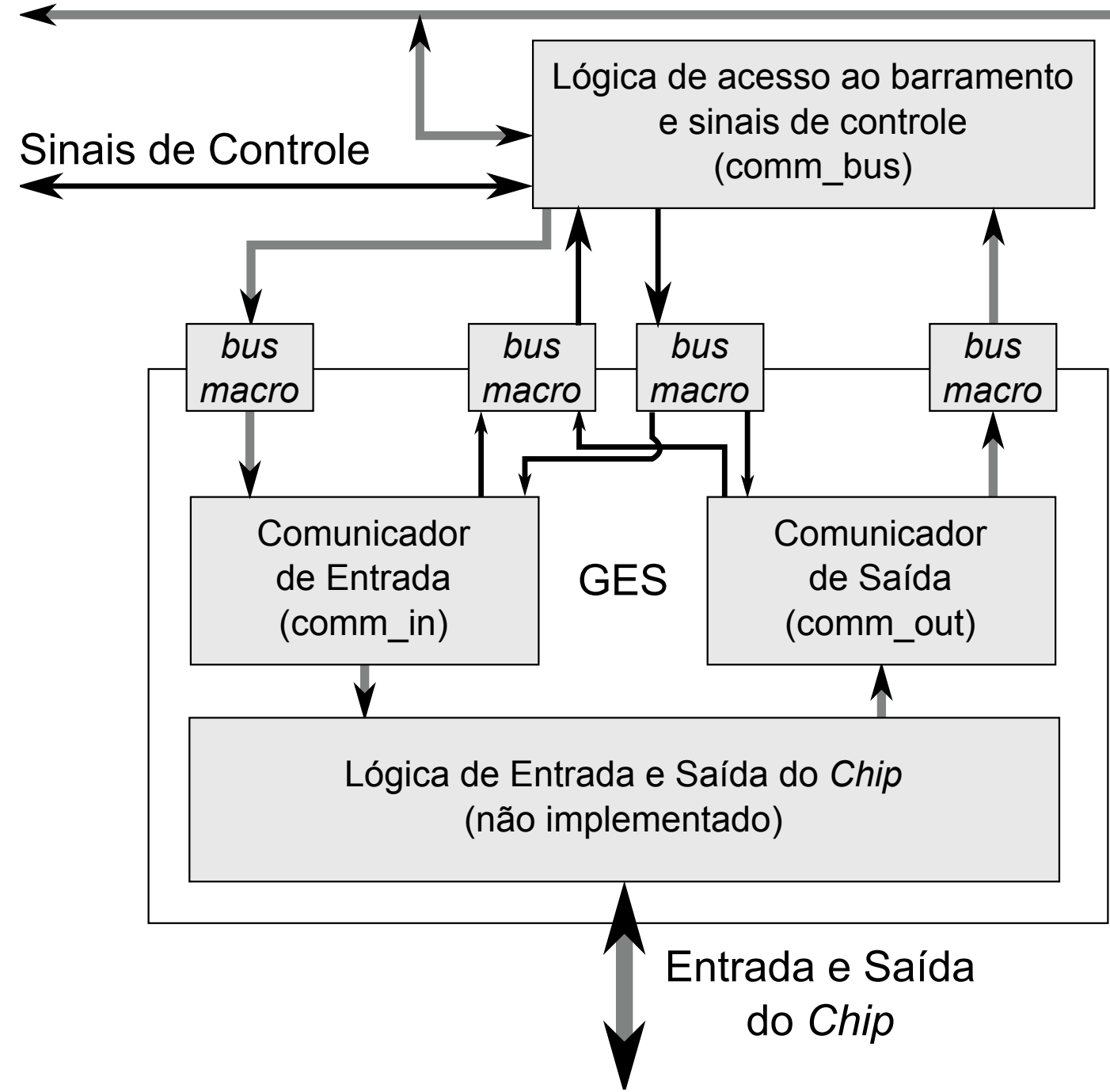

Figura 4.7: Diagrama simplificado da arquitetura da proposta do Gerenciador de Entrada e Saída (GES).

Esses comunicadores são capazes de se comunicar com nós do GFD e com outras partições. Dessa forma, conforme os dados terminem de passar pela partição, eles são enviados pelos comunicadores para as próximas partições. O protocolo de comunicação criado para esses comunicadores pode é apresentado na Seção 4.4 .

\subsubsection{Gerenciador de Entrada e Saída}

Na Figura 4.5 é possível também ver o GES. O GES não foi totalmente proposto e desenvolvido neste trabalho. Seu propósito é fazer a entrada e saída do chip e a comunicação com as instâncias das partições por meio do barramento de dados. Destarte, ele facilita o desenvolvimento da estrutura da arquitetura do modelo de protocolo de partição do ChipCflow, já que torna padrão a comunicação intra-chip.

O GES está anexado ao barramento de dados e ao Árbitro por meio dos sinais de controle, da mesma forma que as partições. Conforme o GES não é um módulo reconfigurável, não há necessidade para se utilizar bus macros. Todavia, para facilitar a implementação 
e padroniza-la, elas foram utilizadas na comunicação da estrutura.

A Figura 4.7 contém um diagrama da arquitetura proposta do GES. Nela, é possível ver comunicadores de entrada e saída ligados ao barramento de dados, assim como na partição (Figura 4.6). Para essa ligação, os sinais passam por meio de bus macros e acessam uma estrutura que controla o acesso ao barramento, com o intuito de evitar colisão de dados.

Os comunicadores também são interligados a unidade de lógica de entrada e saída. Esses comunicadores são os mesmos utilizados nas partições. Uma descrição detalhada desses comunicadores pode ser encontrada na Seção 4.4. A lógica de entrada e saída do chip não foi implementada, posto que não está no contexto deste trabalho.

Na prova de conceitos, o GES apenas serviu como dispositivo de entrada. Também, não houve comunicação externa. Sua implementação para este trabalho consiste em um hardware contendo um buffer de dados que envia o primeiro token para a execução do algoritmo. Desta forma, pôde-se simular a entrada de dados no GFD. Embora o algoritmo utilizado também retorne um dado depois de sua execução, o GES não foi implementado de forma a receber esse dado e envia-lo para fora do chip.

\subsection{4 Árbitro}

O módulo Árbitro é responsável por coordenar o acesso ao barramento, decidindo quem deve ler e escrever os dados no barramento. Embora esse módulo tenha papel fundamental na elaboração do projeto, ele não foi totalmente desenvolvido neste trabalho. Assim, a versão utilizada aqui é bastante rudimentar.

\subsection{Proposta do Protocolo de Comunicação}

Conforme já visto na Seção 4.3, toda comunicação intra-chip entre as partições e outras unidades é feita através de um barramento de dados e de sinais de controle específicos. Essa comunicação é feita por uma unidade de comunicação, que é dividida em duas unidades: a unidade de entrada (comm_in) e unidade de saída (comm_out) (Figura 4.8).

A unidade de entrada é responsável por receber os dados das partições e enviar corretamente para os nós do GFD correspondente. Para isso, ela é ligada diretamente nos nós de entrada da partição. Essa ligação é feita pelo protocolo descrito na Seção 4.2.1. De forma oposta, a unidade de saída é responsável por enviar os dados dos nós de saída do GFD para as outras partições. Da mesma forma que a unidade de entrada, os nós são ligados diretamente nessa unidade.

Todavia, há uma pequena variação no protocolo de comunicação descrito na Seção 4.2.1 para comunicação dos nós com a unidade de saída. Quatro novos sinais foram adicionados:

- op_dt_in_partition: Esse sinal é utilizado para se especificar a partição de destino do token. Esse valor deve ser um número natural de 8 bits. O identificador de 


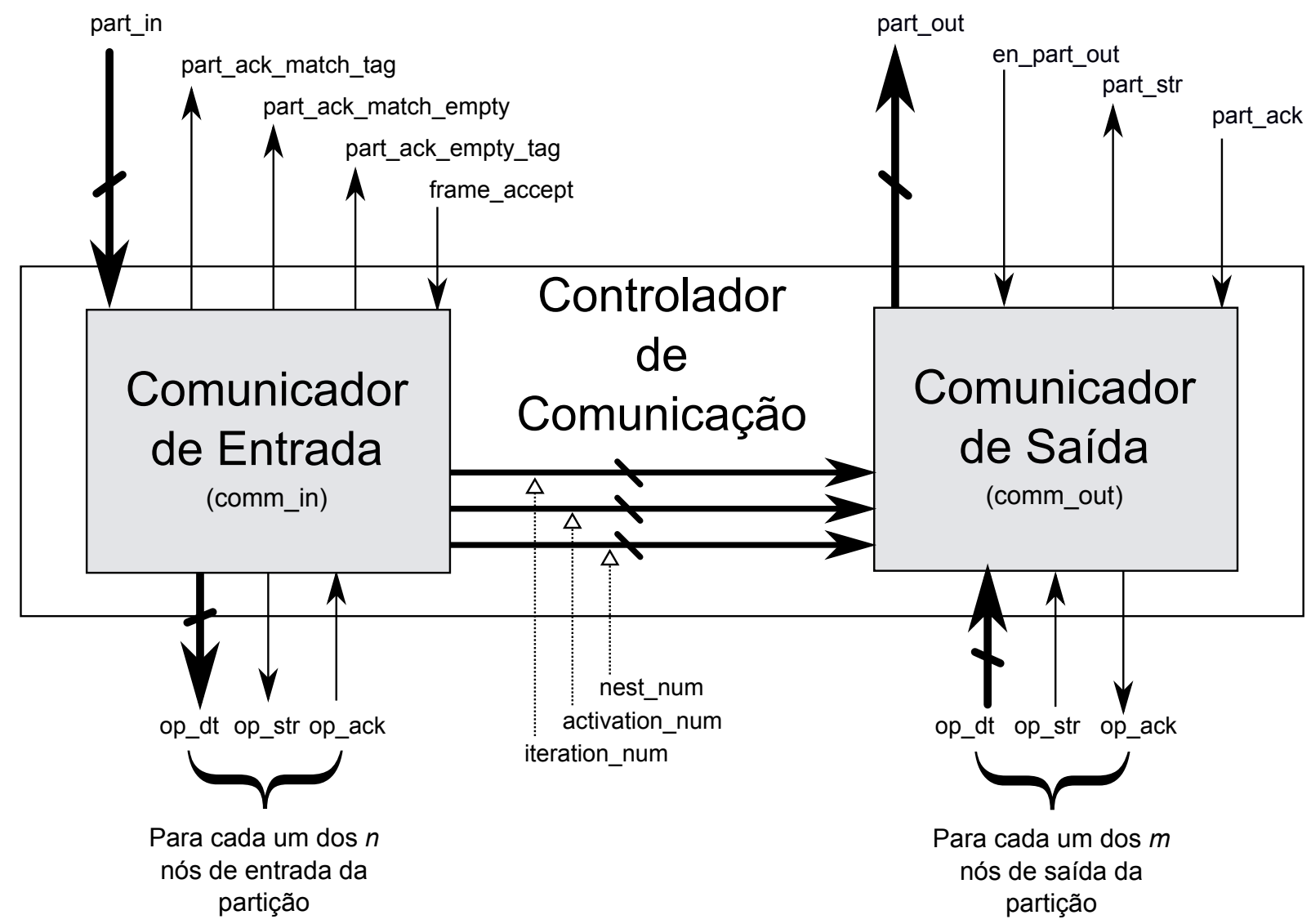

Figura 4.8: Diagrama simplificado da arquitetura da proposta do Controlador de Comunicação.

cada partição é definido previamente por meio do parâmetro genérico PARTITION_ID presente na unidade de comunicação de entrada;

- op_dt_in_arc: Esse sinal é utilizado para especificar o arco de destino da partição. O identificador do arco da partição é dado na hora de ligação dos nós com o comunicador de entrada. Ou seja, se o arco for ligado ao primeiro índice do comunicador de entrada, ele será o primeiro arco. Esse valor deve ser um número natural de 4 bits;

- op_dt_in_new_it: Caso esse valor seja 1, o valor de 1 é somado à tag atual para ser enviada para a próxima partição. Essa é uma implementação rudimentar do operador next tag, feita apenas para a validação do modelo;

- op_dt_in_enable: Caso esse valor seja 1, o comunicador é habilitado para enviar o dado do arco de saída para a próxima instância.

Dessa forma, uma instância pode estar em dois estados: executando e parada. Quando uma instância está executando, isso significa que um ou mais tokens de entrada já foram aceitos por essa instância e o resultado da execução do subgrafo ainda não foi computada. Uma instância é definida como parada quando os nós de dentro do subgrafo não estão em execução. Ou seja, quando nenhum token de entrada foi aceito pela instância ou quando 
os tokens foram aceitos e o resultado da computação desse subgrafo já foi totalmente enviado para as outras partições.

\subsubsection{Sinais de Controle}

Para que haja comunicação dos tokens descentralizada nessas partições, um barramento de dados é interligado entre elas (sinais part_in e part_out na Figura 4.8. Os sinais da unidade de entrada part_ack_match_tag, part_ack_match_empty, part_ack_empty_tag e frame_accept e da unidade de saída en_part_out, en_part_out, part_str e part_ack são sinais de controle que são ligados diretamente no árbitro.

Esses sinais de controle são necessários por dois motivos:

1. Para que a escrita ao barramento seja feita apenas por uma instância (por meio do en_part_out e part_str);

2. Para que conflitos de interesse por tokens sejam resolvidos de forma correta.

Sempre que houver necessidade de uma instância enviar um token para outra instância qualquer, o sinal part_str deve ser ativado. A partir daí, o árbitro é responsável por coordenar e decidir quem deve escrever no barramento. Caso uma determinada instância deva escrever no barramento, o árbitro deverá ativar o sinal en_part_out dessa instância. Com isso, o Controlador de Comunicação dessa instância passa do modo leitura para o modo escrita e o token é enviado pelo barramento por meio dos sinais part_out.

Enquanto o token é enviado, todas as outras instâncias devem receber e interpretar esse token. Nesse ponto, posto que o modelo de fluxo de dados utilizado dentro das partições é estático, ou seja, cada instância será responsável por um tag apenas, existem cinco casos em que a instância que receberá o token poderá se enquadrar:

1. A partição da instância que recebeu o token não é a mesma partição de destino desse token e essa instância está em execução;

2. A partição da instância que recebeu o token é a mesma partição de destino desse token, essa instância está em execução e o tag da instância é diferente do tag de destino do token;

3. A partição da instância que recebeu o token é a mesma partição de destino desse token, essa instância está em execução e o tag da instância é igual ao tag de destino do token;

4. A partição da instância que recebeu o token é a mesma partição de destino desse token e essa instância está parada;

5. A partição da instância que recebeu o token não é a mesma partição de destino desse token e essa instância está parada. 
Apenas uma instância pode receber cada token enviado. Para garantir isso, o Árbitro coordena quem deve aceitar ou não o token. Os três primeiros casos são casos relativamente simples, em que o árbitro não deve decidir. Para o primeiro e o segundo caso, a instância deverá apenas ignorar o token. No terceiro caso, o sinal part_ack_match_tag deverá ser ativado e a instância poderá automaticamente aceitar o token. Dessa forma, o árbitro será informado de que uma instância de partição recebeu o token de acordo com seu tag e informará isso à instância que está enviando o token que este foi aceito, por meio da ativação do sinal part_ack da instância remetente. Assim, o árbitro não precisará decidir quem deve aceitar o token, posto que ele já tem destino certo.

Os outros dois casos são mais complexos. Nesses casos, o Árbitro deverá decidir quem deve receber o token por meio da ativação do sinal frame_accept. Para isso, existe uma fila de prioridades que o Árbitro deve usar para definir quem deverá aceitar o token. Essa fila estabelece que instâncias que se encaixam no quarto caso tem preferência em relação a instâncias que se enquadram no quinto caso.

Para o quarto caso, a instância que recebeu o token deve informar o Árbitro de que está vazia e que é da mesma partição de destino do token por meio do sinal part_ack_match_empty. Essa instância não pode aceitar automaticamente o token porque pode haver mais instâncias da mesma partição e igualmente vazias. Dessa forma, aceitar automaticamente esse token poderia levar a uma situação de conflito, sendo que duas partições teriam o mesmo tag e processariam os mesmos dados.

Outro problema de se aceitar automaticamente o token nesse tipo de caso é que pode haver uma outra partição que já é responsável por essa tag. Isso levaria a uma outra situação de conflito, com o mesmo token executando em nós diferentes.

Para o quinto e último caso, a instância que recebeu o token deve informar o Árbitro de que está vazia (e consequentemente de que não é do mesmo tipo de partição de destino do token) por meio do sinal part_ack_empty_tag. Dessa forma, caso não hajam instâncias da outra partição disponíveis para o token, o Árbitro pode ordenar que uma nova reconfiguração seja feita com uma instância adequada dentro desse PRR livre.

Assim, o Árbitro é responsável por decidir quem deve aceitar esse token. Para casos em que todas as instâncias estejam ocupadas, existem duas alternativas que podem ser exploradas:

A alternativa mais fácil - e implementada neste trabalho - consiste no Árbitro simplesmente não ativar o sinal part_ack da instância remetente e essa deve mater esse token em um buffer interno, com o intuito de envia-lo posteriormente. O problema de se usar essa alternativa é que uma instância não fica livre enquanto não envia todos os dados, o que ocasiona perda de desempenho e, em determinadas configurações, até deadlocks.

Uma outra alternativa, mais sofisticada, consiste em ligar ao barramento um módulo que atua como buffer de tokens. Dessa maneira, esse token aceita esses tokens e os repassa assim que houver uma instância disponível para eles. O principal benefício de se usar esse modelo é que nenhuma instância ficará em execução desnecessariamente, apenas com 
Tabela 4.3: Pacote do token do protocolo de comunicação.

\begin{tabular}{c|c|c|c|c|c|c} 
Sincronizar & Partição & Ativação & Iteração & Aninhamento & Arco & Dado \\
\hline 8 bits & 8 bits & 8 bits & 8 bits & 4 bits & 4 bits & 32 bits
\end{tabular}

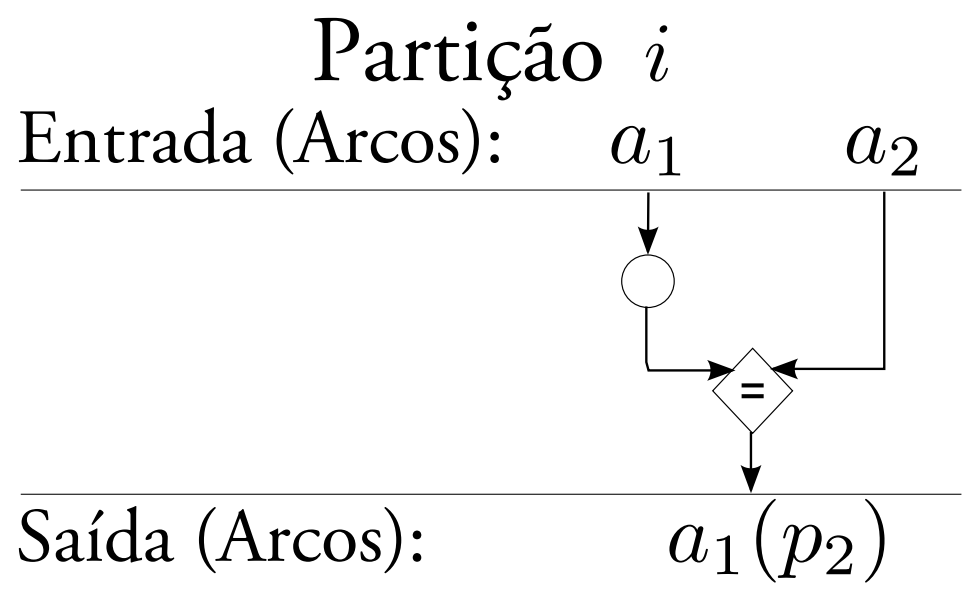

Figura 4.9: Exemplo de subgrafo particionado: $i$ representa o identificador da partição, $a_{j}$ são os índices dos arcos de entrada e de saída da partição.

tokens no buffer de saída. Com esse buffer agregado, também, fica possível implementar circuitos com heurísticas que auxiliam no envio mais efetivo desses dados presentes nesse buffer.

Negativamente, essa alternativa requer mais lógica reconfigurável, o que nem sempre pode ser viável para o projeto.

\subsubsection{Transferência de tokens}

Os tokens são transferidos pelo barramento de dados de instância de partição para instância de partição. O nome utilizado para essa transferência é "pacote". Devido à utilização de um barramento em comum para todos as PRRs e instâncias, algumas informações complementares precisam estar no pacote, além do próprio token. O fato das partições serem dinâmicas e serem identificadas por tags também inclui alguns campos no pacote.

A Tabela 4.3 mostra o tamanho (64 bits) e o formato dos pacotes dos tokens. O campo "Sincronizar" é fixo, e deve ser sempre 0xFF. Ele é utilizado para sincronizar a comunicação. Sempre que um comunicador de entrada receber esse valor, ele deve esperar um pacote completo depois. Os campos "Ativação", "Iteração" e "Aninhamento" contém os dados da tag do token. Esses campos foram definidos em Silva 2006. A escolha dos tamanhos dos campos para a prova de conceitos foi arbitrária, e eles podem ser modificados futuramente.

Os campos "Partição" e "Arco" são utilizados para endereçar corretamente o token para a instância da partição desejada. Conforme o GFD é dividido em subgrafos por meio do particionamento, haverão diversas partições que serão serão endereçadas no campo "Partição". Conforme essas partições terão uma ou mais arcos de entrada, esses arcos 
serão identificados por meio do campo "Arco" (Figura 4.9).

Finalmente, o campo "Dado" é o dado correspondente que deve ser processado pelo nó do GFD.

\subsection{Metodologia de Validação e Implementação}

O principal objetivo deste trabalho consistiu em validar o modelo baseado em fluxo de dados executando em um hardware reconfigurável, com o recurso de RPD. O objetivo principal do ChipCflow é diminuir o tempo de execução de diversas partes de algoritmos utilizando Computação Reconfigurável. Com o intuito de se chegar a esse objetivo, foram levantados dois requisitos para o modelo de partição e protocolo do ChipCflow que devem ser atendidos integralmente:

1. Inicialmente, o ChipCflow deve ser capaz de executar GFDs em hardwares capazes de se reconfigurar parcialmente;

2. Posteriormente, os mecanismos utilizados no modelo de partição e protocolo não podem atrapalhar sobremaneira no desempenho de execução desses GFDs.

O primeiro requisito é auto-evidente, e diz respeito a possibilidade de se executar GFD s em hardwares com RPD. Essa tarefa, conforme já visto neste Capítulo, não é trivial e é crítica para o projeto. Os mecanismos da RPD impõe limitações severas que precisam ser corrigidas com os circuitos de partição e protocolo. Esses circuitos, então, junto com a RPD não podem simplesmente atrapalhar no desempenho da execução do GFD, sob pena de inviabilizar todo o projeto.

\subsubsection{Metodologia de Validação}

Para validar o modelo com o primeiro requisito, a metodologia utilizada foi dividida em 3 etapas, entre elas:

1) Implementação de uma biblioteca composta pelos nós do GFD propostos por Astolfi \& Silva [2007] (fluxo de dados estático), criação um projeto com um algoritmo em C, conversão desse projeto para GFD e implementação desse projeto com a biblioteca criada. Com isso é posível validar a execução de um determinado GFD estático.

2) Implementação de uma biblioteca do modelo de partição e protocolo proposto aqui. Dessa forma, é possível validar a viabilidade de se criar um hardware que atende as especificações do modelo de partição e protocolo e as limitações da RPD e que efetivamente funcione conforme o esperado.

3) Implementação de um projeto do algoritmo criado na etapa 1 utilizando a biblioteca do modelo de partição e protocolo. Destarte, com o algoritmo em GFD e com a biblioteca do modelo de partição validados, é possível validar a execução de um algoritmo 
em conjunto ao modelo proposto. Isso, finalmente, seria o suficiente para demonstrar que essas especificações são capazes de atender o primeiro requisito proposto.

Já a validação do segundo requisito é um pouco mais complexa. Definir qual é o limiar que define que o tempo utilizado no modelo de partição e protocolo atrapalha ou não a execução dos GFDs não é uma tarefa trivial. Devido a essa dificuldade, duas metodologias foram adotadas:

1) Divisão do tempo de uma execução do algoritmo com o tempo de overhead. O tempo de overhead é considerado todo tempo que o hardware do modelo de partição (e o protocolo de comunicação) executa funções de controle da arquitetura (e apenas do modelo de partição). Por exemplo, o tempo de envio de um pacote de comunicação entre as partições é tido como overhead. Com isso é possível estimar o tempo de overhead frente ao tempo de operação sobre os dados do GFD.

2) Comparação da execução total do GFD (com o overhead incluso) à execução do algoritmo escrito em C, compilado e executado em um processador convencional. Assim, ainda que efetivamente o tempo de overhead seja proporcionalmente maior que o tempo de execução do algoritmo, é possível comparar o tempo total de execução à uma alternativa já existente. Todavia, uma ressalva deve ser feira em relação a essa comparação: não é possível comprovar que o GFD gerado é equivalente ao algoritmo escrito em C. Apesar do GFD ter sido criado a partir do algoritmo, esse processo de conversão foi manual e é profundamente diferente do processo de compilação do algoritmo em C.

\subsubsection{Implementação}

Para por em prática a metodologia de validação, os seguintes hardwares foram implementados:

- Nós de um GFD. operador (operator_op), branch (branch_op), copy (copy_op), decider (decider_op), merge (merge_op) e buffer (buff_op);

- Comunicador: Comunicador de Saída (comm_out), Comunicador de Entrada (comm_in) e lógica de acesso ao barramento e sinais de controle(comm_bus);

- Árbitro (arbiter);

- Simulador do Gerenciador de Entrada e Saída:

- GFD do algoritmo Fibonacci: O algoritmo foi dividido em duas partições (fibp1 e fibp2).

Essa implementação foi feita utilizando-se a plataforma da Xilinx - por meio deVHDLcom target para um dispositivo Xilinx xv2p30, que é capaz de realizar a RPD por meio das interfaces SelectMAP e ICAP. Para as simulações do hardware, foi utilizado o simulador Modelsim XE 6.2c. 
Para síntese da VHDL, foi utilizado a ferramenta Xilinx ISE 9.1 com o patch de reconfiguração parcial versão 11. A versão 9.2 da ferramenta ISE também suporta RPD. Todavia, ela não estava disponível para os autores do trabalho durante a realização do mesmo. A versão atual do ISE, 11.1, também traz o recurso de RPD. Todavia, essa versão não segue o mesmo fluxo de desenvolvimento apresentado aqui, sendo totalmente novo. O recurso de RPD também está restrito à um número limitado de usuários.

Ainda que a ferramenta de síntese não seja a versão mais nova - não acompanhando totalmente a evolução tecnológica - isso não é um problema para este projeto, posto que o intuito com ele é apenas a prova de conceitos, e não a geração de um produto final. Além de várias pesquisas na área para a criação de FPGAs com suporte a RPD, esse parece ser um recurso que está se tornando interessante comercialmente para as empresas. Além da Xilinx, outras empresas estão investindo na ideia de RPD. Destarte, com a concorrência empresarial e a pesquisa acadêmica, a tendência é que as restrições diminuam e, com novos FPGAs, o processo de se criar projetos com suporte a RPD seja simplificado.

Para facilitar o fluxo de desenvolvimento e processo de floorplaning suportado pelo ISE 9.1, foi utilizada a ferramenta Xilinx PlanAhead 10.1. Essa ferramenta suporta o fluxo de desenvolvimento descrito no Capítulo 3. Ela auxilia este processo criando scripts para o processo de Place and Route $(\overline{\mathrm{PAR}}$ dos módulos reconfiguráveis e área estática, além de permitir que as PRRs sejam criadas e as bus-macros sejam postas no FPGA, por meio de uma interface visual, o que facilita o processo de criação das PRRs.

\subsection{Considerações Finais}

Este capítulo abordou o modelo de partição e protocolo proposto da ferramenta ChipCflow, baseando-se em modelos teóricos e em trabalhos já criados da ferramenta. Embora a estrutura proposta pareça factível do ponto de vista técnico, não é uma tarefa fácil definir teoricamente o overhead real gerado por tal estrutura. O maior gargalo de execução, provavelmente, será na reconfiguração do hardware e na comunicação entre os nós, devido às já citadas limitações da plataforma utilizada. Ainda assim, para isso, no Capítulo 5 serão apresentados os resultados de alguns experimentos realizados com o intuito de discutir e validar a proposta deste trabalho. 


\section{Capítulo}

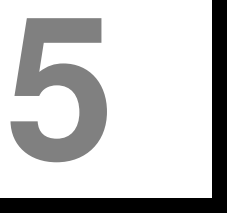

\section{Experimentos, Resultados e Discussão}

Com o modelo de partição e protocolo proposto e as metodologias de implementação e validação definidas, o próximo passo consiste em realizar os experimentos que atendam os requisitos do modelo e sigam a metodologia proposta para adquirir os resultados necessários e, finalmente, analisá-los para enfim validar a proposta como um todo. Neste capítulo serão apresentados os experimentos realizados

\subsection{Experimentos}

Em um passo inicial, foram criadas implementações dos nós do GFD em VHDL. Os nós implementados foram: operadores de soma e subtração (operator_op), branch (branch_op), copy (copy_op), decider (decider_op), merge (merge_op) e buffer (buff_op).

Esses operadores foram testados e validados por meio de uma simulação temporal na ferramenta ModelSim. Para validação, alguns sinais aleatórios foram estimulados nas entradas e os sinais de saída foram comparados com valores esperados. Para todos os testes realizados, os resultados foram compatíveis com as expectativas.

\subsubsection{Algoritmo Fibonacci}

Em um segundo momento, um algoritmo iterativo do Fibonacci (Algoritmo 5.1) foi escrito e, a partir dele, um GFD correspondente foi criado (Figura 5.1). Como é possível ver na Figura 5.1, o GFD apresentado utiliza-se dos mecanismos de máquinas baseadas em tagged-token descritos em Veen [1986] para lidar com a parte iterativa do código.

Para a criação de partições, a estratégia adotada consistiu em definir os pontos de geração, atualização e destruição de tags. Esses pontos são encontrados em fluxos cíclicos 
Input: $n \geq 0$, sendo que $n$ é o número de iterações do Algoritmo

\section{begin}

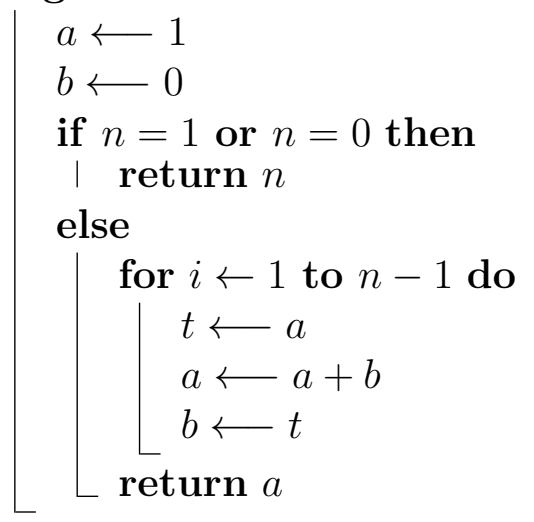

Algoritmo 5.1: Algoritmo Fibonacci iterativo.

nos grafos, proporcionados por chamadas de procedimentos e laços. Neste algoritmo há apenas um laço e, assim, existe apenas uma área em que há a necessidade de se manipular tags, como pode ser visto na Figura 5.1 (área entre os operadores "new tag area" e "restore tag").

Destarte, foi necessária a criação de uma partição para a área estática do grafo e outra partição para a área dinâmica. A primeira partição $\left(p_{1}\right)$ para todos os cálculos fora do escopo do laço (Figura 5.2) e uma segunda partição $\left(p_{2}\right)$ para os cálculos de dentro do escopo do laço (Figura 5.3). Neste caso, apenas uma partição para esse subgrafo dinâmico foi necessária, posto que que o subgrafo é pequeno. Em casos em que o subgrafo é maior, ele pode ser dividido em várias partições também.

A única restrição no que tange o atual processo de particionamento é de que os nós de criação e atualização de tags precisam estar no fim das partições. Isso é necessário porque os GFDs das partições são GFDs estáticos e não dinâmicos.

Alguns nós non-deterministic merges foram retirados nesse particionamento. Isso se deu devido a característica dos arcos de entradas das partições. Como qualquer instância pode enviar um token para qualquer arco de qualquer partição, não há a necessidade de um non-deterministic merge para se definir que o token de um arco de entrada pode vir de mais de um arco de saída. Ou seja, embora a representação da partição do GFD esteja levemente diferente da representação não particionada, o comportamento do GFD deve ser o mesmo.

\subsubsection{Experimento Estático com o GFD do Algoritmo Fibonacci}

Para validar esse GFD (Figuras 5.2 e 5.3), foram criadas algumas versões do GFD utilizando o método code-copying Veen, 1986]. O método utilizado consistiu em ligar umas as outras diretamente a quantidade exata de instâncias partições estáticas que são necessárias para uma determinada entrada de $n$. Ou seja, para cada valor de $n$ que foi estimulado, um GFD correspondente com uma partição $p_{1}$ e a quantidade necessária de cópias da partição $p_{2}$ foi definido em tempo de síntese. A Figura 5.4 contém um exemplo 


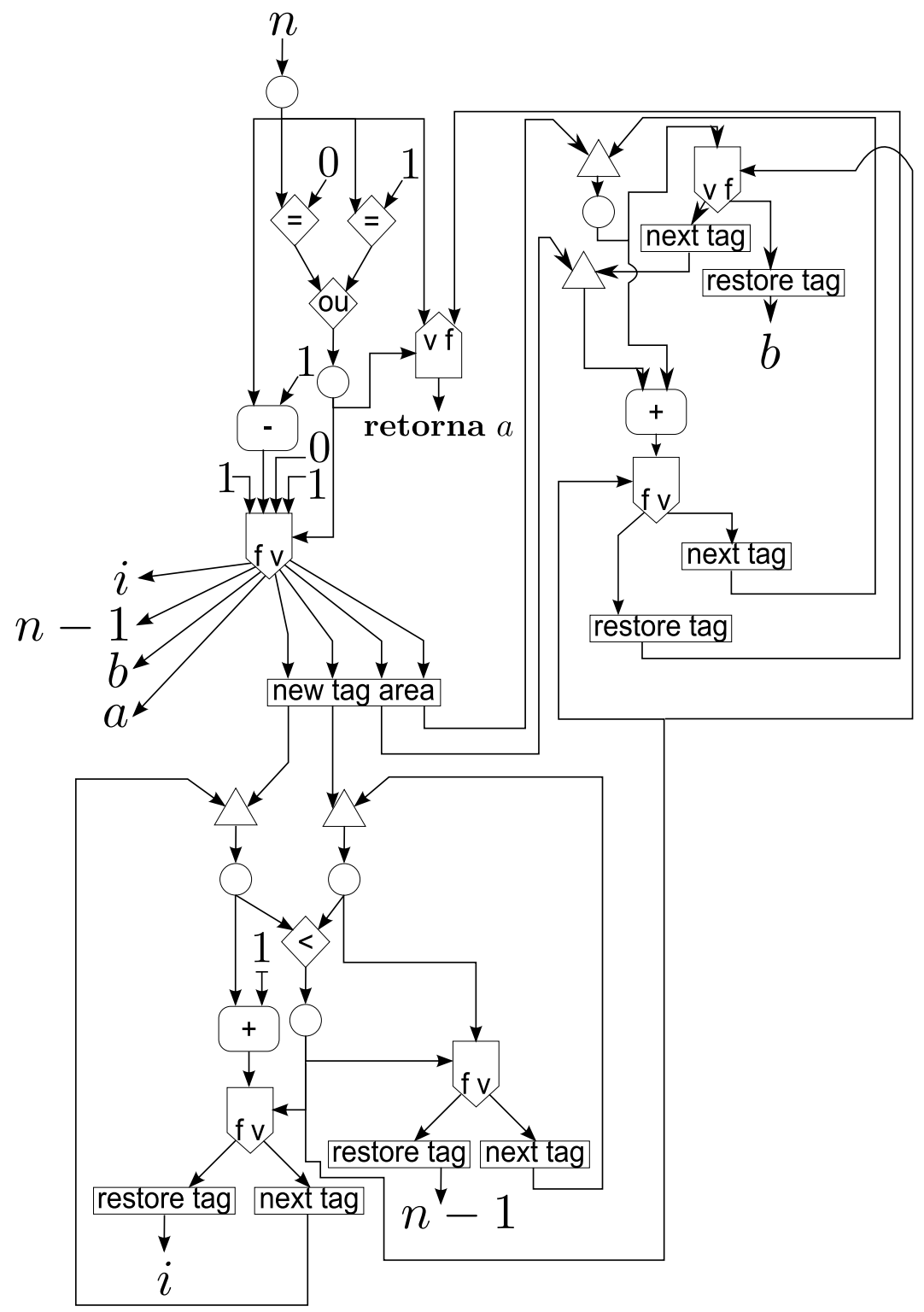

Figura 5.1: Diagrama do GFD do algoritmo Fibonacci (Algoritmo 5.1).

de diagrama do GFD utilizando o método utilizado.

Na Figura 5.4, é possível ver uma instância da partição $p_{1}$ e duas instâncias da partição $p_{2}$. Para $n=3$, apenas duas operações de soma para o cálculo do valor de Fibonacci serão realizadas $(1+1$ e $2+1)$, dessa forma, é necessária pelo menos uma instância da partição $p_{1}$ e duas instâncias da partição $p_{2}$.

Para que esse teste não só valide a funcionalidade do hardware mas também se o código é sintetizável em um dispositivo real, utilizou-se simulações temporais pós-roteamento na ferramenta Modelsim XE 6.2c. Com essas simulações, é possível medir com bastante precisão o tempo de execução do hardware reconfigurável depois de que ele foi devidamente sintetizado dentro do FPGA. O dispositivo de destino escolhido foi uma Virtex 2, modelo xv2p30-7ff896. O hardware foi sintetizado e simulado com um clock de 4.250 ns.

Foram estimulados valores de $n$ variando de 0 até 14 . Na Figura 5.5 é possível ver testes para os valores de $n \in[0,1,2,14]$ (Figuras 5.5a, 5.5b, 5.5c e 5.5d). Os valores da entrada do GFD são definidos no sinal n_dt_in_1, os testbenchs foram programados 


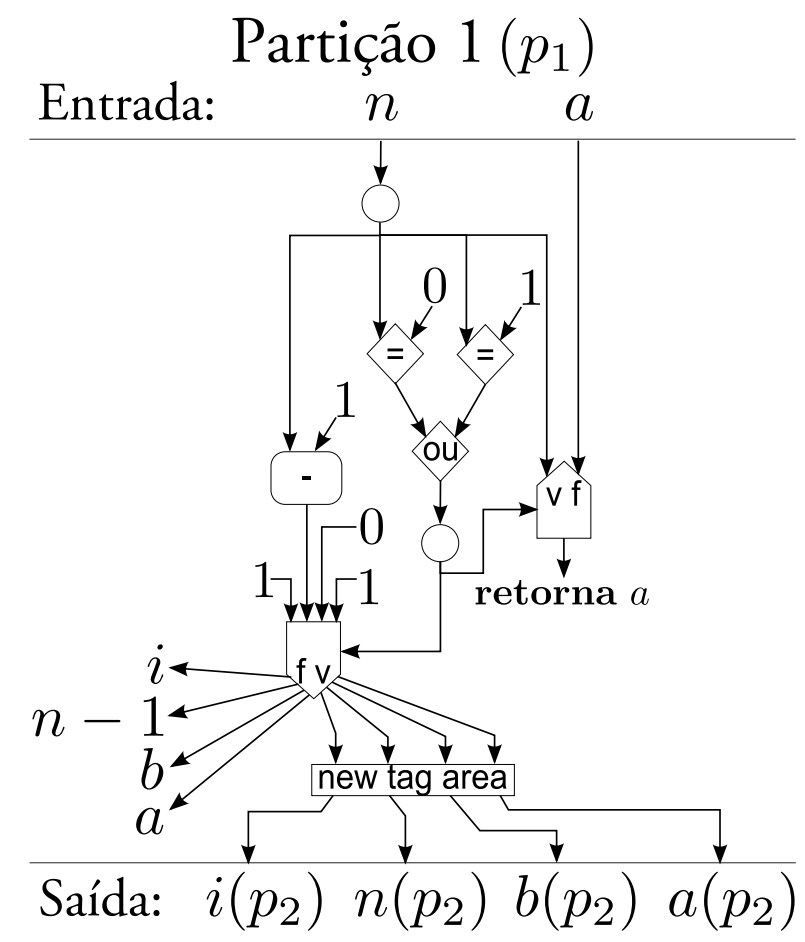

Figura 5.2: Diagrama da primeira partição do GFD $p_{1}$ do algoritmo Fibonacci (Algoritmo 5.1 .

para lidar com o protocolo de comunicação do arco de entrada internamente, por isso os sinais referentes ao protocolo não são vistos na Figura. O valor de saída do algoritmo pode ser visto no sinal return_dt_out_1. O sinal return_dt_out_1_str indica quando o hardware do GFD retornou o valor esperado.

O valor em picosegundos na cor branca é o tempo aproximado estipulado pela ferramenta para a execução do GFD. A Tabela 5.1 contém os tempos de execução para cada valor de $n$ testado.

Para comparação, o algoritmo descrito no Algoritmo 5.1 foi escrito em C e comparado à execução do GFD do algoritmo Fibonacci.

O algoritmo em C foi executado um computador Dell Vostro 1310, com um processador Intel Core 2 Duo T5670 à 1,8GHz. O compilador utilizado foi o MingW32 (port do GCC para Windows) Mingw.org, 2009. As opções de compilação foram -00 -g0. Em seguida a compilação, os símbolos de debug e informações de número de linha foram removidos por meio do comando "strip".

Para computação do tempo de execução, foram utilizadas duas metodologias: O método 1 consistiu em utilizar a API do Windows com a função QueryPerformanceCounter Microsoft Corporation, 2010] e o método 2 consistiu em utilizar diretamente o comando em Assembly rdtsc [ntel Corporation, 1998. Para ambos os casos, foram realizadas medições para a execução de 10 mil vezes o algoritmo Fibonacci para cada valor de $n$ (variando de 0 até 6 ). Com essas 10 mil execuções, o valor final da execução desse tempo seria dividido por 10 mil. Com isso, é possível ter uma média de tempo de execução dessas 10 mil execuções. Isso é necessário porque a ferramenta de medição tem precisão de apenas microsegundos, sendo que a precisão necessária era de nanosegundos. 


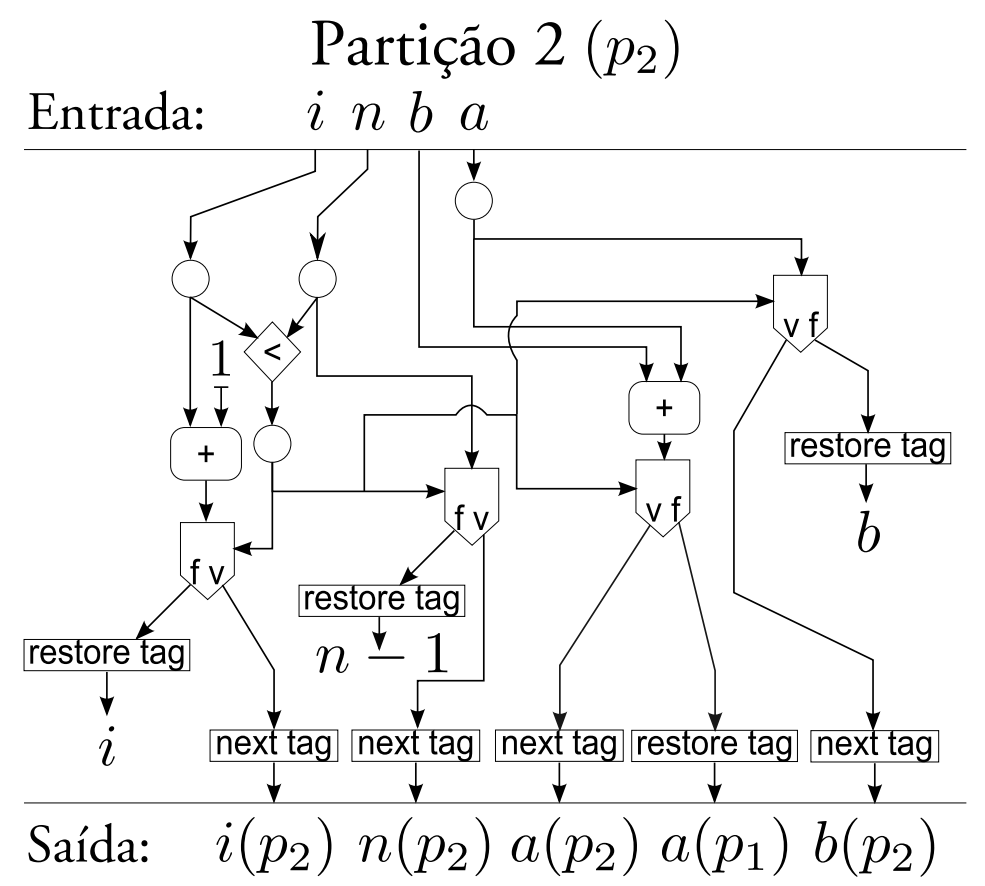

Figura 5.3: Diagrama da segunda partição do GFD $p_{2}$ do algoritmo Fibonacci (Algoritmo 5.1).

Essas 10 mil execuções foram executadas 20 mil vezes. Com isso, foi possível obter uma média e um desvio padrão das medições anteriores. Para excluir o overhead dos loops adicionais criados e também das funções responsáveis por adquirir o tempo, foi medida também o tempo necessário apenas nas funções utilizadas para avaliação do tempo e do loop gerado para repetição dos experimentos.

Nas Tabelas 5.2 e 5.3 , é possível ver que o tempo de execução para o código em C é muito inferior ao tempo de execução do GFD estático do algoritmo. A Figura 5.6 contém um gráfico comparativo do speedup obtido na implementação do código em C em relação ao GFD estático em hardware. A linha vermelha representa o speedup obtido com o código em C com o método de medição de tempo 1 e o GFD estático. A linha azul diz respeito ao speedup obtido com o código em $\mathrm{C}$ utilizando o método de medição de tempo 2 e o GFD estático. A linha verde, por sua vez, denota a proporção do clock do processador $(1753,466 \mathrm{MHz})$ em relação ao clock utilizado nos testes temporais $(235,3 \mathrm{MHz})$. Os dados exatos da Figura 5.6 podem ser vistos na Tabela 5.4 .

Segundo a Figura 5.6 e a Tabela 5.4, há uma tendência em que o speedup obtido com o código em $\mathrm{C}$ seja próximo a proporcionalidade do clock do processador e do clock do hardware reconfigurável. Com isso, talvez seja possível aferir que em um determinado valor de $n$ o speedup conseguido pelo código em $\mathrm{C}$ seja menor que a proporção dos clocks de ambos os dispositivos. Todavia, há um limite de espaço no hardware reconfigurável, o que em certo momento impossibilitaria o aumento do valor de $n$.

Dessa forma, é possível dizer que, para os valores testados neste algoritmo, apenas o aumento de clock não é responsável pelo speedup do processador tradicional em relação ao GFD estático com o protocolo estático do ChipCflow. Isso pode ser concluído posto 


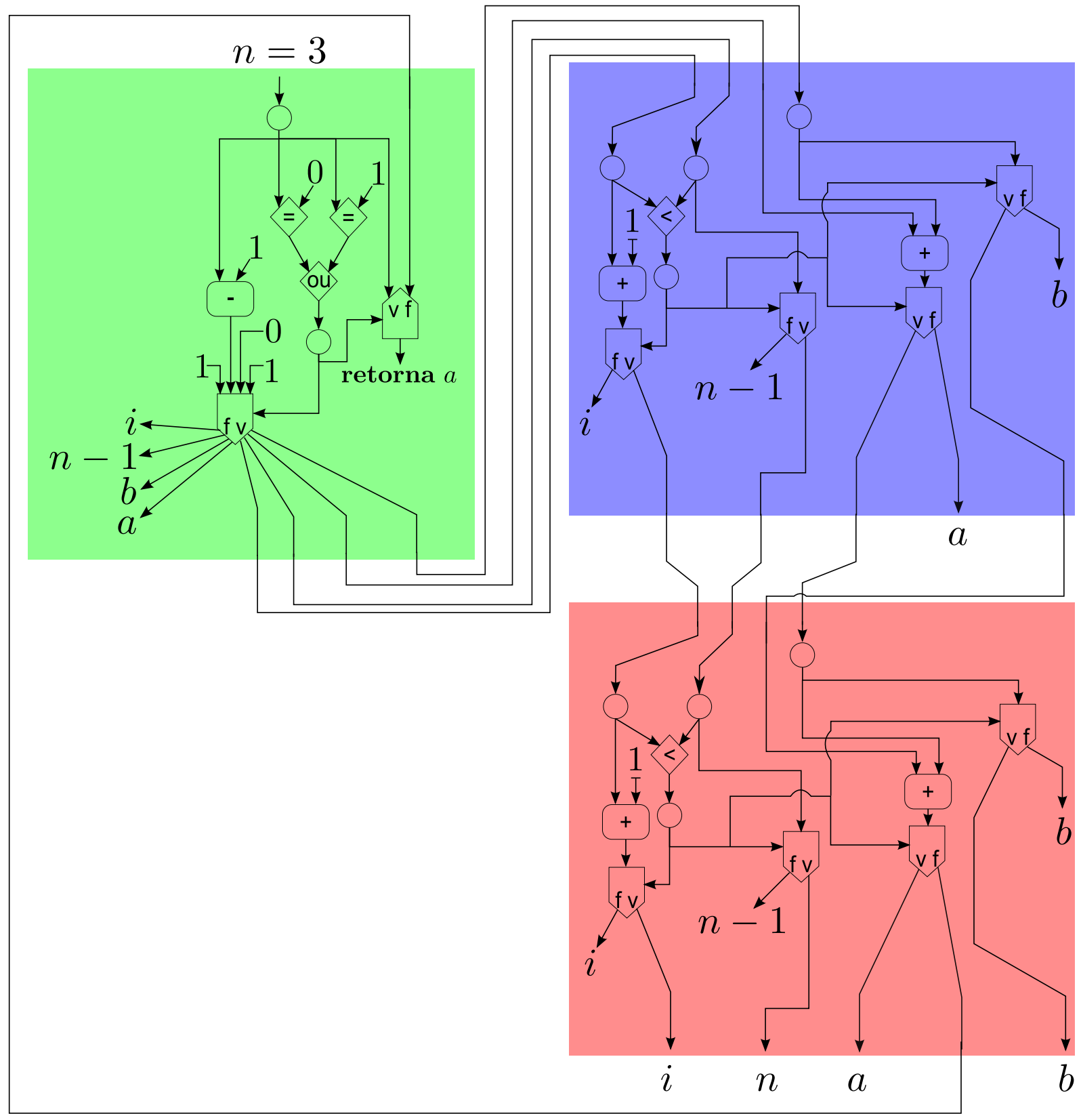

Figura 5.4: Diagrama do GFD do algoritmo Fibonacci utilizando o método de codecopying para $n=3$.

que o speedup conseguido é maior que a proporção entre os clocks do processador e do hardware reconfigurável. Assim, os prováveis motivos para essa diferença de desempenho podem ser:

1. Os mecanismos de comunicação dos nós estáticos estão introduzindo um overhead grande;

2. O hardware responsável pelas operações matemáticas no processador é mais rápido que o equivalente no FPGA;

3. O GFD do algoritmo Fibonacci não é paralelo ou não foi paralelizado o suficiente para que ocorra ganho de desempenho. 


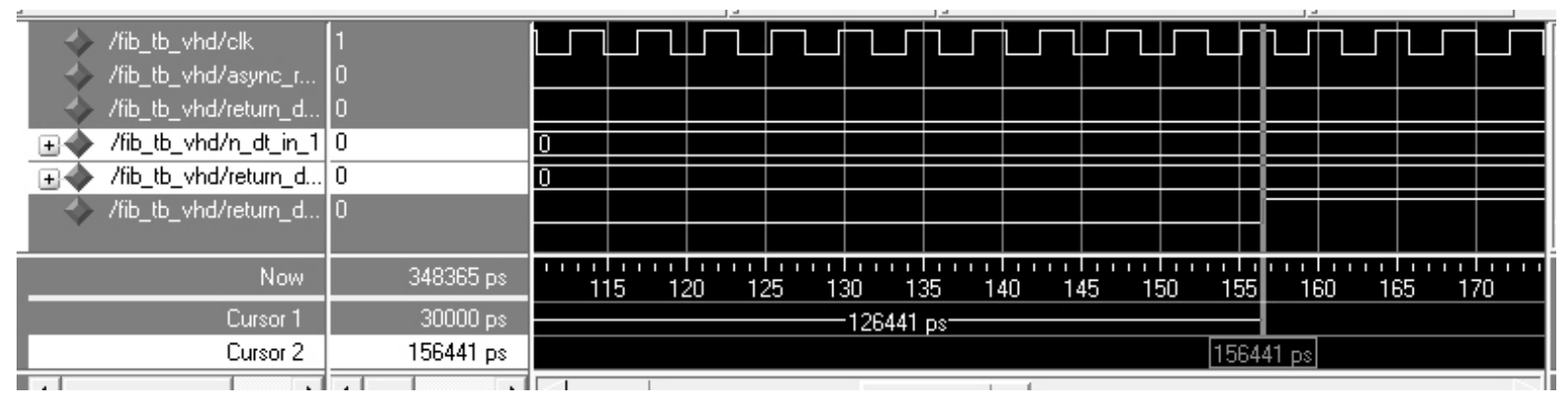

(a) Teste para $n=0$. Tempo de execução: 126 ns.

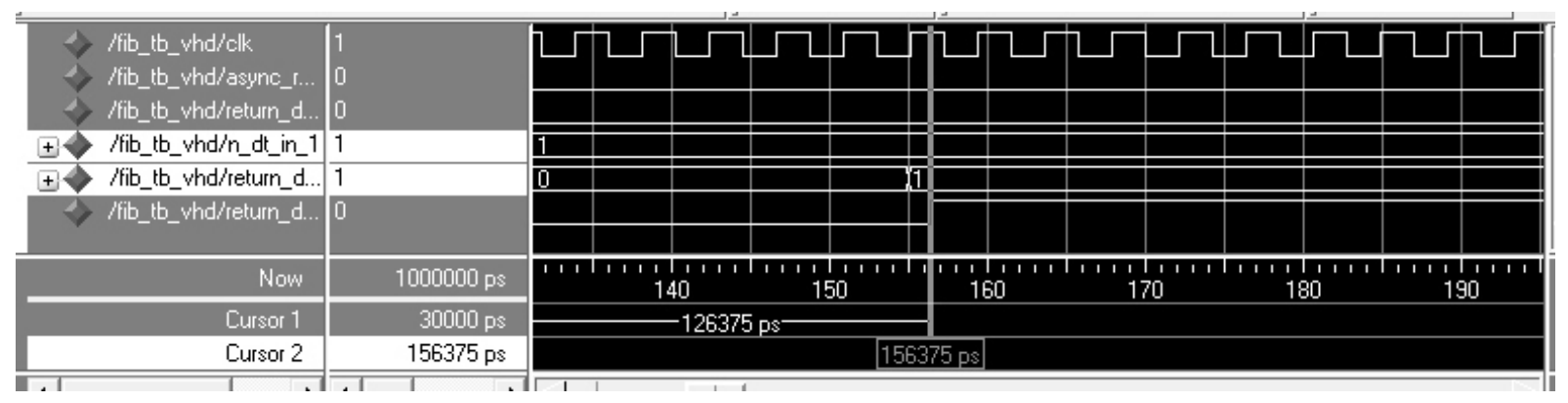

(b) Teste para $n=1$. Tempo de execução: 126 ns.

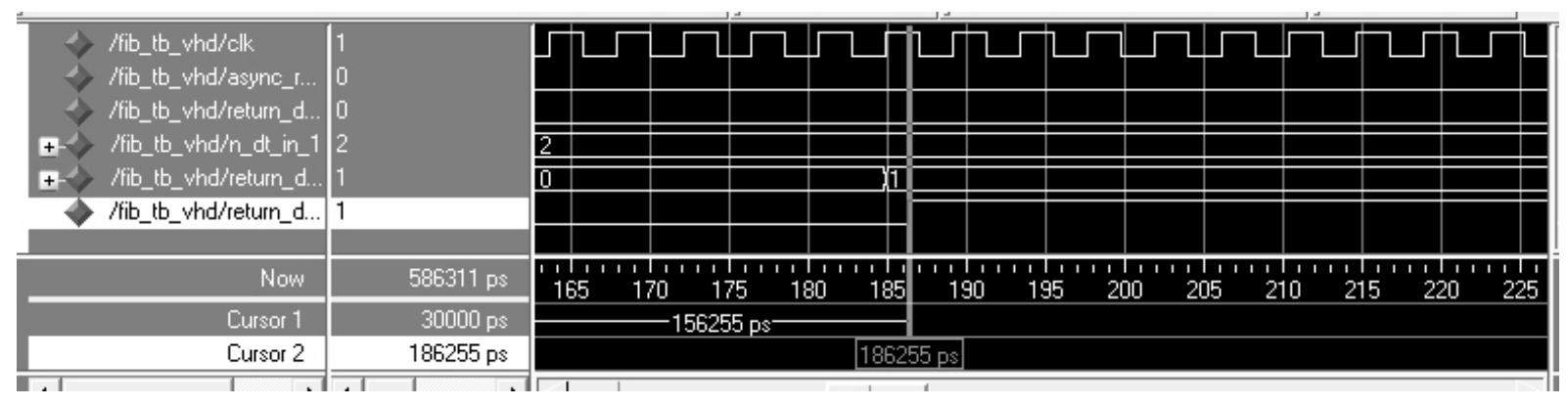

(c) Teste para $n=2$. Tempo de execução: 156 ns.

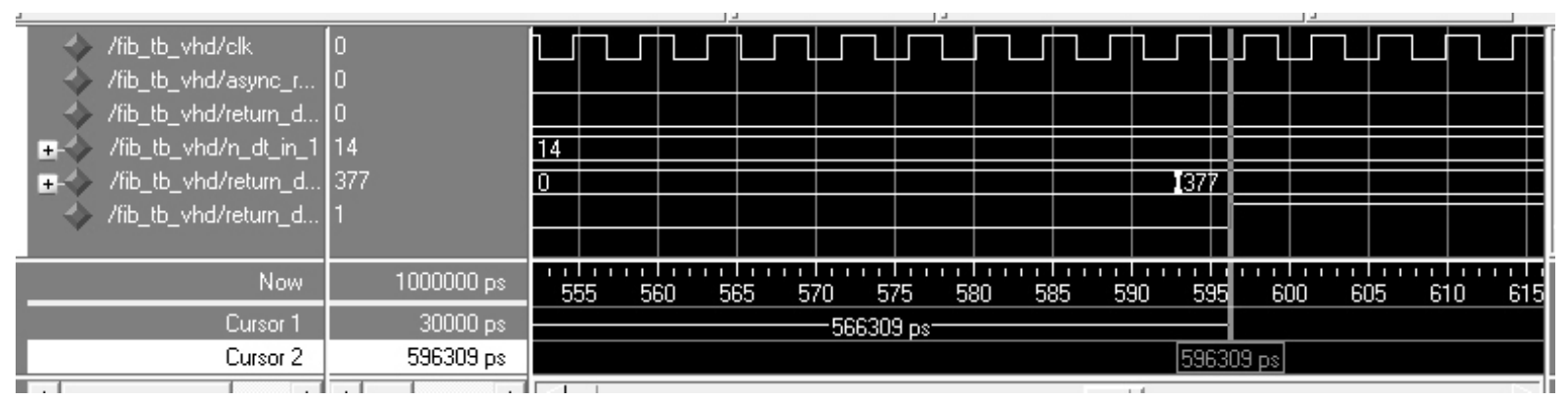

(d) Teste para $n=14$. Tempo de execução: 566 ns.

Figura 5.5: Resultados dos testes realizados em GFDs estáticos do algoritmo Fibonacci sem utilização do modelo de partição e protocolo.

O primeiro e o segundo motivos não têm sua investigação fundamentada no escopo deste trabalho. O terceiro motivo deve ter grande influência no resultado, posto que este algoritmo tem muitas estruturas de controle e poucas operações sobre os dados em si. Outra explicação é que o paralelismo conseguido nesse exemplo se deu apenas dentro das partições. Ou seja, nesse caso, conforme há conhecimento do valor de $n$ na hora da síntese do hardware, os valores de $a$ e $b$ poderiam ser propagados até o final da execução diretamente. Isso não ocorreu porque essa propagação entre as partições precisa ser regida 
Tabela 5.1: Tempo de execução do GFD estático do Algoritmo Fibonacci sem utilização do modelo de partição e protocolo.

\begin{tabular}{c|c}
$n$ & Tempo total \\
\hline \hline 0 & $126 \mathrm{~ns}$ \\
\hline 1 & $126 \mathrm{~ns}$ \\
\hline 2 & $156 \mathrm{~ns}$ \\
\hline 3 & $189 \mathrm{~ns}$ \\
\hline 4 & $224 \mathrm{~ns}$ \\
\hline 5 & $257 \mathrm{~ns}$ \\
\hline 6 & $292 \mathrm{~ns}$ \\
\hline 7 & $325 \mathrm{~ns}$ \\
\hline 8 & $360 \mathrm{~ns}$ \\
\hline 9 & $393 \mathrm{~ns}$ \\
\hline 10 & $417 \mathrm{~ns}$ \\
\hline 11 & $461 \mathrm{~ns}$ \\
\hline 12 & $496 \mathrm{~ns}$ \\
\hline 13 & $530 \mathrm{~ns}$ \\
\hline 14 & $566 \mathrm{~ns}$
\end{tabular}

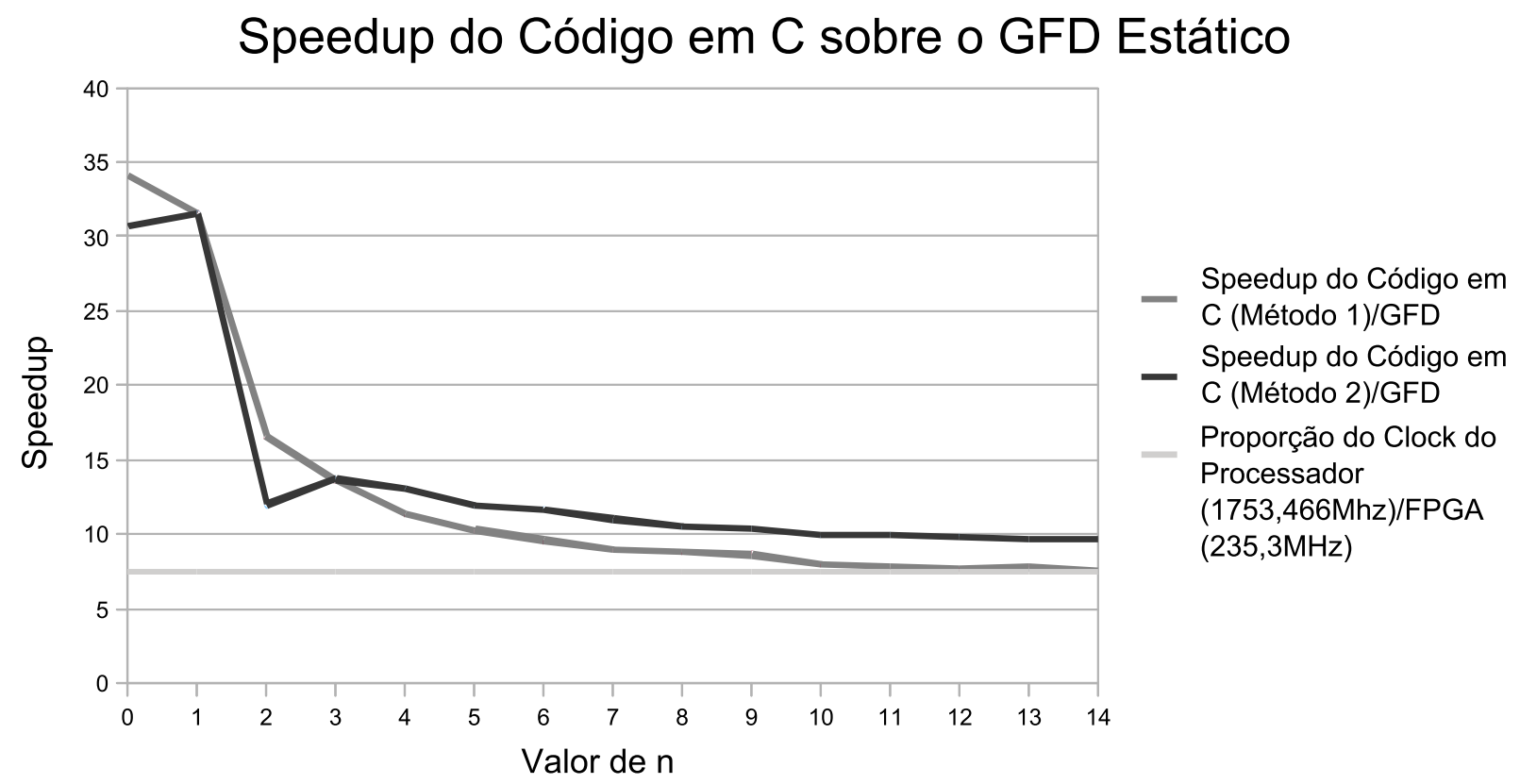

Figura 5.6: Gráfico comparativo do Speedup do Código em C sobre o GFD estático.

pelos nós branchs, dado que o valor de $n$, em uma situação real, é definido dinamicamente.

Ainda assim, com valores maiores de $n$ (de 10 à 14), o speedup foi perto da proporcionalidade da diferença dos clocks dos dispositivos. Esse resultado, por si só, viabiliza estudos futuros dentro da arquitetura ChipCflow, já que essa é uma arquitetura em fase embrionária de projeto que obteve resultados em certo ponto comparáveis à resultados de processadores comerciais amplamente pesquisados pelo meio acadêmico e pela indústria.

Não obstante, o experimento feito demonstrou que o GFD criado do Algoritmo Fibonacci e seu particionamento estão corretos já que os valores de saída do GFD obtidos foram os esperados. Resta agora implementar esse GFD dentro do modelo de partição e 
Tabela 5.2: Tempo de execução do código em C do Algoritmo Fibonacci para o método 1.

Média do tempo do loop vazio: $5.138 \mathrm{~ns}$

\begin{tabular}{c|c|c|c}
\hline \hline$n$ & Média do tempo total & $\sigma$ do tempo total & Tempo total - loop vazio \\
\hline \hline 0 & $8.826 \mathrm{~ns}$ & $0.557 \mathrm{~ns}$ & $3.759 \mathrm{~ns}$ \\
\hline 1 & $9.082 \mathrm{~ns}$ & $0.504 \mathrm{~ns}$ & $4.015 \mathrm{~ns}$ \\
\hline 2 & $14.477 \mathrm{~ns}$ & $3.241 \mathrm{~ns}$ & $9.409 \mathrm{~ns}$ \\
\hline 3 & $19.058 \mathrm{~ns}$ & $1.029 \mathrm{~ns}$ & $13.991 \mathrm{~ns}$ \\
\hline 4 & $24.900 \mathrm{~ns}$ & $1.048 \mathrm{~ns}$ & $19.832 \mathrm{~ns}$ \\
\hline 5 & $30.020 \mathrm{~ns}$ & $1.506 \mathrm{~ns}$ & $24.953 \mathrm{~ns}$ \\
\hline 6 & $35.483 \mathrm{~ns}$ & $2.438 \mathrm{~ns}$ & $30.416 \mathrm{~ns}$ \\
\hline 7 & $41.340 \mathrm{~ns}$ & $1.938 \mathrm{~ns}$ & $36.273 \mathrm{~ns}$ \\
\hline 8 & $46.124 \mathrm{~ns}$ & $1.963 \mathrm{~ns}$ & $41.057 \mathrm{~ns}$ \\
\hline 9 & $50.673 \mathrm{~ns}$ & $2.183 \mathrm{~ns}$ & $45.606 \mathrm{~ns}$ \\
\hline 10 & $57.293 \mathrm{~ns}$ & $2.799 \mathrm{~ns}$ & $52.226 \mathrm{~ns}$ \\
\hline 11 & $64.145 \mathrm{~ns}$ & $3.861 \mathrm{~ns}$ & $59.078 \mathrm{~ns}$ \\
\hline 12 & $69.580 \mathrm{~ns}$ & $3.075 \mathrm{~ns}$ & $64.513 \mathrm{~ns}$ \\
\hline 13 & $73.627 \mathrm{~ns}$ & $3.470 \mathrm{~ns}$ & $68.559 \mathrm{~ns}$ \\
\hline 14 & $79.739 \mathrm{~ns}$ & $3.183 \mathrm{~ns}$ & $74.672 \mathrm{~ns}$
\end{tabular}

protocolo proposto para, então, validar o modelo com um algoritmo real.

\subsubsection{Modelo de Partição e Protocolo}

Para validar o Modelo de Partição e Protocolo, foram propostos dois experimentos: o primeiro consiste em colocar um GFD devidamente particionado e validado dentro de um modelo estático para simulação. No caso de uma simulação correta, parte-se para o segundo experimento: a implementação desse GFD (dentro do modelo de partição e protocolo) como hardware parcialmente reconfigurável.

\subsubsection{GFD do Algoritmo Fibonacci}

Com o GFD validado, então, partiu-se para o primeiro experimento. Para valida-lo dentro do Modelo de Partição e Protocolo, optou-se apenas por fazer uma validação estática desse modelo. A validação dinâmica implicaria em implementar um sistema para busca de partições e instanciamento das partições via RPD, o que não é escopo deste trabalho e não foi realizado por nenhum outro pesquisador do projeto. A abordagem adotada é possível desde que o árbitro não veja necessidade de reconfiguração no hardware. Para isso, criou-se um hardware contendo previamente várias partições do GFD já instanciadas.

É interessante notar que, para essa implementação, a Figura 5.2 e a Figura 5.3 contém apenas representações gráficas comportamentais do GFD, sem contudo ter todas as instâncias correspondentes em VHDL dos nós descritos.

A Figura 5.7 e a Figura 5.8 contém dois diagramas demonstrando as implementações 
Tabela 5.3: Tempo de execução do código em C do Algoritmo Fibonacci para o método 2 .

Média do tempo do loop vazio: 5,258 ns

\begin{tabular}{c|c|c|c}
\hline \hline$n$ & Média do tempo total & $\sigma$ do tempo total & Tempo total - loop vazio \\
\hline \hline 0 & $9.286 \mathrm{~ns}$ & $0.481 \mathrm{~ns}$ & $4.168 \mathrm{~ns}$ \\
\hline 1 & $9.122 \mathrm{~ns}$ & $0.425 \mathrm{~ns}$ & $4.004 \mathrm{~ns}$ \\
\hline 2 & $18.202 \mathrm{~ns}$ & $7.569 \mathrm{~ns}$ & $13.084 \mathrm{~ns}$ \\
\hline 3 & $18.985 \mathrm{~ns}$ & $0.964 \mathrm{~ns}$ & $13.867 \mathrm{~ns}$ \\
\hline 4 & $22.394 \mathrm{~ns}$ & $0.927 \mathrm{~ns}$ & $17.276 \mathrm{~ns}$ \\
\hline 5 & $26.659 \mathrm{~ns}$ & $1.225 \mathrm{~ns}$ & $21.541 \mathrm{~ns}$ \\
\hline 6 & $30.177 \mathrm{~ns}$ & $1.230 \mathrm{~ns}$ & $25.059 \mathrm{~ns}$ \\
\hline 7 & $34.715 \mathrm{~ns}$ & $1.587 \mathrm{~ns}$ & $29.597 \mathrm{~ns}$ \\
\hline 8 & $39.392 \mathrm{~ns}$ & $1.926 \mathrm{~ns}$ & $34.274 \mathrm{~ns}$ \\
\hline 9 & $43.195 \mathrm{~ns}$ & $2.047 \mathrm{~ns}$ & $38.077 \mathrm{~ns}$ \\
\hline 10 & $47.293 \mathrm{~ns}$ & $1.972 \mathrm{~ns}$ & $42.175 \mathrm{~ns}$ \\
\hline 11 & $51.542 \mathrm{~ns}$ & $2.241 \mathrm{~ns}$ & $46.424 \mathrm{~ns}$ \\
\hline 12 & $55.646 \mathrm{~ns}$ & $2.257 \mathrm{~ns}$ & $50.528 \mathrm{~ns}$ \\
\hline 13 & $60.179 \mathrm{~ns}$ & $2.631 \mathrm{~ns}$ & $55.061 \mathrm{~ns}$ \\
\hline 14 & $63.869 \mathrm{~ns}$ & $2.619 \mathrm{~ns}$ & $58.751 \mathrm{~ns}$
\end{tabular}

\section{Barramento de Dados}

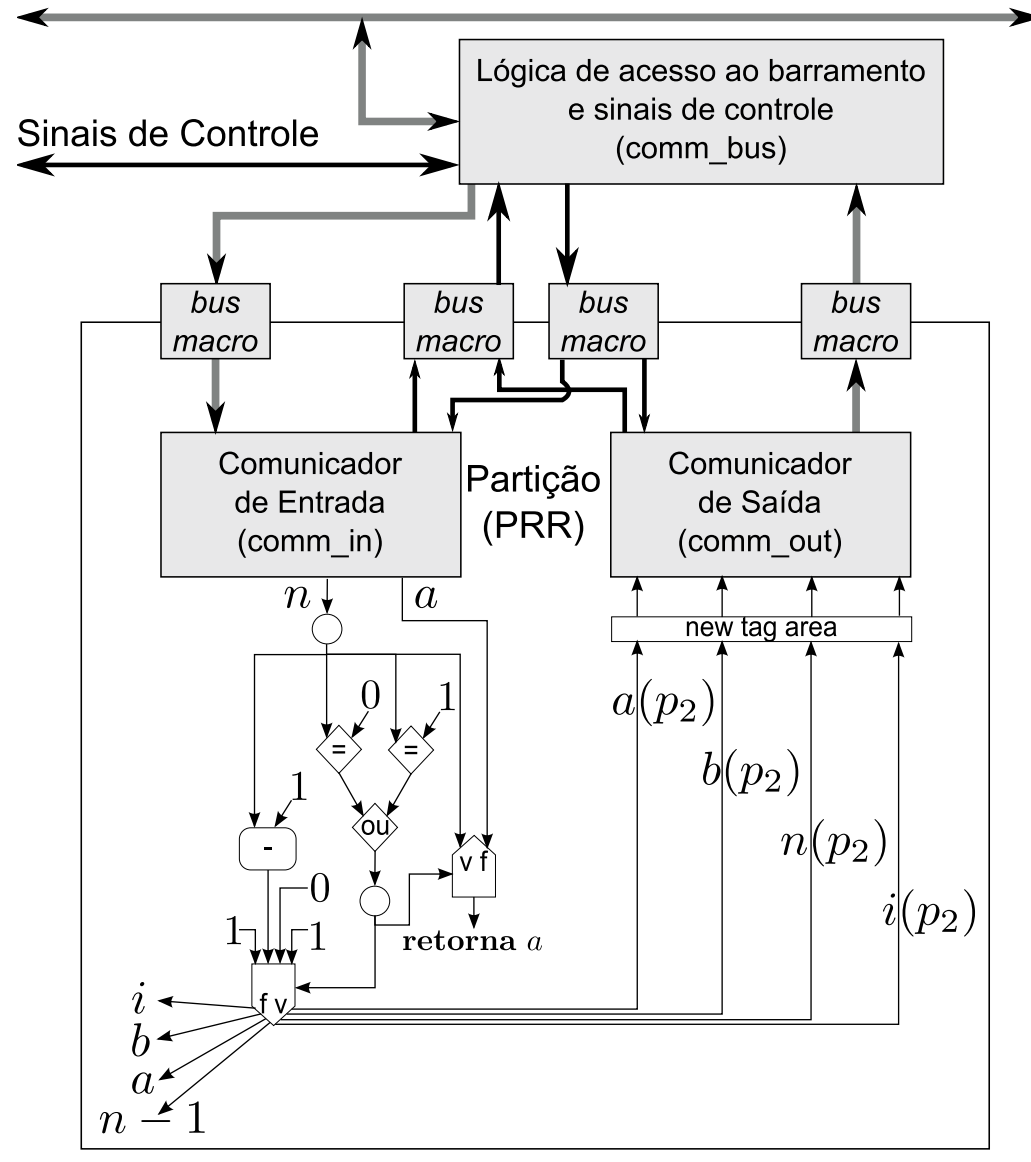

Figura 5.7: Hardware da implementação da partição 1 do GFD do algoritmo Fibonacci.

em hardware já dentro do modelo de partição e protocolo propostos. Novamente, ressaltando que o GFD apresentado é apenas comportamental, sendo que não nem todos os 
Tabela 5.4: Speedup do tempo de execução do código em C do Algoritmo Fibonacci sobre o GFD Estático.

Proporção dos clocks do Processador e FPGA: 7,45

\begin{tabular}{c|c|c}
\hline \hline$n$ & Método 1 & Método 2 \\
\hline 0 & 34,05 & 30,73 \\
\hline 1 & 31,5 & 31,5 \\
\hline 2 & 16,6 & 12 \\
\hline 3 & 13,6 & 13,7 \\
\hline 4 & 11,31 & 13,02 \\
\hline 5 & 10,28 & 11,91 \\
\hline 6 & 9,61 & 11,68 \\
\hline 7 & 8,98 & 11,02 \\
\hline 8 & 8,78 & 10,53 \\
\hline 9 & 8,62 & 10,34 \\
\hline 10 & 7,99 & 9,9 \\
\hline 11 & 7,81 & 9,94 \\
\hline 12 & 7,69 & 9,82 \\
\hline 13 & 7,74 & 9,64 \\
\hline 14 & 7,59 & 9,64 \\
\hline
\end{tabular}

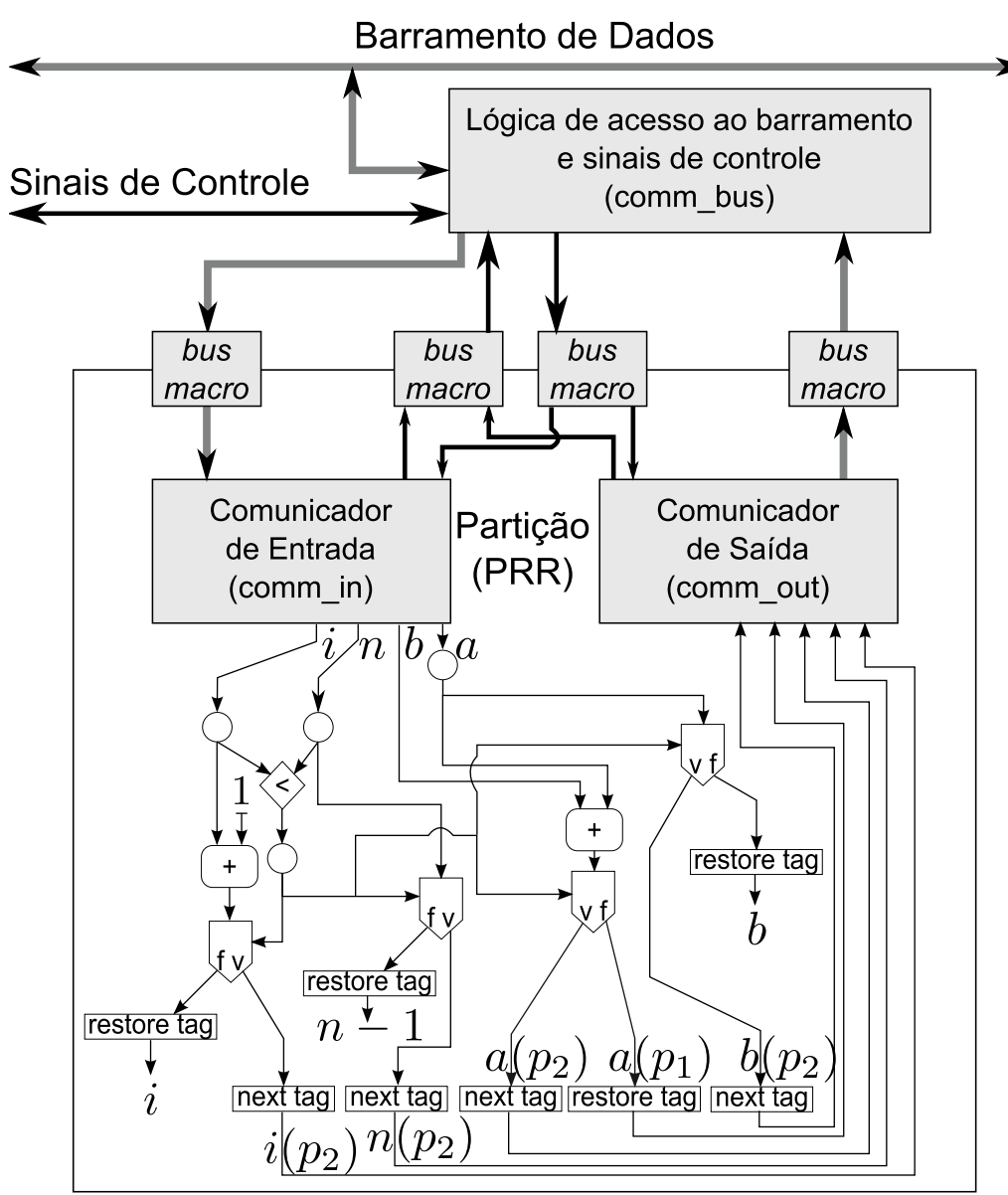

Figura 5.8: Hardware da implementação da partição 2 do GFD do algoritmo Fibonacci.

nós são diretamente instanciados como componentes VHDL.

Com o intuito de minimizar o tempo de execução do hardware, não foram criadas 
instâncias de hardware de todos os nós branchs. Ainda assim, o comportamento esperado do GFD foi conseguido graças ao sinal op_dt_in_enable. Dessa forma, a saída dos nós deciders foram diretamente ligadas no sinal op_dt_in_enable.

Os nós de manipulação de tags não foram integralmente implementados também. Os nós "new tag area" e "restore tag" não foram implementados. O nó "next tag" contou com uma implementação deveras simplista, em que apenas o valor 1 era somado a tag. Essa implementação foi feita diretamente no comunicador de saída. Com isso, alguns comportamentos podem ser previstos:

1. Se um token passar por um nó "new tag area" e não passar por nenhum nó "next tag", a tag poderá ser recebida pelo comunicador de entrada corretamente, posto que o comunicador a tag não foi modificada e o comunicador espera aquele valor da tag;

2. Se um token passar por um nó "next tag", o comunicador de entrada correspondente não conseguirá recebe-lo, posto que o tag estará modificado e o nó "restore tag" não foi implementado (não podendo assim restaurar o tag).

3. Em um algoritmo com mais de um nível de reentrância (ou seja, dois nós "new tag area") pode haver conflito de tokens, caso esse passe por dois nós "next tag" de níveis diferentes.

O GFD do algoritmo Fibonacci (Figura 5.1) possui apenas um nível de reentrância, o que impede que haja conflitos entre os tokens. Todavia, um problema que será encontrado em execuções com valores de $n>2$. Com esses valores, o comunicador de entrada da instância da Partição $p_{1}$ não será capaz de receber o token correto da variável $a$, saído de uma instância da Partição $p_{2}$.

Neste GFD específico, desde que haja pelo menos uma instância de cada partição, só haverá necessidade de reconfiguração caso haja mais iterações no laço do que a quantidade de instâncias da Partição $p_{2}$. Dessa forma, desde que a simulação mantenha um valor de $n$ inferior ao número de instâncias da Partição $p_{2}$ menos $2(m-2)$, não haverá necessidade de se ativar a APR para se criar novas instâncias.

No exemplo utilizado foram criadas 11 PRRs (Figura 5.9). As 10 primeiras PRRs são capazes de abrigar instâncias da partição $p_{1}$ e $p_{2}$. Sendo que uma PRR contém uma instância da Partição $p_{1}$ (PRR 1), 9 PRRs contém uma instância da Partição $p_{2}$ cada (PRR 2 até PRR A) e a última PRR contém uma instância de um simulador do módulo de entrada e saída (PRR B). Esse simulador é responsável por enviar o valor de $n$ desejado para a primeira instância da partição $p_{1}$ por meio do protocolo definido. Destarte, a execução do algoritmo deverá fluir naturalmente no hardware até que a saída seja obtida.

Para demonstrar que o circuito de comunicação entre as partições está funcionando, foi criado uma simulação em que um pacote contendo um token é enviado para uma 


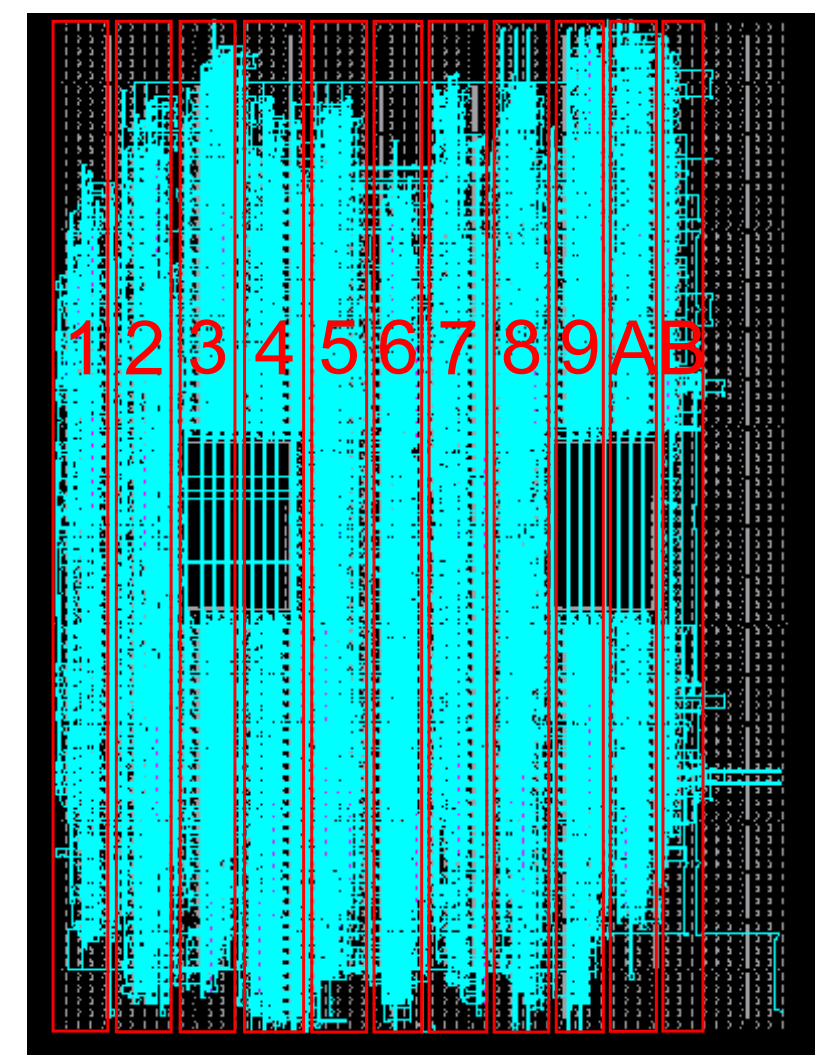

Figura 5.9: Screenshot da ferramenta FPGA Editor com uma visão da ocupação do hardware sintetizado da implementação estática do GFD do algoritmo Fibonacci no modelo de partição e protocolo em um dispositivo xv2p30. Os retângulos indicam onde ar PRRs estão localizadas.

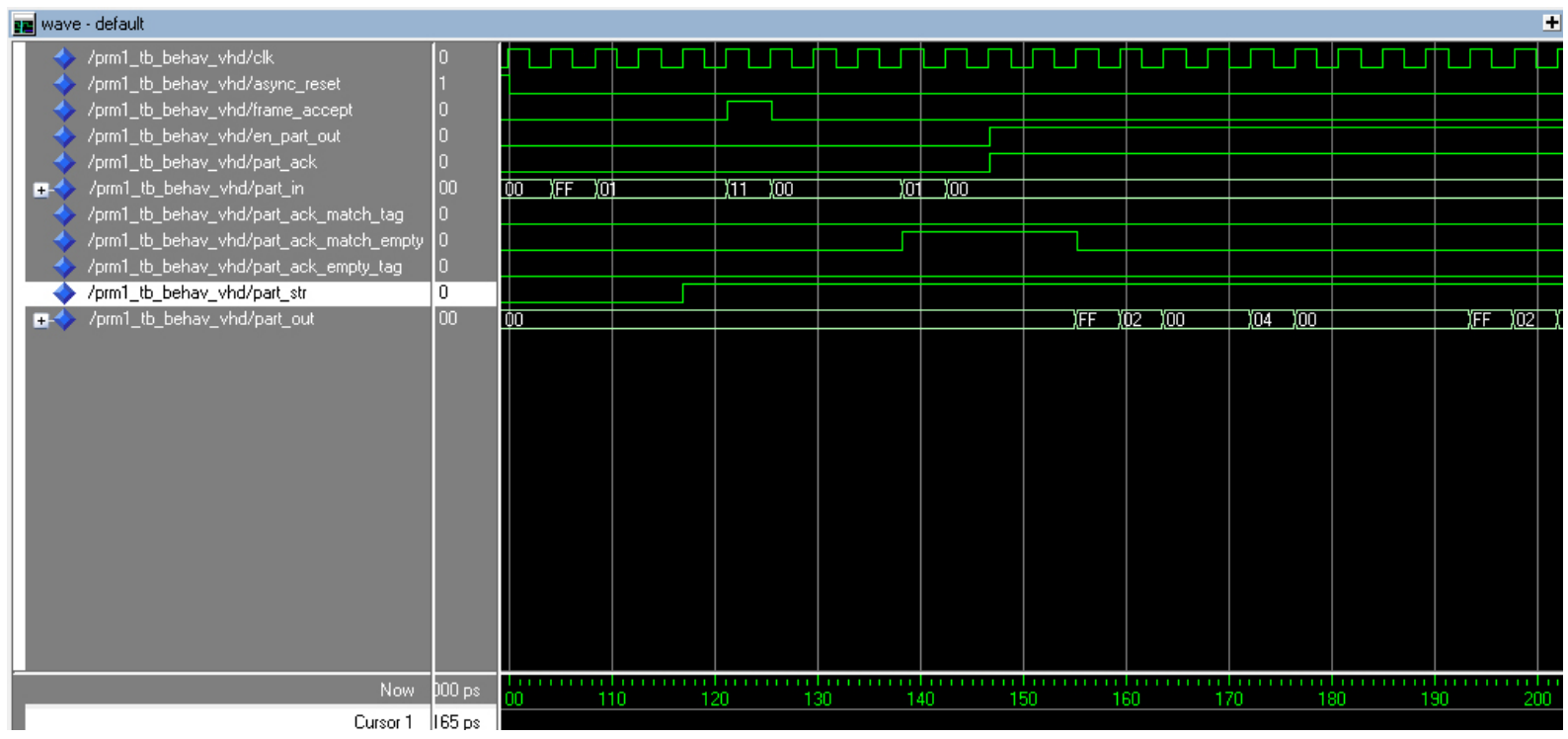

Figura 5.10: Simulação temporal de envio de token para uma instância da partição $p_{1}$.

instância da partição $p_{1}$. O pacote enviado é destinado ao arco $n$ da partição $p_{1}$, que, na implementação, é identificado pelo número 1. A partição $p_{1}$ também é identificada pelo número 1. A Figura 5.10 contém um screenshot da simulação desse circuito, sem árbitro e com circuito de envio simulado no testbench.

Na Figura 5.10 é possível ver que, logo após o sinal de reset ser desligado 


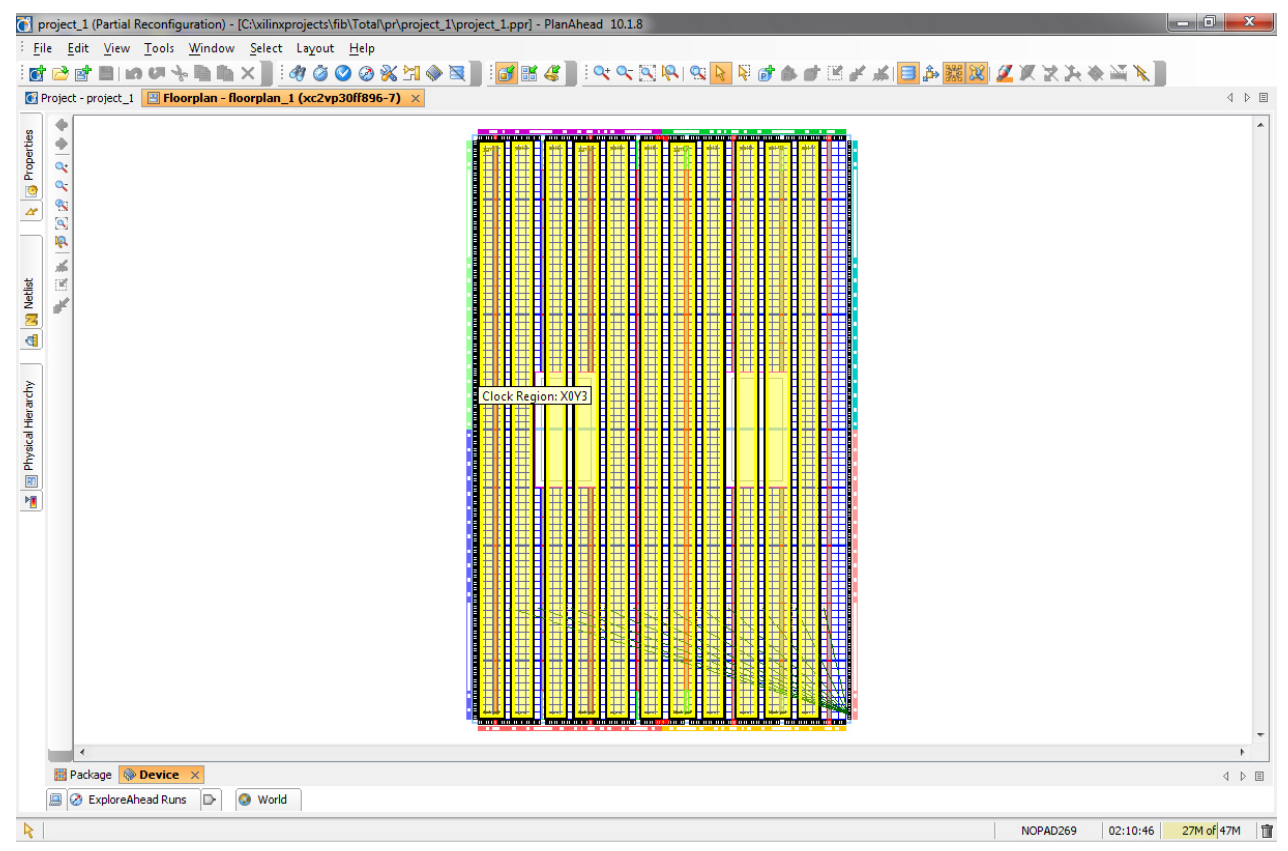

Figura 5.11: Screenshot da ferramenta PlanAhead com uma visão da ocupação dos módulos sintetizados da implementação dinâmica do GFD do algoritmo Fibonacci no modelo de partição e protocolo em um dispositivo xv2p30. Os retângulos amarelados indicam onde ar PRRs estão localizadas.

(async_reset) o token começa a ser enviado para o barramento (barramento part_in). O valor 0xFF indica que um pacote começou a ser enviado. Conforme já citado, a simulação está programada para enviar um pacote independente da confirmação do árbitro.

Depois dos primeiros 8 bits de sincronia, são enviados 8 bits contendo o valor $0 \times 01$. Esse valor identifica a partição $p_{1}$. Novamente, são enviados 8 bits e depois mais 8 bits com o valor 0x01. Dessa vez, esses bits contém dados dos campos "Ativação" e "Iteração". Mais 8 bits são enviados, dessa vez com valor 0x11. Os primeiros 4 bits desse valor (0x1) são dados do campo "Aninhamento" e os outros 4 bits são dados do campo "Arco".

Com esses dados, a instância da partição $p_{1}$ pode verificar o endereço correto daquele pacote conforme os critérios indicados no Capítulo 4 . Neste caso, conforme a primeira instância da partição $p_{1}$ está vazia, ela deve indicar para o árbitro que o pacote está endereçado para a partição correta e que ela é capaz de recebe-lo, pois não está executando nenhum outro dado. Isso é indicado pelo sinal part_ack_match_empty.

Neste caso, o testbench implementado força automaticamente a aceitação do pacote pelo sinal frame_accept. E, finalmente, depois do 40 bits contendo informações de sincronização e endereçamento do token, o dado é enviado divido em 4 pacotes de 8 bits cada.

\subsubsection{Compatibilidade com o fluxo de desenvolvimento EAPR}

Parte do processo de validação do modelo consiste em criar um hardware reconfigurável por meio do fluxo de desenvolvimento do processo de reconfiguração parcial. O fluxo utilizado, EAPR, já foi descrito no Capítulo 3. 


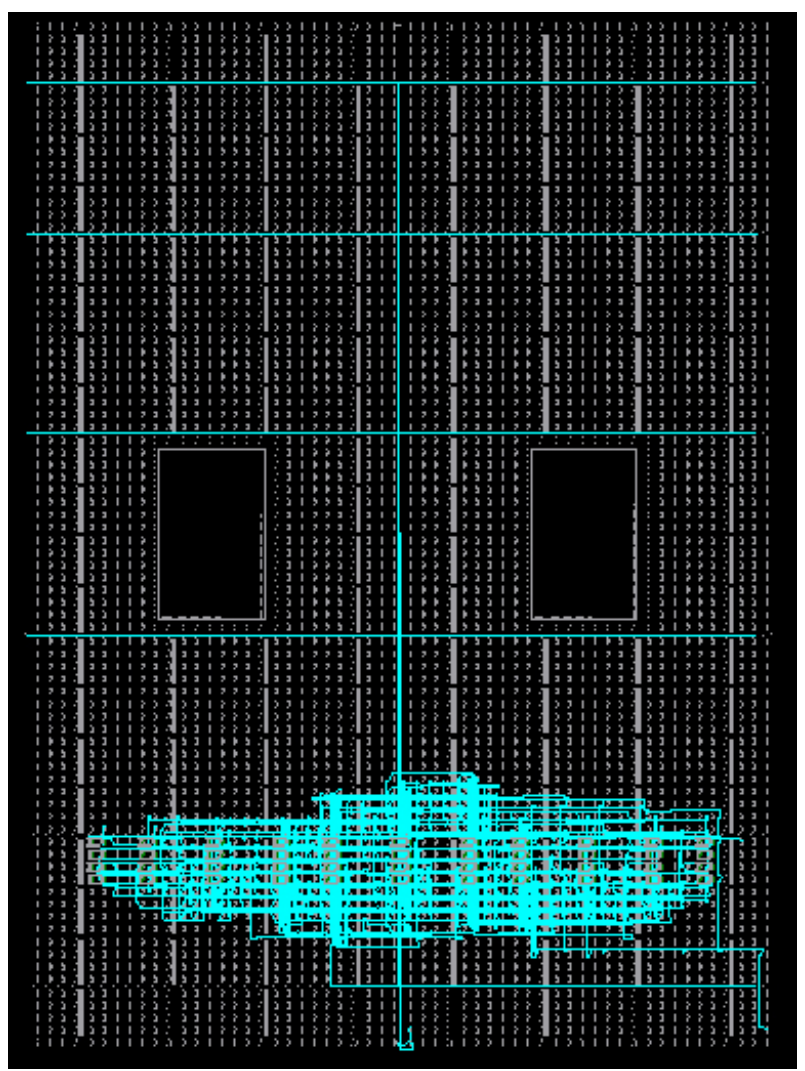

Figura 5.12: Screenshot da ferramenta FPGA Editor com uma visão da ocupação do hardware sintetizado da parte estátida da implementação dinâmica do GFD do algoritmo Fibonacci no modelo de partição e protocolo em um dispositivo xv2p30.

Para auxiliar o fluxo de desenvolvimento, foi utilizada a ferramenta Xilinx Planahead 10.1. No exemplo utilizado foram criadas 11 PRRs (Figura 5.11). As 10 primeiras PRRs são capazes de abrigar instâncias da partição $p_{1}$ e $p_{2}$. A última PRR contém uma instância de um simulador do módulo de entrada e saída (PRR B). A configuração inicial necessária de PRMs foi a mesma do teste estático. Com esses dados, então, sintetizou-se o hardware e criou-se os bitstreams para todos as PRRs e PRMs disponíveis.

A Figura 5.12 contém um screenshot da ferramenta FPGA Editor mostrando a ocupação da área estática do hardware. É importante notar que, mesmo que pareça que o hardware estático está dentro da área dos PRMs, isso não acontece. A ferramenta de roteamento cuida para que apenas os sinais de comunicação passem por essa área. Dessa forma, a RPD não afeta o funcionamento do hardware estático.

Na Figura 5.13 é possível ver um screenshot da ferramenta FPGA Editor mostrando a ocupação do hardware da PRM1 (partição $p_{1}$ ) na área PRR1. Apesar de parecer que o hardware sintetizado extrapola os limites da PRR1 (o sinal mostrado no meio do FPGA é o sinal de clock GCLCK), isso é apenas um resquício de roteamento da ferramenta de PAR. Em análises realizadas nos bitstreams gerados, eles não apresentam qualquer configuração fora das áreas delimitadas pela PRR1.

A Figura 5.14 possui um screenshot da ferramenta FPGA Editor com a ocupação do hardware da PRM2 (partição $p_{2}$ ) na área PRR1. Da mesma forma, apesar de parecer que 


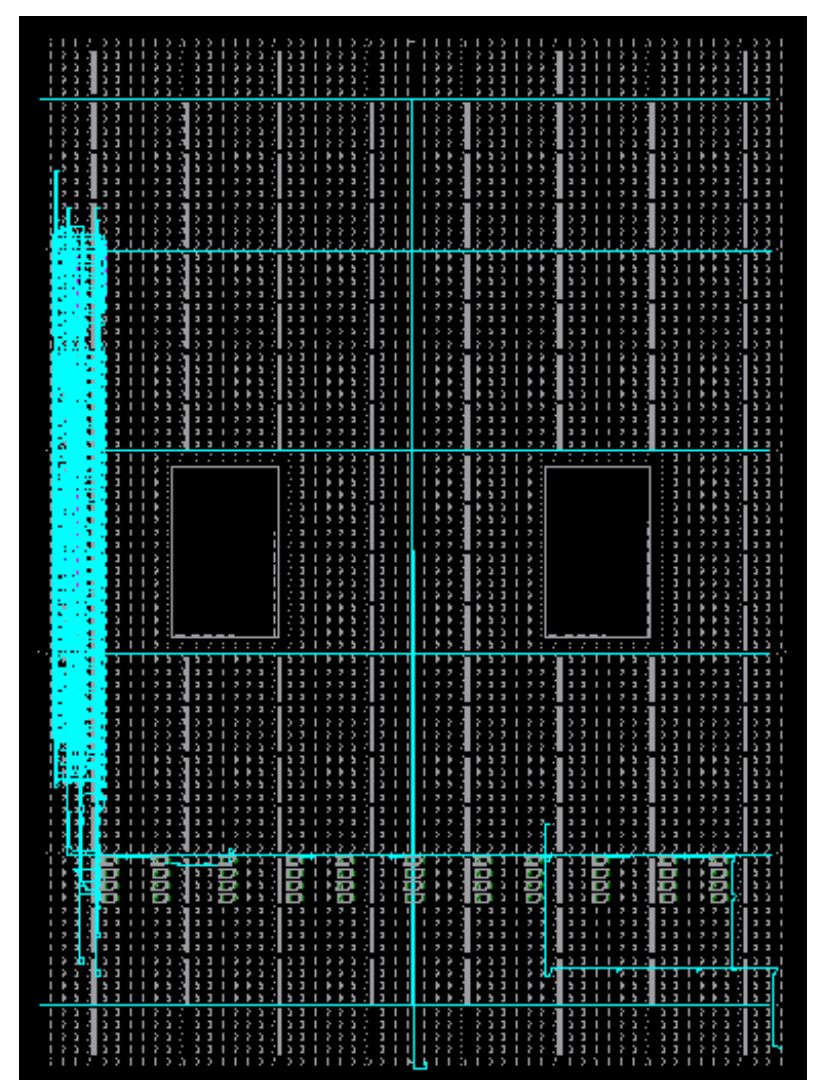

Figura 5.13: Screenshot da ferramenta FPGA Editor com uma visão da ocupação do hardware sintetizado do módulo PRM1 na PRR2 da implementação dinâmica do GFD do algoritmo Fibonacci no modelo de partição e protocolo em um dispositivo xv2p30.

o hardware sintetizado extrapola os limites da PRR1, esses dados não são colocados no bitstream final do módulo.

Da mesma forma, as outras PRRs e PRMs foram roteadas para que bitstreams desses módulos fossem gerados. Destarte, o modelo de partição e protocolo se demonstra parcialmente validado: o hardware funciona em simulações estáticas e o processo de geração de bitstreams dinâmicos foi satisfatório.

\subsection{Análise de Overhead}

Com o hardware do modelo de partição e protocolo validados, cabe então fazer uma análise final do overhead introduzido pelo modelo de partição e protocolo. Para isso, será necessário comparar execuções dos algoritmos dentro de ambos os modelos: GFD estático e GFD dinâmico com o modelo.

O ideal para essa comparação seria criar criar um modelo temporal para comparar as duas formas de execuções. Todavia, essa é uma tarefa difícil, posto que um GFD tem uma execução paralela, o que influencia na comunicação entre as instâncias das partições. Além disso, o próprio processo de particionamento é variável, o que pode modificar brutalmente os resultados obtidos no modelo. 


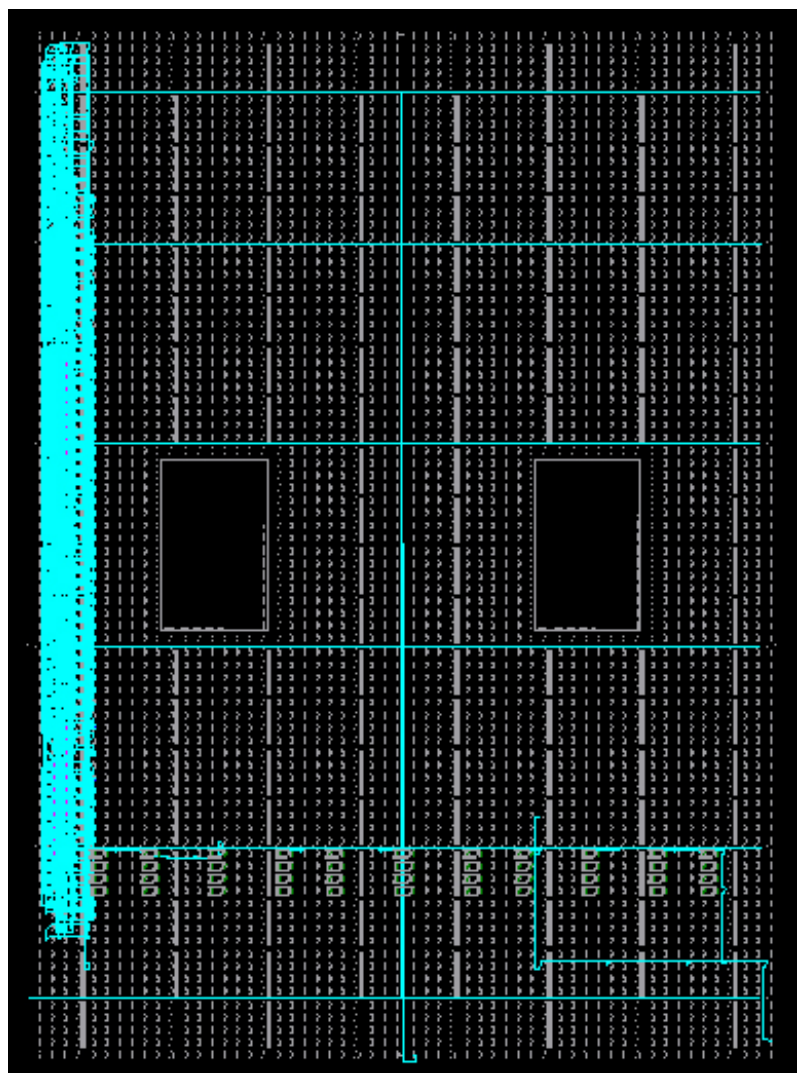

Figura 5.14: Screenshot da ferramenta FPGA Editor com uma visão da ocupação do hardware sintetizado do módulo PRM2 na PRR2 da implementação dinâmica do GFD do algoritmo Fibonacci no modelo de partição e protocolo em um dispositivo xv2p30.

Devido a essas limitações, a saída encontrada foi comparar os GFDs do algoritmo Fibonacci entre o modelo estático e o modelo dinâmico. Essa comparação é bastante subjetiva e é relativa apenas ao GFD implementado. Todavia, ela pode dar evidências do overhead que será introduzido em outras aplicações.

A metodologia utilizada consiste em criar execuções com a letra $n$ variando de 0 até 14, assim os dados gerados podem ser comparados com os dados da execução estática já obtida. Para que haja igualidade nas comparações, o clock utilizado será o mesmo da execução estática (4.250 ns). A ferramenta utilizada para simulação é a ferramenta ModelSim. A Tabela 5.5 contém os dados obtidos com essa simulação.

Na Figura 5.15 é possível ver um gráfico com os tempos de execução do GFD estático e do GFD dentro do modelo de partição e protocolo. Como é possível ver, os tempos de execução com o modelo de partição e protocolo ficam muito maiores. Por exemplo, para $n=14$, o tempo de execução fica quase 6 vezes maior. O motivo desse tempo ser maior é a troca de pacotes entre as instâncias das partições, o que se torna um gargalo.

Na maior parte do tempo da execução do GFD, vários pacotes precisam ser trocados entre as partições (uma média de 4 por iteração). Conforme esses pacotes precisam ser trocados por uma barramento de 8 bits de forma serial, a execução do GFD é interrompida devido os dados não estarem disponíveis no buffer dos nós. Uma evidência disso é que, com valores de $n=[0,1]$, o tempo de execução foi bem próximo do GFD estático. Isso 
Tabela 5.5: Tempo de execução do GFD estático do Algoritmo Fibonacci sem utilização do modelo de partição e protocolo.

\begin{tabular}{c|c}
$n$ & Tempo total \\
\hline \hline 0 & $148 \mathrm{~ns}$ \\
\hline 1 & $148 \mathrm{~ns}$ \\
\hline 2 & $484 \mathrm{~ns}$ \\
\hline 3 & $798 \mathrm{~ns}$ \\
\hline 4 & $1049 \mathrm{~ns}$ \\
\hline 5 & $1244 \mathrm{~ns}$ \\
\hline 6 & $1474 \mathrm{~ns}$ \\
\hline 7 & $1712 \mathrm{~ns}$ \\
\hline 8 & $1950 \mathrm{~ns}$ \\
\hline 9 & $2187 \mathrm{~ns}$ \\
\hline 10 & $2425 \mathrm{~ns}$ \\
\hline 11 & $2663 \mathrm{~ns}$ \\
\hline 12 & $2901 \mathrm{~ns}$ \\
\hline 13 & $3139 \mathrm{~ns}$ \\
\hline 14 & $3378 \mathrm{~ns}$
\end{tabular}

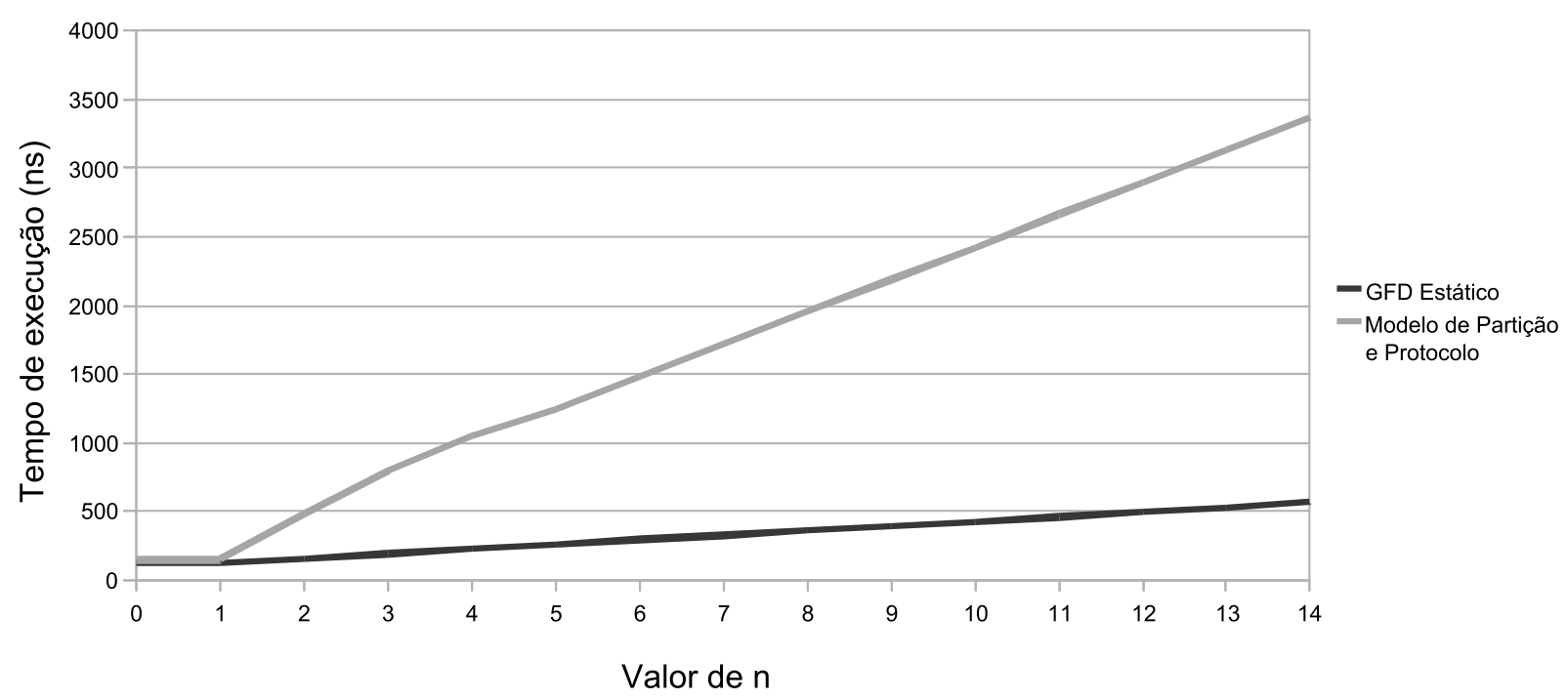

Figura 5.15: Gráfico com os tempos de execução do GFD estático e o GFD no modelo de partição e protocolo.

acontece porque apenas dois pacotes foram passados pelo modelo de partição e protocolo (entrada do $n$ e retorno do GFD), o que influencia pouco no tempo de execução total do GFD.

Todavia, esse gargalo pode ser diminuído de duas formas: aumentando a largura do barramento de dados e multiplicando a quantidade de barramentos para troca de dados. Aumentar a largura do barramento de dados permite que os pacotes sejam transferidos em menos ciclos de clock. Multiplicar a quantidade de barramentos permite que mais pacotes sejam transferidos concomitantemente pelo FPGA, todavia essa alternativa requer que se multiplique também o número de árbitros utilizados (um para cada barramento) além da quantidade de Controladores de Comunicação (um para cada barramento dentro da 
instância).

Com o modelo de partição e protocolo é possível que as instâncias das partições sejam reutilizadas caso tenham terminado de executar sua porção dos dados. Por exemplo, neste algoritmo, sem este recurso, para valores $n>10$, não haveria espaço físico para se alocar novas PRRs para as instâncias da partição $p_{2}$ (como é possível ver na Figura 5.12 , não há mais espaço para se definir novas PRRs). Sem o modelo de protocolo de partição, a execução desse algoritmo especificamente seria inviável para valores de $n$ muito grandes, posto que o tamanho do hardware sintetizado estaria diretamente atrelado ao valor de $n$ executado.

O modelo de partição e protocolo permite que execução com valores de $n$ maiores que o número de instâncias configuradas no hardware, posto que instâncias de partições vazias devem ser reutilizadas assim que sua execução terminar. Para isso, seria necessário um mecanismo que descobre quando as instâncias estão vazias. Ou seja, quando elas estão sem dados nos arcos do GFD ou executando nos nós. Dessa forma, as instâncias utilizadas poderiam receber dados assim que elas ficassem novamente vazias. Entretanto, esse mecanismo não foi definido ou implementado neste trabalho.

Com esse recurso, o GFD do algoritmo Fibonacci seria capaz de executar com apenas 3 PRRs para qualquer valor de $n$. Isso acontece porque quando uma iteração do laço estiver começando, a outra estará terminando. Assim, sempre que uma nova tag for gerada, uma instância da partição $p_{2}$ logo estará vazia novamente.

\subsubsection{Tempos de Reconfiguração}

Os tempos anteriormente obtidos são tempos sem levar em consideração a reconfiguração das instâncias das partições no FPGA. Com a reconfiguração, o tempo total da execução de um GFD deve aumentar consideravelmente. Um estudo sobre os tempos de reconfiguração em dispositivos xv2p30 já havia sido publicado em Souza Junior et al. 2010.

Para o cálculo total do tempo total de reconfiguração das instâncias das partições, partiu-se do principio que o modelo seja capaz de reutilizar instâncias livres depois de sua execução completa. Dessa forma, só há necessidade de reconfiguração quando não houver instâncias livres para aquele token.

Outro ponto importante do cálculo, é que nem sempre o árbitro e os controladores de comunicação serão capazes de fazer um escalonamento ótimo para o envio de dados. $\mathrm{Ou}$ seja, embora nesse caso específico com apenas duas instâncias da partição $p_{2}$ seja possível obter o máximo de paralelismo do GFD (dadas as limitações do modelo), o árbitro e os controladores de comunicação podem enviar pacotes em que mais instâncias concomitantes sejam necessárias.

O cálculo do tempo de reconfiguração foi feito utilizando a Equação 3.1. Os valores

para $T_{p p c \rightarrow h w i c a p}$ e $T_{\text {hwicap } \rightarrow c m}$ utilizados foram os mesmos utilizados em Souza Junior et al., 2010. 
Tabela 5.6: Tempo de reconfiguração do GFD dinâmico do Algoritmo Fibonacci com a utilização do modelo de partição e protocolo.

\begin{tabular}{c|c|c|c|c} 
& \multicolumn{2}{|c|}{ Partições } & \multicolumn{2}{c}{ Tempo de Reconfiguração } \\
\hline \hline$n$ & $p_{1}$ & $p_{2}$ & 3 colunas & 4 colunas \\
\hline \hline 0 & 1 & 0 & $46,58 \mathrm{~ms}$ & $61,4 \mathrm{~ms}$ \\
\hline 1 & 1 & 0 & $46,58 \mathrm{~ms}$ & $61,4 \mathrm{~ms}$ \\
\hline 2 & 1 & 1 & $93,16 \mathrm{~ms}$ & $122,81 \mathrm{~ms}$ \\
\hline 3 & 1 & 2 & $139,74 \mathrm{~ms}$ & $184,21 \mathrm{~ms}$ \\
\hline 4 & 1 & 3 & $186,32 \mathrm{~ms}$ & $245,61 \mathrm{~ms}$ \\
\hline 5 & 1 & 4 & $232,90 \mathrm{~ms}$ & $307,02 \mathrm{~ms}$ \\
\hline 6 & 1 & 4 & $232,90 \mathrm{~ms}$ & $307,02 \mathrm{~ms}$ \\
\hline 7 & 1 & 4 & $232,90 \mathrm{~ms}$ & $307,02 \mathrm{~ms}$ \\
\hline 8 & 1 & 4 & $232,90 \mathrm{~ms}$ & $307,02 \mathrm{~ms}$ \\
\hline 9 & 1 & 4 & $232,90 \mathrm{~ms}$ & $307,02 \mathrm{~ms}$ \\
\hline 10 & 1 & 4 & $232,90 \mathrm{~ms}$ & $307,02 \mathrm{~ms}$ \\
\hline 11 & 1 & 4 & $232,90 \mathrm{~ms}$ & $307,02 \mathrm{~ms}$ \\
\hline 12 & 1 & 4 & $232,90 \mathrm{~ms}$ & $307,02 \mathrm{~ms}$ \\
\hline 13 & 1 & 4 & $232,90 \mathrm{~ms}$ & $307,02 \mathrm{~ms}$ \\
\hline 14 & 1 & 4 & $232,90 \mathrm{~ms}$ & $307,02 \mathrm{~ms}$
\end{tabular}

A Tabela 5.6 contém valores dos tempos de reconfiguração calculados para execuções do GFD do algoritmo Fibonacci para valores de $n$ variando de 0 até 1 . A coluna "Partição" indica a quantidade de instâncias da partição $p_{1}$ e $p_{2}$ que devem ser reconfiguradas para determinado valor de $n$. É interessante ressaltar que a Tabela 5.6 contém o pior caso de execução, que é quando nenhuma partoção está previamente instanciada no FPGA.

Como é possível ver nos valores da Tabela 5.6, os tempos de reconfiguração são muito superiores aos tempos de execução do GFD. Enquanto a escala do tempo de execução do GFD está em nanossegundos e microssegundos, a escala do tempo de reconfiguração está em milissegundos. O tempo de execução do GFD com o modelo de partição e protocolo para $n=14$ é equivalente à $0,00145 \%$ do tempo de reconfiguração total para as 5 instâncias das partições que precisam ser reconfiguradas para esse valor de $n$.

Ainda assim, esse valor pode ser melhorado a partir do momento que nem o árbitro e nem os controladores de comunicação estão fazendo uma comunicação ótima. A prova disso é que 5 instâncias de partições estão sendo necessárias para valores de $n>4$ (sendo que 4 são da partição $p_{2}$ ), quando apenas 3 são necessárias (1 para a partição $p_{1}$ e duas para a partição $\left.p_{2}\right)$.

Os tempos de reconfiguração mostrados na Tabela 5.6 não necessariamente deverão ser totalmente acrescidos ao tempo de execução também. Isso acontece porque a reconfiguração das instâncias pode ser feita de forma paralela. Dessa forma, enquanto uma instância está sendo reconfigurada, uma outra instância que estava em execução pode (e certamente irá) ficar livre durante o tempo de reconfiguração.

Para isso, todavia, seria necessário que o árbitro e os controladores de comunicação fossem capazes de detectar essa situação para que o envio de pacotes fosse escalonado de 
forma a maximizar as instâncias livres. Para este exemplo, partindo do pressuposto que o árbitro e os controladores de comunicação fossem capazes de detectar isso, o fluxo começaria correr normalmente a partir que a segunda instância da partição $p_{2}$ fosse reconfigurada no FPGA.

\subsection{Considerações Finais}

Neste Capítulo foi possível ver os experimentos realizados com o intuito de validar o modelo de partição e protocolo. No próximo Capítulo, será apresenta uma análise aprofundada e as conclusões dessa análise acerca dos resultados obtidos com os experimentos realizados. 


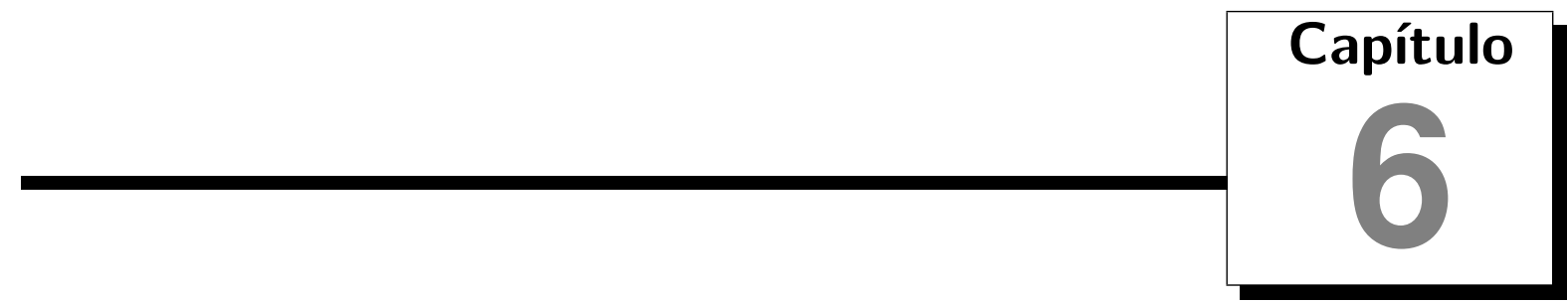

\section{Conclusões e Trabalhos Futuros}

Após a apresentação das premissas básicas do projeto da ferramenta ChipCflow e os experimentos realizados com o intuito de validar o projeto, cabe avaliar os resultados obtidos com esses experimentos. Inicialmente, serão reapresentados os requisitos para a validação do projeto e então ao longo do Capítulo uma discussão sobre esses requisitos e os resultados obtidos será apresentada.

O objetivo inicial do ChipCflow era utilizar reconfiguração dinâmica para solucionar o problema de tempo de matching de dados de nós utilizando Grafos baseados em Fluxo de Dados dinâmicos com o conceito de tagged-token. Para validar se o modelo de partição e protocolo proposto e implementado cumprissem esse objetivo, foram definidos dois requisitos no Capítulo 4

1. O ChipCflow deve ser capaz de executar GFDs em hardwares capazes de se reconfigurar parcialmente;

2. Posteriormente, os mecanismos utilizados no modelo de partição e protocolo não podem atrapalhar sobremaneira no desempenho de execução desses GFDs.

\subsection{Primeiro Requisito}

Para validar o primeiro requisito foi feita uma implementação do modelo de partição e protocolo utilizando as ferramentas de reconfiguração parcial da Xilinx. Embora foram gerados bitstreams normalmente utilizando o fluxo de desenvolvimento dinâmico das ferramentas Xilinx, esses bitstreams não foram executados em um FPGA real e assim não podem ser validados completamente.

Todavia, os resultados obtidos nas simulações foram satisfatórios, indicando que o hardware deve funcionar em FPGAs reais com nenhum ou poucos ajustes na implemen- 
tação. A utilização do fluxo de desenvolvimento para geração de bitstreams capazes de reconfiguração também satisfez os requisitos do fluxo e os bitstreams foram gerados sem problema.

Dessa forma, com os resultados obtidos por meio dos experimentos realizados pode-se concluir que o primeiro requisito foi parcialmente validado.

\subsection{Segundo Requisito}

Para tentar atender o segundo requisito, o sistema não podia invalidar as restrições para o primeiro requisito. Com essa limitação, tentou-se criar um modelo de comunicação de acordo com as restrições geradas pelo fluxo de desenvolvimento para RPD da Xilinx. Esse modelo, na aplicação testada e com as configurações testadas, inclui um gargalo de tempo de execução considerável na execução do GFD se comparado com a execução do GFD estático. O overhead gerado varia de 1,17x até 5,97x do tempo de execução. Valores maiores de $n$ não foram testados, mas a tendência pelo gráfico gerado é que esse overhead fique ainda maior.

Destarte, pode-se considerar que este tópico do segundo requisito não pode ser validado pelos experimentos demonstrados, posto que o tempo de execução para comunicação entre as partições fica consideravelmente maior que o tempo de execução desses dados. Todavia, conforme já explicitado no Capítulo 5. esse tempo pode eventualmente ser melhorado mudando parâmetros de configuração para a comunicação.

O alto tempo de reconfiguração, por sua vez, invalida a ideia inicial de utilizar a RPD para diminuir o tempo de matching dos tokens nos nós do GFD. O que, por sua vez, não valida o segundo requisito proposto para o modelo de partição e protocolo. Todavia, ainda assim, apesar dos tempos de reconfiguração altos, a RPD abre uma nova possibilidade para o ChipCflow, dado que, com a RPD, é possível haver virtualmente um hardware infinito, possibilitando que esse hardware seja escalonado no FPGA durante a execução de um GFD.

\subsection{Trabalhos Futuros}

Conquanto a validação do modelo de partição e protocolo não foi possível nos requisitos propostos, sugere-se que o foco do modelo de partição e protocolo da ferramente ChipCflow seja outro. Assim, ainda tentando explorar a RPD, mas agora para que seja possível manter um hardware virtualmente infinito a disposição da execução, e não como método de redução do tempo de matching de tokens.

Assim, sugere-se pesquisar sobre formas de diminuir ao máximo a necessidade de reconfigurações do FPGA, propondo heurísticas que seriam capazes de antever a utilização de uma determinada instância de partição para que essa seja reconfigurada previamente. Outras heurísticas capazes de particionar um GFD de forma melhor, com o intuito de se 
diminuir instancimentos de partições também podem ser estudadas.

Dentro do escopo da RPD, ainda, pode-se estudar uma nova forma de modelo de partição e protocolo. De forma com que o modelo novo reconfigure a menor quantidade de dados possível. O modelo atual reconfigura todos os nós tal como seus sinais de comunicação. Um modelo novo poderia manter os nós reconfigurados e ajustar dinamicamente apenas as interconexões desses nós.

Pode-se também tentar um algoritmo de escalonamento de pacotes para o árbitro mais eficiente. Destarte, o árbitro seria capaz de escalonar a comunicação de instâncias de partições de modo que pacotes para instâncias que já estão em execução fossem priorizadas.

Os canais de comunicação entre as partições também podem ser aumentados. Esses barramentos podem ter sua largura aumentada ou podem ser simplesmente multiplicados. Dessa forma, o grande gargalo que ocorre na comunicação entre as partições seria evitado.

Outro aspecto que pode ser explorado é o método de particionamento. Neste trabalho, o método de particionamento foi manual e não obedeceu nenhuma heurística e regra clara. O resultado desse particionamento pode ser visto em uma grande quantidade de tokens que precisavam trafegar entre as partições. Um método de particionamento pode ser estudado para que o número de tokens que trafeguem entre as partições seja diminuído também. 


\section{Referências Bibliográficas}

Alle, M., Varadarajan, K., Fell, A., Nandy, S. K., \& Narayan, R. (2009). Compiling techniques for coarse grained runtime reconfigurable architectures. In Reconfigurable Computing: Architectures, Tools and Applications, volume 5453 of Lecture Notes in Computer Science (pp. 204-215).: Springer Berlin / Heidelberg. 40

Arvind (2005). Dataflow: Passing the token. ISCA Keynote. 2

Asano, S., Maruyama, T., \& Yamaguchi, Y. (2009). Performance comparison of fpga, gpu and cpu in image processing. In Field Programmable Logic and Applications, 2009. FPL 2009. International Conference on (pp. 126-131). 13,20

Astolfi, V. \& Silva, J. (2007). Execution of algorithms using a dynamic dataflow model for reconfigurable hardware - commands in dataflow graph. In Programmable Logic, 2007. SPL '07. 2007 3rd Southern Conference on (pp. 225-230). 3, 43, 45, 46, 59

Astolfi, V. F. (2009). Chipcflow - em hardware dinamicamente reconfigurável. Master's thesis, Universidade de São Paulo. 44

Blodget, B., James-Roxby, P., Keller, E., McMillan, S., \& Sundararajan, P. (2003). A selfreconfiguring platform. In Field-Programmable Logic and Applications, volume 2778 of Lecture Notes in Computer Science (pp. 565-574).: Springer Berlin / Heidelberg. 36

Bobda, C. (2007). Introduction to Reconfigurable Computing: Architectures, Algorithms, and Applications. Springer, 1 edition. xv, 5, 6, 8, 9, 10, 11, 16, 25, 26

Bonato, V. (2008). Proposta de uma arquitetura de hardware em FPGA implementada para SLAM com multi-câmeras aplicada à robótica móvel. PhD thesis, Universidade de São Paulo. 20

Bonato, V., Peron, R., Wolf, D., de Holanda, J., Marques, E., \& Cardoso, J. (2007). An FPGA implementation for a kalman filter with application to mobile robotics. In Industrial Embedded Systems, 200\%. SIES '0\%. International Symposium on (pp. 148155). 13 
Bulman, P. (1999). Nist announces encryption standard finalists. 12

Cardoso, J. \& Neto, H. (2003). Compilation for FPGA-based reconfigurable hardware. Design $\&$ Test of Computers, IEEE, 20(2), 65-75. 2

Collins, L. (2003). Chip makers hit heat barrier. IEE Review, 49(1), 22-23. 1

Compton, K. \& Hauck, S. (1999). An Introduction to Reconfigurable Computing. Technical report, Northwestern University, Dept. of ECE. 25, 26, 29

Compton, K. \& Hauck, S. (2002). Reconfigurable computing: a survey of systems and software. ACM Comput. Surv., 34(2), 171-210. 5, 12, 25, 26

da Costa, K. A. P. (2009). Uma ferramenta para execução de algoritmos utilizando o modelo a fluxo de dados dinâmico em hardware reconfigurável para a arquitetura Chip Cflow: módulo de conversão $C$ em grafo a fluxo de dados. $\mathrm{PhD}$ thesis, Universidade de São Paulo. 44

Dennis, J. B. (1980). Data flow supercomputers. IEEE Computers, 13(11), 48-56. 2

Dennis, J. B. \& Misunas, D. P. (1974). A preliminary architecture for a basic data-flow processor. SIGARCH Comput. Archit. News, 3(4), 126-132. 2

El-Araby, E., Gonzalez, I., \& El-Ghazawi, T. (2009). Exploiting partial runtime reconfiguration for High-Performance reconfigurable computing. ACM Trans. Reconfigurable Technol. Syst., 1(4), 1-23. 40

Elbirt, A. J. \& Paar, C. (2000). An FPGA implementation and performance evaluation of the serpent block cipher. In Proceedings of the 2000 ACM/SIGDA eighth international symposium on Field programmable gate arrays (pp. 33-40). Monterey, California, United States: ACM. 12

Estrin, G. \& Turn, R. (1963). Automatic assignment of computations in a variable structure computer system. Electronic Computers, IEEE Transactions on, EC-12(6), 755773. 8

Estrin, G. \& Viswanathan, C. R. (1962). Organization of a "Fixed-Plus-Variable" structure computer for computation of eigenvalues and eigenvectors of real symmetric matrices. J. $A C M, 9(1), 41-60.8$

Gajski, D., Padua, D., Kuck, D., \& Kuhn, R. (1982). A second opinion on data flow machines and languages. Computer, 15(2), 58-69. 2, 3

Gelsinger, P. (2001). Microprocessors for the new millennium: Challenges, opportunities, and new frontiers. In Solid-State Circuits Conference, 2001. Digest of Technical Papers. ISSCC. 2001 IEEE International (pp. 22-25). 1 
GholamHosseini, H. \& Hu, S. (2008). A high speed vision system for robots using fpga technology. In Mechatronics and Machine Vision in Practice, 2008. M2VIP 2008. 15th International Conference on (pp. 81 -84). 13,20

Goldstein, S., Schmit, H., Moe, M., Budiu, M., Cadambi, S., Taylor, R., \& Laufer, R. (1999). PipeRench: a coprocessor for streaming multimedia acceleration. In Computer Architecture, 1999. Proceedings of the 26th International Symposium on (pp. 28-39). 19, 40

Hauck, S. \& DeHon, A. (2007). Reconfigurable Computing: The Theory and Practice of FPGA-Based Computation. Morgan Kaufmann, illustrated edition edition. xv, xvi, 6, 7, 19, 20, 25, 26, 27, 28, 29,

Hauser, J. \& Wawrzynek, J. (1997). Garp: a MIPS processor with a reconfigurable coprocessor. In FPGAs for Custom Computing Machines, 199\%. Proceedings., The 5th Annual IEEE Symposium on (pp. 12-21). xv, 18, 40

Hur, J. Y., Wong, S., \& Vassiliadis, S. (2007). Partially reconfigurable point-to-point interconnects in Virtex-II pro FPGAs. In Reconfigurable Computing: Architectures, Tools and Applications, volume 4419 of Lecture Notes in Computer Science (pp. 4960).: Springer Berlin / Heidelberg. 40, 41

Intel (2005). Intel developer forum. Documentação Técnica. 1

Intel Corporation (1998). Using the rdtsc instruction for performance monitoring. 66

Kalte, H., Langen, D., Vonnahme, E., Brinkmann, A., \& Ruckert, U. (2002). Dynamically reconfigurable system-on-programmable-chip. Parallel, Distributed and Network-based Processing, 2002. Proceedings. 10th Euromicro Workshop on, (pp. 235-242). 40, 41

Koch, D., Beckhoff, C., \& Teich, J. (2008). Recobus-builder: A novel tool and technique to build statically and dynamically reconfigurable systems for fpgas. In Field Programmable Logic and Applications, 2008. FPL 2008. International Conference on (pp. 119 $-124) .36$

Kohler, S., Schirok, J., Braunes, J., \& Spallek, R. G. (2008). Efficiency of dynamic reconfigurable datapath extensions - a case study. In Reconfigurable Computing: Architectures, Tools and Applications, volume 4943 of Lecture Notes in Computer Science (pp. 300-305).: Springer Berlin / Heidelberg. xv, 21, 40

Lee, B. \& Hurson, A. R. (1993). Issues in dataflow computing. Advances in Computers, 37, 285-333. 2

Lee, D., Villasenor, J., Luk, W., \& Leong, P. (2006). A hardware gaussian noise generator using the Box-Muller method and its error analysis. Computers, IEEE Transactions on, 55(6), 659-671. 12 
Ling, X. P. \& Amano, H. (1993). Wasmii: a data driven computer on a virtual hardware. In FPGAs for Custom Computing Machines, 1993. Proceedings. IEEE Workshop on (pp. 33-42). 22, 25, 40

Lopes, J., Luiz, J., Marques, E., \& Cardoso, J. (2006). A benchmark approach for compilers in reconfigurable hardware. In System-on-Chip for Real-Time Applications, The 6th International Workshop on (pp. 120-124). 2, 3

Lopes, J. J. (2007). Estudos e avaliações de compiladores para arquiteturas reconfiguráveis. Master's thesis, Universidade de São Paulo. 2

Matos, D., Concatto, C., Carro, L., Kastensmidt, F., \& Susin, A. (2009). The need for reconfigurable routers in networks-on-chip. In Reconfigurable Computing: Architectures, Tools and Applications, volume 5453 of Lecture Notes in Computer Science (pp. 275280).: Springer Berlin / Heidelberg. xvi, 40, 41,42

McBader, S. \& Lee, P. (2003). An FPGA implementation of a flexible, parallel image processing architecture suitable for embedded vision systems. In Parallel and Distributed Processing Symposium, 2003. Proceedings. International (pp. 5 pp.). 12

Microsoft Corporation (2010). Queryperformancecounter function. 66

Mingw.org (2009). Mingw - minimalist gnu for windows. 66

Moraes, F., Calazans, N., Möller, L., Brião, E., \& Carvalho, E. (2005). Dynamic and partial reconfiguration in FPGA SoCs: Requirements tools and a case study. In New Algorithms, Architectures and Applications for Reconfigurable Computing (pp. 157-168).: Springer US. 40

Motomura, M., Aimoto, Y., Shibayama, A., Yabe, Y., \& Yamashina, M. (1997). An embedded DRAM-FPGA chip with instantaneous logic reconfiguration. In VLSI Circuits, 1997. Digest of Technical Papers., 1997 Symposium on (pp. 55-56). 28

Papadimitriou, K., Anyfantis, A., \& Dollas, A. (2007). Methodology and experimental setup for the determination of system-level dynamic reconfiguration overhead. In Proceedings of the 15th Annual IEEE Symposium on Field-Programmable Custom Computing Machines (pp. 335-336).: IEEE Computer Society. 32

Parkhurst, J., Darringer, J., \& Grundmann, B. (2006). From single core to multi-core: preparing for a new exponential. In Proceedings of the 2006 IEEE/ACM international conference on Computer-aided design (pp. 67-72). San Jose, California: ACM. 1

Pellerin, D. \& Thibault, S. (2005). Practical FPGA Programming in C. Prentice Hall Professional TR. 2 
Rammig, F. J. (1977). A concept for the editing of hardware resulting in an automatic hardware-editor. In Proceedings of the 14th conference on Design automation (pp. 187193).: IEEE Press. 8

Resano, J., Mozos, D., \& Catthoor, F. (2005). A hybrid prefetch scheduling heuristic to minimize at run-time the reconfiguration overhead of dynamically reconfigurable hardware [multimedia applications]. Design, Automation and Test in Europe, 2005. Proceedings, (pp. 106-111 Vol. 1). 29

Resano, J., Mozos, D., Verkest, D., Vernalde, S., \& Catthoor, F. (2003). Run-time minimization of reconfiguration overhead in dynamically reconfigurable systems. In Field-Programmable Logic and Applications, volume 2778 of Lecture Notes in Computer Science (pp. 585-594).: Springer Berlin / Heidelberg. 29

Ronen, R., Mendelson, A., Lai, K., Lu, S., Pollack, F., \& Shen, J. (2001). Coming challenges in microarchitecture and architecture. Proceedings of the IEEE, 89(3), 325340. 1

Sanches, L. (2010). Chipcflow - partição e protocolo de comunicação no grafo a fluxo de dados dinâmico. Master's thesis, Universidade de São Paulo. 44, 49

Sidhu, R. P. S., Mei, A., \& Prasanna, V. K. (1999). Genetic programming using selfreconfigurable FPGAs. In Field Programmable Logic and Applications, volume 1673 of Lecture Notes in Computer Science (pp. 301-312).: Springer Berlin / Heidelberg. 40

Silva, J. L. (2006). Execution of algorithms using a dynamic dataflow model for reconfigurable hardware - a purpose for matching data. In System-on-Chip for Real-Time Applications, The 6th International Workshop on (pp. 115-119). 3, 43, 45,58

Silva, J. L. \& Marques, E. (2006). Executing algorithms for dynamic dataflow reconfigurable hardware -The operators protocol. In Reconfigurable Computing and FPGA's, 2006. ReConFig 2006. IEEE International Conference on (pp. 1-7). 3, 43, 45

Souza Junior, F., Silva, J., Sanches, L., \& Astolfi, V. (2010). Research and partial analysis of overhead of a partition model for a partially reconfigurable hardware in a data-driven machine - ChipCflow. In Programmable Logic, 2010. SPL '10. 2010 6rd Southern Conference on. Xvi, xix, 3, 32, 43, 44, 47, 48, 50, 51, 81

Spracklen, L. \& Abraham, S. (2005). Chip multithreading: opportunities and challenges. In High-Performance Computer Architecture, 2005. HPCA-11. 11th International Symposium on (pp. 248-252). 1

Taher, M. (2005). Exploiting processing locality for adaptive computing systems. PhD thesis, The George Washington University. 29 
Takayama, A., Shibata, Y., Iwai, K., \& Amano, H. (2000). Dataflow partitioning and scheduling algorithms for WASMII, a virtual hardware. In Field-Programmable Logic and Applications: The Roadmap to Reconfigurable Computing, volume 1896 of Lecture Notes in Computer Science (pp. 685-694).: Springer Berlin / Heidelberg. 23

Takayama, A., Shibata, Y., Iwai, K., Miyazaki, H., Higure, K., \& Ling, X.-P. (1999). Implementation and evaluation of the compiler for wasmii, a virtual hardware system. Parallel Processing, 1999. Proceedings. 1999 International Workshops on, (pp. 346351). 23

Trimberger, S., Carberry, D., Johnson, A., \& Wong, J. (1997). A time-multiplexed fpga. FPGAs for Custom Computing Machines, 1997. Proceedings., The 5th Annual IEEE Symposium on, (pp. 22-28). 28

Tyrrell, A. M., Sanchez, E., Floreano, D., Tempesti, G., Mange, D., Moreno, J.-M., Rosenberg, J., , \& Villa, A. E. (2003). POEtic tissue: An integrated architecture for bio-inspired hardware. In Evolvable Systems: From Biology to Hardware, volume 2606 of Lecture Notes in Computer Science (pp. 269-294).: Springer Berlin / Heidelberg. 40

Upegui, A. \& Sanchez, E. (2005). Evolving hardware by dynamically reconfiguring xilinx FPGAs. In Evolvable Systems: From Biology to Hardware, volume 3637 of Lecture Notes in Computer Science (pp. 56-65).: Springer Berlin / Heidelberg. 40

Veen, A. H. (1986). Dataflow machine architecture. ACM Comput. Surv., 18(4), 365-396. 2, 47, 63,64

Vuillemin, J., Bertin, P., Roncin, D., Shand, M., Touati, H., \& Boucard, P. (1996). Programmable active memories: Reconfigurable systems come of age. Very Large Scale Integration (VLSI) Systems, 4. xv, 11, 14, 16

Wirthlin, M. \& Hutchings, B. (1995). A dynamic instruction set computer. In P. Athanas \& K. L. Pocek (Eds.), IEEE Symposium on FPGAs for Custom Computing Machines (pp. 99-107). Los Alamitos, CA: IEEE Computer Society Press. xv, 15, 17, 29, 40

Xilinx (1997). XC6200 Field Programmable Gate Arrays, 1.10 edition. 29

Xilinx (2006). Early Access Partial Reconfiguration User Guide. xvi, 39

Xilinx (2007a). Difference-Based Partial Reconfiguration, 2.0 edition. 40

Xilinx (2007b). Virtex-II Platform FPGA User Guide, 2.2 edition. xvi, 30, 32

Xilinx (2007c). Virtex-II Pro and Virtex-II Pro X FPGA User Guide. xvi, 30, 31,35

Xilinx (2008). Early Access Partial Reconfiguration User Guide. Xilinx, 1.2 edition. xvi. 36, 37,50 


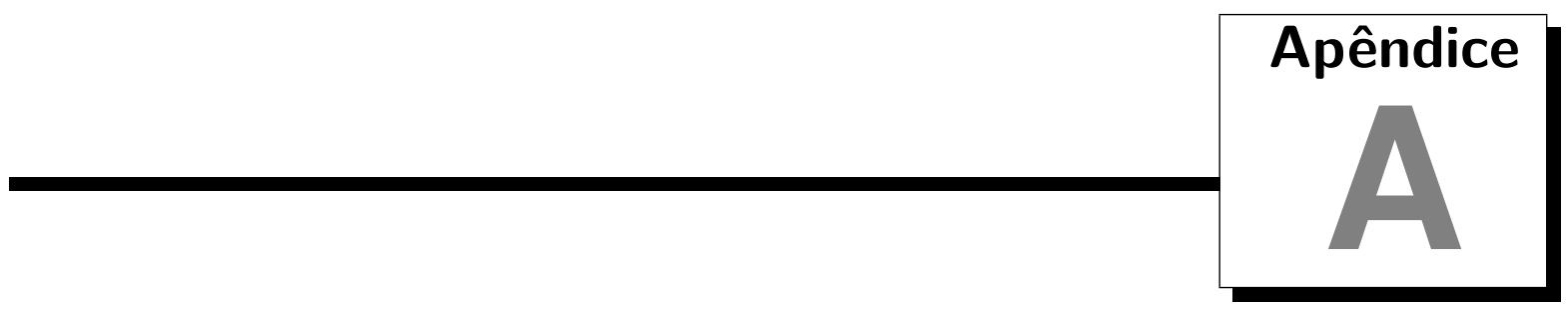

\section{Arquivos de Descrição do hardware desenvolvido}

\footnotetext{
Os arquivos LDH (linguagem VHDL) do hardware desenvolvido pode ser integralmente encontrado em http://www.chico.net.br/chipcflow.7z. Neste arquivo também é encontrado os arquivos de restrição (.ucf) do hardware gerado. Para abrir o arquivo, é necessário instalar a ferramente 7-Zip.
} 